\title{
Papers and Posters Presented at the 34th Annual Meeting of the Psychonomic Society The Omni Shoreham Hotel, Washington, D.C. November 5-7, 1993
}

\author{
IMPLICIT MEMORY I \\ Palladian Room, Friday Morning, 8:00-9:55
}

Chaired by Kim Kirsner, University of Western Australia

8:00-8:10 (1)

Directed Forgetting in Conceptual and Perceptual Implicit Tests. BARBARA H. BASDEN, DAVID R. BASDEN, \& RICHARD TORZYNSKI, California State University, Fresno-List- and word-method directed forgetting were contrasted by measuring priming in various perceptual and conceptual tests. Know and Remember judgments in recognition memory were also assessed. Results supported the validity of Basden, Basden, and Gargano's (1993) suggestion that the processes underlying word- and list-method directed forgetting differ. Selected conceptual tests showed directed forgetting with the word method but not with the list method, consistent with predictions from Roediger's transfer appropriate processing approach.

8:15-8:30 (2)

Effects of Imagery on Perceptual Implicit Memory Tests. KATHLEEN B. MCDERMOTT \& HENRY L. ROEDIGER III, Rice University (read by Henry L. Roediger III)-Priming on perceptual implicit memory tests is highly specific to symbolic form (e.g., little priming occurs from words to picture-fragment tests). We report several experiments in which instructing subjects to imagine relevant percepts (see a word and imagine its referent) promoted priming, but only on appropriate (i.e., pictorial) tests. These results support transfer appropriate processing interpretations of priming, but show that priming is mediated by more central processes than the phrase "data-driven" would suggest. 8:35-8:55 (3)

Implicit Memory in Another Form. DOUGLAS L. NELSON, DANI McKINNEY, \& JIE XU, University of South Florida-Association norms were used to compute association networks for 2,500 words. This database was used to select words whose networks systematically varied in size and connectivity. Some networks are more highly interconnected than others, and some have fewer outside connections. The results of several experiments illustrating the effects of connections inside and outside the immediate associative network will be reported, and implications for a theory of implicit memory will be discussed.

\section{9:00-9:15 (4)}

Further Support for a Generation/Recognition Account of Performance on Word-Fragment Cued Tests. BRADFORD H. CHALLIS, University of Toronto, \& ENDEL TULVING, Rotman Research Institute (read by Endel Tulving)-The generation/recognition account of performance on word-fragment cued tests holds that implicit processes of a perceptual and semantic nature underlie generation of items, and depending on the test instructions, recognition is used to select studied items from those generated. In three experiments, we used single-solution word-fragment test cues and varied study condition (level of processing, modality of presentation) and test instruction (fragment completion, cued recall, exclusion, inclusion). The findings were consistent with the generation/recognition account.

$$
\text { 9:20-9:30 (5) }
$$

Priming and Recognition Memory Within and Between Vision and Touch. RANDOLPH D. EASTON, KAVITHA SRINIVAS, \& ANTHONY J. GREENE, Boston College-Cross modal transfer was examined on a priming and a recognition memory task for novel shapes presented vibrotactually or visually. For the priming task, significant effects occurred within and between modalities, which did not differ in magnitude. In contrast, recognition was highest for shapes studied visually. The relation between vision and touch is considered in terms of implicit and explicit memory systems.
9:35-9:50 (6)

Components of Information: A Framework for Memory Research. JOAN GAY SNODGRASS \& CHUN RONG LUO, New York University-A components-of-information framework assumes different memory tasks have different item and associative information requirements. Levels of processing affects whether surface or semantic features of items are stored, while explicit retrieval instructions affect whether contextto-item associations are required. A comparison of perceptual identification and word fragment completion tests under levels-of-processing and explicit retrieval manipulations showed that the two manipulations were separable and that word fragment completion relies less on surface features than perceptual identification does.

\section{ATTENTION I}

Diplomat Room, Friday Morning, 8:00-9:55

Chaired by Yehoshua Tsal, Tel Aviv University

\section{8:00-8:20 (7)}

Measuring the Relative Magnitude of Unconscious Influences. PHILIP M. MERIKLE \& STEVE JOORDENS, University of Waterloo-Perception without awareness was measured using an exclusion task that required subjects NOT to use briefly presented, masked words to complete three-letter word stems. With this task, the more frequently subjects fail to exclude words they are instructed not to use, the greater are the unconscious influences relative to the conscious influences. We show that the exclusion task predicts qualitative differences in performance such that stimuli perceived with and without awareness lead to different consequences.

\section{8:25-8:40 (8)}

Implicit Learning of Correlations Between Attended and "Unattended" Visual Stimuli. JOHN H. FLOWERS \& KIETH A. CARLSON, University of Nebraska-In a flanker task, subjects exhibited learning without awareness when correlations existed between simultaneously presented flankers (@, *, or \#) and targets (letters or digits). Informing subjects of the exact probability relationships did not improve performance relative to uninformed subjects. However, when flankers on trial $\mathrm{N}$ predicted targets on trial $\mathrm{N}+1$, no evidence for either implicit or explicit learning of correlations was found.

\section{8:45-9:00 (9)}

Effects of Semantic Relations on the Attentional Blink. WILLIAM S. MAKI, KAREN FRIGEN, \& KRISTEN PAULSON, North Dakota State University-The attentional blink is the transient loss in accuracy of identification of the second of two targets (T1 and T2) in an RSVP stream. In our research, $\mathrm{T} 1$ and $\mathrm{T} 2$ are words. When $\mathrm{T} 2$ is an associate of $\mathrm{T} 1$, reporting of $\mathrm{T} 2$ is much improved, but the attentional blink is still present. We will report the results of additional experiments on associative relations among targets and distractors.

\section{9:05-9:20 (10)}

Probe Manipulations in the Attentional Blink Paradigm. KIMRON L. SHAPIRO, TARA MOROZ, \& JANE E. RAYMOND, University of Calgary-Previous investigations into the Attentional Blink (AB) effect focused on aspects of the first target task to determine what causes the AB. The present investigation focuses on aspects of the second target task (probe) by differentiating it from the distractor stream. Results reveal that the $\mathrm{AB}$ is completely eliminated when the probe is a luminance change but is actually enhanced when it is a gap condition. When used as targets, both conditions reveal no $\mathrm{AB}$.

9:25-9:35 (11)

Perceptual Grouping in RSVP. JANE E. RAYMOND, University of Calgary, JUDY I. CALDWELL, University of Victoria, \& KIMRON 
L. SHAPIRO, University of Calgary-Attentional blink (AB) effects found in dual-target RSVP paradigms may result from interference between target and distractor stimuli, especially immediate posttarget stimuli. Can perceptual grouping factors be used to minimize target-distractor interference? We presented targets that differed in colour, luminance, position, or orientation from distractor items and manipulated similarity between target and immediate posttarget stimuli. It appears that grouping factors which facilitate spatial visual organization may have limited effect temporally.

$$
\text { 9:40-9:50 (12) }
$$

Negative Priming: Effects of Pattern Masking. W. TRAMMELL NEILL \& KATHLEEN M. TERRY, Adelphi University-Previous research suggests that "negative priming"' by ignored objects is reversed if they are rendered unreportable by a pattern mask. However, both target and distractor stimuli were masked, obviating the requirement for selection and response. In the present experiments, compatible or incompatible flanking letters were masked while subjects identified target letters. Negative priming is attenuated or reversed by masking, but may not directly reflect flanker reportability or interference effects.

\section{NEUROPSYCHOLOGY/LATERALITY Hampton Room, Friday Morning, 8:00-10:20}

Chaired by Richard M. Vardaris, Kent State University

8:00-8:15 (13)

Within- Versus Between-Hemisphere Integration During Implicit Versus Explicit Tasks. JACQUELINE LIEDERMAN, DANIEL PALOMO, YOUNG-SOOK PARK, \& EILEEN SEMAN, Boston University-Experiments will be reported which compare within vs. between hemisphere integration of information presented in the context of two different tasks. The first task is a priming task wherein memory to previously displayed stimuli is tested only implicity. The second task uses the same basic materials but tests for explicit memory of the materials. Generally, inter- and intra-hemispheric priming were equivalent, whereas inter- and intra-hemispheric performance differed for explicit memory. 8:20-8:30 (14)

Are Fingerprints a Genetic Marker for Handedness? STANLEY COREN, University of British Columbia-Fingerprints and handedness were measured in 2,169 subjects. Left-handers were more likely to have simpler patterns (more arches and radial loops, fewer whorls and lower pattern intensity) than right-handers. Differences were most marked on the left hand which showed significant differences on four of the five digits related to handedness. This finding suggests a genetic mechanism in the development of handedness and may provide a means of separating pathological from natural left-handers.

8:35-8:50 (15)

Individual Differences in Hemispheric Asymmetry and Interhemispheric Interaction. JOSEPH B. HELLIGE, University of Southern California, \& MICHAEL I. BLOCH, UCLA-Right- versus left-handed men and women participated in four experiments examining different aspects of hemispheric asymmetry and interhemispheric interaction. Left-handers showed the same asymmetries as right-handers, with some of the asymmetries being smaller for the left-handed group. Measures of the direction and magnitude of various performance asymmetries were computed for each task. The pattern of correlations among these measures sheds light on the mechanisms that might underlie individual variation in hemispheric asymmetry and interhemispheric interaction.

\section{8:55-9:10 (16)}

Processes Involved in Dichotic Tasks: A Factor Analytic Approach. DAVID B. BOLES, Rensselaer Polytechnic Institute-The results of several studies are presented that reveal the factor structure of ear asymmetries obtained with dichotic tasks. Word, digit, and syllable recognition asymmetries load on a common auditory linguistic factor, while emotion and environmental sound asymmetries load on two additional factors. All are independent of visual lexical asymmetries. These re- sults indicate that hemispheric asymmetry is both process- and modalityspecific.

$$
\text { 9:15-9:35 (17) }
$$

Cerebral Mechanisms Underlying Processing of Speech and Music. ROBERT J. ZATORRE, Montreal Neurological Institute-Focal changes in cerebral blood flow associated with specific cognitive functions were studied via PET. Results indicate that laterally specialized temporal neocortical systems are involved in initial perceptual analysis of speech syllables and melodies. Further processing engages distinct networks: Tasks requiring access to the phonetic structure of speech activate left Broca's area, suggesting articulatory recoding. Judgments about pitch elicit participation of right frontal cortex, but complex frontotemporal interactions are observed with increased working memory load.

$$
\text { 9:40-10:00 (18) }
$$

Perceptual Correlates of Cortical Reorganization; Phantom Limbs, Scotomas, and Squint. V. S. RAMACHANDRAN \& D. ROGERSRAMACHANDRAN, University of California, San Diego-After arm amputation, adult human subjects "refer" sensations from their face to the phantom limb, a perceptual correlate of the neural remapping reported by Pons (1991). We also studied patients with exotropia and showed that a complete remapping of egocentric space occurs selectively for one eye alone. (But binocular rivalry and stereopsis occurred before the site of "remapping.") These effects demonstrate a remarkable degree of plasticity in the adult human brain.

10:05-10:15 (19)

Preference for Left and Right in Portraits. JOHN P. McLAUGHLIN \& KIMBERLY E. MURPHY, University of Delaware-Artists who have painted portraits overwhelmingly represented the sitter with the head turned, emphasizing one check. When the sitter was female, the left cheek was shown with much greater frequency than the right. However, in forced-choice judgments between original and mirror-reversed portraits, versions emphasizing the right cheek were preferred by male and female, left- and right-handed subjects, irrespective of the sitter's sex. Cultural, not biological, influences may be responsible for the bias.

\section{LETTER/WORD PROCESSING I}

Blue Room, Friday Morning, 8:00-10:20

Chaired by Rebecca Treiman, Wayne State University

8:00-8:10 (20)

Effect of the Proper/Common Distinction on Duration. D. H. WHALEN, Haskins Laboratories, \& HEIDI E. WENK, Yale University and Haskins Laboratories-Previous research has shown that in frequent words are longer in pure frequency lists than frequent words. Lists with proper/common homonyns (e.g., Grant/grant) led to a surprising result: Although (printed) names are less frequent than words, name lists were faster than word lists. This could be due to the difficulty of focusing on one aspect of a homonym, commonness of name lists, greater frequency for names in speech, or special treatment for names.

\section{8:15-8:30 (21)}

Adaptive Modulations in the Naming Task. ALAIN CONTENT, Université libre de Bruxelles, \& RONALD PEEREMAN, Université de Bourgogne, Dijon-We examined how naming performance varies as a function of list contents. Naming times were collected on printed words mixed with word or pseudoword fillers. Length and regularity effects increased whereas frequency and neighborhood effects decreased in the presence of pseudowords. The observed dissociations cannot be explained by single route models and support a functional distinction between addressing and assembling processes.

$$
\text { 8:35-8:50 (22) }
$$

The Role of Neighborhood, Stress, and Frequency in Word Naming. LUCIA COLOMBO, University of Padova, STEPHEN J. LUPKER, \& PATRICK BROWN, University of Western Ontario-The influences of list composition (blocked versus unblocked), frequency, lexical stress, neighborhood, and lexicality on naming words and non- 
words were investigated in a set of experiments. The main aim was to determine whether subjects use different criteria to start articulation depending upon the composition of the list. The results show that the subjects' tendency to shift criteria as list composition changes is primarily influenced by frequency and lexicality. 8:55-9:10 (23)

Strategic Control in a Naming Task: Changing Routes or Changing Deadlines. STEPHEN J. LUPKER, PATRICK BROWN, University of Western Ontario, \& LUCIA COLOMBO, Universita degli Studi di Padova-Naming times for high-frequency irregular words and, in some cases, nonwords are shorter in pure blocks than in mixed blocks, effects attributed to strategic deemphasis of the assembly route (Monsell et al., 1992). This explanation was examined in four experiments. The results strongly challenge the strategic deemphasis explanation and support an explanation based on a mixed-block output criterion that causes fast stimuli to be named more slowly and slow stimuli to be named more rapidly.

$$
\text { 9:15-9:35 (24) }
$$

The Locus of Word Frequency Effects Revealed by Patterns of Task Interference. ROGER W. REMINGTON, NASA-Ames Research Center, \& ROBERT S. McCANN, Sterling Software-Word frequency effects in lexical decision have been associated with lexical encoding, central decision, or both. We investigate the locus of the word frequency effect in two Psychological Refractory Period experiments consisting of a tone discrimination task followed by a lexical decision task. The locus is inferred from patterns of additivity and underadditivity between effects of word frequency and task 1-task 2 SOA. The implications of our results for theories of visual word processing are discussed.

$$
\text { 9:40-9:55 (25) }
$$

"Crowding," Attention, and Motivation: Foveal Versus Parafoveal Word Processing. EVA DREIKURS FERGUSON, Southern Illinois University-Edwardsville-Previous studies by the investigator found that hunger (vs. satiation) facilitates word recognition under foveal but not under parafoveal viewing. It is not known why the two types of word processing conditions differ. Is it attention? A foveal-cue and a parafoveal-cue study assessed this. A second set of two studies assessed if crowding under cortical magnification is relevant. Neither variable fully explains the foveal versus parafoveal difference in word processing.

$$
\text { 10:00-10:15 (26) }
$$

Effects of Lexical Neighborhood Density on Phoneme Perception. JAMES R. SAWUSCH, ROCHELLE S. NEWMAN, \& PAUL A. LUCE, SUNY at Buffalo-Previous studies of the influence of lexical status on phoneme perception have found both substantial data supporting a role for lexical influences and variability in the effects across stimulus sets. Using nonword series in which the density of the lexical neighborhoods for the nonwords was varied, listeners consistently identified ambiguous stimuli as containing the phoneme from the higher density lexical neighborhood. Thus, the lexical neighborhood influences phoneme perception for nonwords as well as words.

\section{MOTOR CONTROL}

Empire Room, Friday Morning, 8:00-10:50

\section{Chaired by James C. Johnston, NASA-Ames Research Center}

\section{8:00-8:15 (27)}

Bimanual Movements Lead to Reduced Timing Variability in Healthy Subjects and Cerebellar Patients. RICHARD B. IVRY, LAURA L. HELMUTH, \& ELIZABETH A. FRANZ, University of California, Berkeley-We compared single-handed and two-handed repetitive tapping $(2.5 \mathrm{~Hz})$. Within-hand variability is reduced during bimanual tapping. The improvement is not due to feedback from the opposite hand and is found with nonhomologous movements. We propose 1) there are separate timers associated with each effector; 2) the outputs of these timers are integrated prior to movement implementation. Patients with cerebellar lesions also show improved performance when tapping with their impaired hand under bimanual conditions.

\section{8:20-8:35 (28)}

Can Aerobic Exercise Influence Cognitive and Motor Functioning for Older Individuals? BETH KERR, MICHAEL SCOTT, \& MICHAEL V. VITIELLO, University of Washington-Healthy older men and women (mean age $=67$ years) were randomly assigned to a 6-month aerobic-exercise program or a control stretching-exercise program. Subjects underwent comprehensive physiological evaluation and completed a one-hour battery of cognitive and motor tests prior to and following the exercise programs. Aerobic exercise training improved cardiovascular fitness. However, we were not able to demonstrate that aerobic exercise training was associated with improved cognitive and motor function.

\section{8:40-8:55 (29)}

Effector Independence in Hierarchically Structured Motor Programs for Handwriting. CHARLES E. WRIGHT \& PATRICIA LINDEMANN, Columbia University-Over several months, subjects learned to write fluently with their nondominant hand. By successively introducing different strokes, letters, and words, we discovered that effector-specific information is confined to representations at the stroke level or below and that the representations at the letter and word levels are effector independent. These results suggest a "virtual machine" organization with synergies for each effector that organize its degrees of freedom to produce actions (possibly strokes) specified abstractly. 9:00-9:20 (30)

Computations for Obstacle Avoidance. LOUKIA D. LOUKOPOULOS, DAVID A. ROSENBAUM, University of Massachusetts, RUUD G. J. MEULENBROEK, Nijmegen Institute for Cognition \& Information, \& JONATHAN VAUGHAN, Hamilton College (read by David A. Rosenbaum)-Despite the importance of obstacle avoidance in everyday life, remarkably little work has been done on it by students of human motor control. This neglect may be due in part to the lack of a coherent computational model of obstacle avoidance by biological agents. We present such a model and illustrate its implication in the context of reaching. The computations extend a model of motor planning presented at Psychonomics in 1991.

\section{9:25-9:40 (31)}

Inter- and Intra-Hand Timing in Piano Performance. MARK A. SCHMUCKLER \& ELIZABETH A. BOSMAN, University of TorontoTwo experiments examined motor coordination during piano performance. In Experiment 1, pianists played two successive notes with either a single hand (the $2 \mathrm{~F}$ condition) or both hands (the $2 \mathrm{H}$ condition). Latencies to initiate the first note in the $2 \mathrm{H}$ condition exceeded the $2 \mathrm{~F}$ condition; in contrast, no difference occurred between the conditions for the time between the note onsets. Experiment 2 replicates and extends these results, employing pianists who touch type, in both digraph typing and piano performance tasks.

\section{9:45-10:00 (32)}

Role of Position and Distance Movement Codes in Adaptive Spatial Alignment of Eye and Hand. GORDON M. REDDING, Illinois State University, \& BENJAMIN WALLACE, Cleveland State University-Spatial realignment aftereffects failed to appear when reciprocal pointing between optically displaced targets could be controlled simply by commands to reduce the visual distance between simultaneously visible starting and ending limb positions. In contrast, realignment aftereffects were substantial when starting limb position was not visible and movement should be initiated by translation of target coordinates in visual space into position coordinates in proprioceptive limb space.

$$
\text { 10:05-10:20 (33) }
$$

Phase Attraction in Reaching and Grasping Movements. STEPHEN A. WALLACE, University of Colorado-Six adult subjects were required to produce different relative phases of final hand closing in rhythmical movements and synchronized the grasp of an object with the beat of a metronome. The results showed a negative, linear relationship between the required and actual phasing. A preferred pattern was located at a required phasing with the lowest total variability, suggesting that the principles of nonlinear dynamics may be extented to reaching and grasping movements. 


\section{0:25-10:45 (34)}

Optical Information for the Guidance of Targeted Reaching. GEOFFREY P. BINGHAM, JENNIFER ROMACK, \& MICHAEL STASSEN, Indiana University - We provide evidence that the decelerative portion of rapid reaching is visually guided. We describe optical information that may be used to guide reaching. The strategy entails the use of two variables. $\tau_{\Phi}$ specifies the time to close the gap between target and hand; $\tau_{R}$ specifies the time to reach target distance. The strategy is to use $\tau_{R} \geq$ constant $\tau_{\Phi}$. We present evidence from rapid targeted reaches of 4 subjects perturbed via a displacement prism.

\section{TOUCH I}

Ambassador Room, Friday Morning, 8:00-9:30

\section{Chaired by Roger W. Cholewiak, Princeton University}

\section{8:00-8:10 (35)}

Vibrotactile Adaptation Enhances Frequency Discrimination. ALAN K. GOBLE \& MARK HOLLINS, University of North Carolina at Chapel Hill (read by Mark Hollins) -Vibrotactile adaptation has two known psychophysical effects: elevation of detection threshold and reduction of the amplitude difference threshold. In the present study, frequency difference thresholds for $25 \mathrm{~Hz} 20 \mathrm{~dB}$ SL standards were measured in three subjects without and in the presence of $25 \mathrm{~Hz}$ adapting stimuli of various amplitudes. Frequency discrimination was best when the adapting stimulus and standard were identical, extending the enhancement effect of adaptation into the quality domain.

\section{8:15-8:30 (36)}

Tactile Acuity and Aging. JOSEPH C. STEVENS, John B. Pierce Laboratory-Getting older blunts spatial acuity of the skin, more so for peripheral sites (e.g., fingertips, toes) than more central sites (e.g., forearm, lips). Various measures (two-point discrimination, spatial orientation task) reveal this, already commonly in middle age, and almos universally in persons over 65 . Fingertip acuity in most elderly and many middle-aged is poorer than the spacing among the elements of Braille letters, suggesting one functional implication.

$$
\text { 8:35-8:45 (37) }
$$

The Effects of Age on Suprathreshold Responses to Vibrotactile Stimulation. STANLEY J. BOLANOWSKI, KAREN L. HALL, Syracuse University, GEORGE A. GESCHEIDER, Hamilton College, \& RONALD T. VERRILLO, Syracuse University-The purpose of this study was to investigate the effects of aging on the perception of suprathreshold vibratory stimuli $(250 \mathrm{~Hz})$ applied to the thenar eminence of the right hand of human observers with a $2.9 \mathrm{~cm}^{2}$ probe contact area. The sensory magnitudes produced by these stimuli as determined by absolute magnitude estimation were found to be substantially lower across all stimulus intensities in older (average age, 69.2 years) than in younger (average age, 23.4 years) groups of subjects.

\section{8:50-9:05 (38)}

Hypervigilance to Experimental Pain in Fibromyalgia Pain Patients. GARY B. ROLLMAN, University of Western Ontario, \& STEPHAN LAUTENBACHER, Max Planck Institute for Psychiatry, Munich-Earlier studies have demonstrated hyperresponsiveness among patients suffering from fibromyalgia, a rheumatological disorder involving widespread muscle pain. Here, pressure pain thresholds, electrical pain thresholds, and heat pain thresholds were significantly lower for 26 female patients compared to an age-matched control group. Group detection thresholds were generally similar. The data indicate that hypervigilance to experimentally induced pain among fibromyalgia patients reflects a perceptual amplification of all noxious stimuli rather than only those which affect muscle afferents.

$$
\text { 9:10-9:25 (39) }
$$

The Effects of Aging on Vibrotactile Thresholds. GEORGE A. GESCHEIDER, STANLEY J. BOLANOWSKI, K. E. HOFFMAN, KAREN L. HALL, \& RONALD T. VERRILLO, Syracuse University-Thresholds were measured for the detection of vibratory stimuli in subjects ranging in age from 15 to 87 years. Vibratory stimuli of 1 , 10 , and $300 \mathrm{~Hz}$ were delivered to the thenar eminence through a small $\left(.008 \mathrm{~cm}^{2}\right)$ and a large $\left(2.9 \mathrm{~cm}^{2}\right)$ contactor. The results show a reduc- tion in the sensitivity of the $P$ channel of approximately $3 \mathrm{~dB}$ per decade increase in age. The NP I, NP II, and NP III channels show comparatively less reduction in sensitivity as age increases.

\section{HUMAN MEMORY I}

Palladian Room, Friday Morning, 10:05-12:20

Chaired by Catherine G. Penney, Memorial University of Newfoundland

10:05-10:20 (40)

What von Restorff Really Did: The Subtlety of Distinctiveness. R. REED HUNT, University of North Carolina at Greensboro-The concept of distinctiveness is often treated as synonymous with the operation of isolation, leading to the tacit assumption that perceptual/conceptual salience is necessary for distinctiveness. Von Restorff's research often is cited as the mother of such thinking. In fact, von Restorff discounted perceptual salience as necessary for her effect. Her reasoning and experiments will be described along with a replication of the critical experiment. Implication for contemporary views of distinctiveness will be discussed.

\section{0:25-10:40 (41)}

Recollections of Faces Following Judgments of Similarity and Distinctiveness. TIMO MANTYLA, University of Stockholm-The effects of distinctive and relational processing on face recognition were examined in two experiments. Subjects either sorted faces into four categories or rated them on distinctiveness. Subsequently, when recognizing an item, subjects indicated whether they explicitly remembered or merely knew that it was presented previously. Type of encoding interacted with judgments of recollection, so that distinctive encoding produced more "remember" responses than relational encoding, whereas the opposite pattern of results was obtained for "know" responses.

$$
\text { 10:45-11:05 (42) }
$$

Dual Context Theory I: "Distinctiveness" and the Sentence Position Effect. LINDA S. BUYER, D. CHRIS ANDERSON, \& PAUL D. WORLAND, University of Notre Dame (read by D. Chris Anderson)-Worland, Buyer, and Anderson (in preparation) demonstrated that it is distinctiveness in context and not bizarreness or imagery per se that is responsible for the bizarre imagery phenomenon. We extended this by varying the position of a "different" item in an otherwise homogeneous serial list. The "different" item is recalled better the later in the list that it appears. Additionally, recall of the "different" item exceeds that of the identical item in the same position in an entirely homogeneous list.

\section{1:10-11:25 (43)}

The Bizarreness Effect: Imaginal and/or Semantic? DEBRA WEIR \& CHARLES L. RICHMAN, Wake Forest University (read by Charles L. Richman)-The bizarreness effect $(B E)$, superior recall of bizarre relative to common sentences, has been attributed to imaginal (Cornoldi, Einstein, Margres, McDaniel) and semantic (Richman) processes. Seventy-two subjects were instructed to generate 12 common and 12 bizarre images or sentences from 24 concrete nouns. Imagery and sentence generation instructions were equally effective in producing the $B E$. These results, and others to be reported, demonstrate the robust nature and the theoretical importance of studying the $B E$.

\section{1:30-11:50 (44)}

On the Overreliance of Significance Testing in the Social Sciences. GEOFFREY R. LOFTUS, University of Washington-Significance testing is used in most social science experiments to transit from data to conclusions. This is inimical to scientific insight for several reasons. First the logic of significance testing revolves around null hypotheses that are almost always known apriori to be false. Second significance testing deemphasizes experimental power. Third, significance testing results a series of binary decisions (significant/not significant) that often ignore important patterns in the data. I discuss possible alternatives to significance testing.

$$
\text { 11:55-12:15 (45) }
$$

A Storage-Retrieval Analysis of the Tulving-Wiseman Function. DAVID M. RIEFER, California State University, San BernardinoThe Tulving-Wiseman function is analyzed using a multinomial model 
based on retrieval-independence theory. The model contains hypothetical storage and retrieval parameters, and reveals that violations of the function occur only when weak storage is coupled with strong retrieval. This framework easily accounts for both encoding and retrieval exceptions to the function. By assuming that storage and retrieval are positively correlated, the model predicts the equation $P(R n I R L)=P(R N)+$ c[P(RNIRL)][1-P(RNIRL)], which closely approximates the TulvingWiseman function.

\section{PERCEPTION I}

Diplomat Room, Friday Morning, 10:05-12:15

\section{Chaired by Joseph S. Lappin, Vanderbilt University}

10:05-10:25 (46)

Neural Code Efficacy: Different Codes Best Mediate Different Neural Functions. ZIXI CHENG \& GERALD S. WASSERMAN, Purdue University (read by Gerald S. Wasserman)-Multiple Meaning Theory inspired a study of intracellular responses in single photoreceptors and optic nerve fibers. The efficacies of 6 candidate neural codes were determined using Signal Detection Theory. We found that: A) Code, adaptation state, and intensity all affect efficacy. B) Efficacies diminish at the proximal neural locus. C) The dimunition is code dependent. D) The code which most competently transmits signals between cells differs from the code which has the highest efficacy within a cell.

$$
\text { 10:30-10:50 (47) }
$$

Stimulus Generalization and the Indirect McCollough Effect. THOMAS EISSENBERG, LORRAINE G. ALLAN, SHEPARD SIEGEL, \& NICOLE PETROV, McMaster University (read by Lorraine G. Allan)-Following an induction period in which a colored grid (e.g., horizontal) alternates with a complementarily colored field, horizontal grids and orthogonal (i.e., vertical) grids elicit complementary color aftereffects. Several reports indicate that nonorthogonal grids (e.g., diagonals) do not elicit aftereffects, suggesting an underlying, orthogonally organized perceptual mechanism. The present research demonstrates that diagonal grids do elicit color aftereffects. This finding is consistent with an associative interpretation of contingent color aftereffects that incorporates stimulus generalization.

$$
\text { 10:55-11:10 (48) }
$$

Effects of Optical Pitch on Oculomotor Control and Perceived Elevation. MALCOLM M. COHEN, NASA-Ames Research Center, SHELDON M. EBENHOLTZ, SUNY College of Optometry, \& BARRY J. LINDER, Kaiser Permanente-While viewing a pitched visual display, sixteen observers attempted to set a visual target to apparent eye level, and to set their eyes to a relaxed or a horizontal orientation. Both settings of the target and settings of gaze angle (as monitored with an ISCAN infrared video system) systematically varied with the pitch orientation of the display. Our results suggest that an involuntary optostatic response underlies judgments of target elevation under these conditions.

$$
\text { 11:15-11:30 (49) }
$$

Familiar Size and Instruction Effects on Egocentric Distance and Size Estimates. SÉRGIO S. FUKUSIMA \& JOSÉ A. DA SILVA, University of São Paulo at Ribeirão Preto (read by José A. da Silva)Blank cards in reduced-cue condition constrain distance estimates around 1-3 $\mathrm{m}$ and size estimates increasing with visual angle. After replacing them for off-sized or normal playing cards, or suggesting the playing card size, estimates are affected by the known size associated with its visual angle. Objective and apparent instruction do not affect distance but size estimates. An explanation is considered (see Gogel and da Silva's 1987 Two-Process Theory, Perception \& Psychophysics, 41, 220-238).

$$
\text { 11:35-11:50 (50) }
$$

Perceiving an Unstable Visual World. GEORGE W. McCONKIE \& CHRISTOPHER B. CURRIE, University of Illinois-The light pattern on the retina shifts with every saccade, yet we perceive a stable world. Research in which simple stimuli are moved during saccades has suggested a mechanism that remaps the position of the entire retinal signal on each saccade. In research using complex, naturalistic stimuli we find different results. We suggest that, in normal viewing, visual stability is achieved using local stimulus features in the region of the saccade target.

\section{1:55-12:10 (51)}

Effects of Internal Tempo on Time Estimation Behavior. MARILYN BOLTZ, Haverford College-The present research considers how changes in an individual's internal tempo influences the learning and remembering of auditory event durations. In the first set of studies, two groups of individuals were subjected to stressful and relaxing stimuli and then asked to remember the duration of events that had previously been well-learned. Results show that relative to a control group, stressed individuals under-extrapolate an event's duration from memory and falsely recognize shorter durations as identical to those they had learned earlier. Conversely, relaxed individuals tend to over-extrapolate an event's duration and show a high false recognition rate for longer durations. A second set of studies indicate that variations in internal tempo also differentially bias one's ability to learn event durations that vary in their own tempo and total length. These overall findings highlight the need to acknowledge internal factors in cognitive models of time estimation behavior.

\section{3-D/MOVEMENT PERCEPTION I}

Hampton Room, Friday Morning, 10:30-12:15

Chaired by Jack M. Loomis, University of California, Santa Barbara

$$
\text { 10:30-10:50 (52) }
$$

Imagery and Action: Knowing How Objects Look When They Are Moved by Hand Without Vision. JOHN J. RIESER, Vanderbilt University-When you close your eyes and wave your hand around you know what your moving hand looks like, based on afferent and efferent information about the hand's shape and changing positions. Studies conducted with Danial Schwartz show that when you hold an object, it is similarly easy to know what the object looks like while moved through its changing positions, even when the dynamics of the object movement do not specify the changing perspectives. This is equally true for adults and young children. Whereas research on dynamic imagery shows that difficulty of imagining how objects look after they move varies as a function of the distance and complexity of the to-be-imagined movement, our results show this is not the case when the to-be-imagined object movements are accompanied by the corresponding hand movements. 10:55-11:10 (53)

Higher-Level Constraints in the Perception of Biological Motions. BENNETT I. BERTENTHAL \& JEANNINE PINTO, University of Virginia-Recent psychophysical and computational models suggest that moving point-light displays of biological motions are organized by lowlevel processing constraints, such as local rigidity. In the current research, low-level constraints are rendered uninformative with a masking paradigm, while higher-level constraints, such as familiarity, orientation, and symmetry are manipulated. The findings converge to show that the perception of a coherent point-light structure depends on a global representation of the depicted form.

\section{1:15-11:30 (54)}

Competition and Cooperation in Spatiotemporal Boundary Formation. THOMAS F. SHIPLEY, Temple University, \& PHILIP J. KELLMAN, UCLA-Spatiotemporal boundary formation (SBF) refers to perception of continuous boundaries, form, and motion from changes in local elements sparsely distributed in space and time. We report two new findings: 1) Element changes not positioned along the boundary of the moving figure disrupt SBF. 2) If such changes can be organized into a second moving figure, disruption decreases. Two constraints are supported: Certain local events must be incorporated in SBF, and each event is incorporated only once.

\section{1:35-11:50 (55)}

Rotation Amplitude, Frontal Views, and Perceived 3-D Shape. MYRON L. BRAUNSTEIN \& JEFFREY C. LITER, University of California, Irvine-Judged shape in structure-from-motion displays varies with information for rotation, specifically, compression of frontally oriented surfaces. We examined effects of rotation amplitude and of inclusion of a frontal view in the rotation sequence. Perceived depth was reduced with increased rotation out of the frontal view, and was reduced even further when the frontal view was not included. We conclude that absence of a frontal view affects use of compression to judge 3-D shape. 


\section{1:55-12:10 (56)}

The Visual Perception of Surface Orientation. J. FARLEY NORMAN, JAMES T. TODD, \& FLIP PHILLIPS, Ohio State University-In many computational models of shape perception, "shape"' is defined as a point-by-point representation of local surface orientation. To investigate the psychological validity of this approach, we measured observer sensitivity to differences in local orientation for randomly shaped curved surfaces defined by stereo, motion, shading, and texture. Observers judged whether the orientation difference between designated pairs of surface regions was greater than an implicit standard. The results reveal that the perception of local orientation is surprisingly imprecise.

\section{REPETITION/PRIMING EFFECTS I}

Blue Room, Friday Morning, 10:30-12:35

Chaired by Marilyn C. Smith, University of Toronto

10:30-10:45 (57)

Phonological Codes, Repetition Blindness, and Printed Sentence Comprehension. VERONIKA COLTHEART, Macquarie University-With rapid serial visual presentation (RSVP), the second occurrence of a repeated word is unlikely to be detected, a phenomenon termed "repetition blindness." A preceding homophone of the target also causes repetition blindness. Phonological codes are evoked during printed sentence comprehension and cause errors in sentence evaluation. Several experiments examined sentence comprehension and recall using RSVP when sentences were viewed in silence or while concurrent articulation took place.

\section{0:50-11:10 (58)}

Is Implicit Memory Necessary? KIM KIRSNER \& CRAIG SPEELMAN, University of Western Australia-Repetition priming cannot be distinguished procedurally or empirically from more general procedures and principles involving extended practice. Transfer data support a model in which item, task, and other components make separate contributions to performance. Implicit Memory may be nothing more than a special case of more general skill acquisition models involving the power law. One implication of this claim is that individual and group difference studies involving repetition priming may be confounded by practice differences.

\section{1:15-11:30 (59)}

Repetition Detection and "Blindness" in Rapid Lists: Processing and Representation. BRUCE W. A. WHITTLESEA \& K. WAYNE PODROUZEK, Simon Fraser University-Repeated words are poorly detected in rapid lists. We demonstrate that, under these conditions, recall of repeated words is more than double that of nonrepeated words; reports of the first and second occurrences are independent; report of each occurrence depends on recall of adjacent words; and recalling the list facilitates repetition detection. In contrast to recent theories, we concluded that both occurrences are encoded, and that "repetition blindness" is primarily due to poor retrieval conditions.

$$
\text { 11:35-11:50 (60) }
$$

Automatic Memory Retrieval in Repetition Blindness. MICHAEL E. J. MASSON, University of Victoria-Subjects attempted to report the last word in a rapidly presented series containing two orthographically related words (e.g., ...cake turn cave). Report probability was lower than when all preceding words were unrelated to the target (a blindness effect). Reporting errors indicated that this effect was due to automatic retrieval of the related word in the series (cake), cued by the target word (cave). Implications for the interpretation of repetition blindness are considered.

\section{1:55-12:05 (61)}

Interference Effects in Repetition Priming. JAY G. RUECKL, Harvard University-Interference effects on repetition priming were investigated in a study-test paradigm in which pseudowords presented during the study task were blocked on the basis of orthographic similarity. In contrast to previous results, which suggest that repetition priming is not affected by proactive or retroactive interference, in the present study interference affected both identity priming (the priming of previ- ously seen pseudowords) and similarity priming (the priming of new pseudowords that were orthographically related to the primes).

$$
\text { 12:10-12:30 (62) }
$$

Do Subliminal Stimuli Enter the Mind Unnoticed? Tests With a New Method. ANTHONY G. GREENWALD \& SEAN C. DRAINE, University of Washington-Existing methods to test for subliminal activation by undetectable stimuli have been criticized as intrinsically inconclusive. A new method, analyzing the regression relation between direct and indirect measures of responses to near-threshold stimuli, overcomes these criticisms. Results from use of the method replicated the only previous findings using it, showing that subliminal stimuli, even when unnoticed, can influence consciously guided performances. Possible criticisms of the new method are considered.

\section{BEHAVIORAL PHARMACOLOGY Empire Room, Friday Morning, 11:00-12:20}

\section{Chaired by T. L. Davidson, Purdue University}

\section{1:00-11:15 (63)}

5-HT 3 Receptor Regulation of Cocaine Withdrawal. GEORGE R. KING, Duke University Medical Center-Research indicates that the route of cocaine administration influences its subsequent behavioral and neurochemical effects: Daily injections produce sensitization to cocaine's effects, while the continuous infusion of cocaine via osmotic minipump produces tolerance to cocaine's effects. The bases of these effects is not known. However, other research indicates that $5-\mathrm{HT}_{3}$ receptors can regulate the behavioral effects of stimulants as well as mesocorticolimbic dopamine release. The present experiments present evidence that continuous and intermittent cocaine administration differentially alter the ability of $5-\mathrm{HT}_{3}$ receptors to regulate cocaine-induced hyperactivity and DA release.

\section{1:20-11:30 (64)}

Directed Incentive Effects of Signals for Ethanol. MARVIN D. KRANK \& KYNA SQUAREY, Mount Allison University-Discrete localized signals for ethanol elicit several conditioned responses (CRs) relevant to ethanol self-administration. These include anticipatory magazine entries, signal-direct approach and contact, and location specific enhancement of drug-associated responses. This interactive complex of CRs is consistent with incentive/expectancy theories of addictive behavior.

\section{1:35-11:45 (65)}

Amphetamine-Induced Modification of Quinine Palatability: Analysis by the Taste Reactivity Test. LINDA PARKER, Wilfrid Laurier University, \& KIRA LEEB, Concordia University-The effects of low doses of d-amphetamine $(.25-.5 \mathrm{mg} / \mathrm{kg}$, ip) on taste reactions elicited by quinine solutions in a $5-10 \mathrm{~min}$. taste reactivity test are assessed in a series of three experiments. Amphetamine consistently suppressed aversive reactions elicited by quinine solutions. The results suggest that amphetamine, like morphine, attenuates the aversiveness of the taste of quinine solution.

$$
\text { 11:50-12:00 (66) }
$$

Salicylate-Induced Changes in Auditory Thresholds of Adolescent and Adult Rats. JAMES F. BRENNAN, DANIEL CHAMPNEY, University of Massachusetts at Boston, \& PAWEL J. JASTREBOFF, University of Maryland at Baltimore-Shifts in auditory intensity thresholds for different frequencies (1-35 kHz) were tested in 65 pigmented rats using 3 paradigms: appetitively motivated bar press behavior, 1-way and 2-way active avoidance. All methods estimated thresholds through presentations of descending and ascending series of intensities for each test frequency value. Sensitive measures of threshold were found under all methods, and compared to controls, subjects at both age levels injected with $300 \mathrm{mg} / \mathrm{kg}$ salicylate showed upward threshold shifts at selected frequencies.

\section{2:05-12:15 (67)}

The Effect of NAME on Perceptuomotor Learning. GEORGE A. CICALA, LORNA ESTALL, \& STEVEN J. GRANT, University of Delaware-The effects of the nitric oxide synthase inhibitor $\mathrm{N}-\omega$-nitroL-arginine methyl-ester (NAME) on learning was assessed in a modi- 
fied Morris swim tank task. NAME was shown to retard learning in dose-response pattern. Controls ruled out the possibility of sensory or motor impairment. These results suggest that NAME functions like aminophosphonovaleric acid (AP5) a known N-methyl-D-asparate receptor antagonist. AP5 antagonizes the NMDA receptor responsible for nitric oxide production. NAME prevents its synthesis. Either will impair learning.

\section{TOUCH II}

Ambassador Room, Friday Morning, 9:40-11:50

Chaired by Joseph C. Stevens, John B. Pierce Laboratory

\section{9:40-9:55 (68)}

Correlates of Vibrotactile Pattern Perception. ROGER W. CHOLEWIAK \& AMY A. COLLINS, Princeton University-Examining factors that might underlie the rapid and accurate perception of vibrotactile patterns, a battery of different measures, including basic tactile sensitivity as well as simple and complex tactile pattern perception were tested on a number of observers. The ability to learn to identify a large complex set of vibrotactile 2-dimensional patterns appears to be correlated with a number of factors including discrimination performance on a small, simple pattern set. Supported by NIDCD DC00076.

10:00-10:15 (69)

Perceptual Asymmetry in Haptic Discrimination. SOLEDAD BALLESTEROS, Universidad Nacional de Educación a Distancia, DIONISIO MANGA, ANA B. NAVARREDONDA, Universidad Complutense de Madrid, \& JOSÉ MANUEL REALES, Universidad Nacional de Educación a Distancia-Subjects explored two-dimensional unfamiliar raised line patterns with the index and middle fingertips of their right and left hand in different blocks of trials. Using a bilateral symmetry detection task, a left hand advantage in latency but not in accuracy was found. As in previous studies asymmetric patterns were detected more accurately than symmetric patterns. Sex differences in overal performance were not significant. Results are discussed in terms of hemispheric specialization in haptic scanning.

10:20-10:40 (70)

Haptic Perception of the Extent of Statically Held Rods. SAPNA GANESHAN, Bell Northern Research, SUSAN J. LEDERMAN, \& RANDY ELLIS, Queen's University (read by Susan J. Lederman)Turvey, Carello and their colleagues have offered a "direct perception" interpretation of the haptically derived perception of the length of statically held rods. Two alternative models are offered here: a) a psychophysical "force/torque" model, developed from formal mechanical analysis of the inertial parameters of the hand/object system; b) a more interpretive "percept-percept" model, which proposes that haptic length estimates are mapped on to an additional perceptual variable, estimated rod weight. The current study pits these models against one another experimentally.

\section{0:45-11:00 (71)}

Haptic Search on Spatial and Nonspatial Dimensions. ROBERTA L. KLATZKY, Carnegie-Mellon University, SUSAN J. LEDERMAN, \& C. L. O'NEILL, Queen's University-We update a previous report on a haptic search task. The thirty studies included searches on spatial dimensions (e.g., horizontal/vertical; left/right position of raised element) and nonspatial dimensions (e.g., presence/absence of edges and holes and material properties such as hard/soft). Nonspatial dimensions generally produced flat search functions or shallow slopes, relative to spatial dimensions. Correlation patterns between slopes and intercepts will be considered, as will implications for haptic primitives.

\section{1:05-11:25 (72)}

Haptic Perception of Cylinder Length From Longitudinal Momentof-Inertia. PATRICK A. CABE, Pembroke State University, \& LESLIE A. ASHBURN, Wake Forest University-Past research has shown that observers can accurately judge lengths of uniform cylindrical rods rotated about transverse (diametral) axes, using moment-of-inertia information. Moment-of-inertia, however, varies with axis of rotation: We show that observers who haptically rotate unseen cylinders about a longitudinal axis are ordinally accurate in judging cylinder lengths. Evidence indicates that moment-of-inertia informs these judgments, independent of radius information. Present results extend the generality of past findings to a novel axis of rotation.

$$
\text { 11:30-11:45 (73) }
$$

The Time Course of Tactile Selective Attention. PAUL M. EVANS, Willamette University, \& JAMES C. CRAIG, Indiana University (read by James $\mathrm{C}$. Craig) - The processing of a target stimulus may be interfered with by the presentation of a nontarget stimulus at a nearby location. With visual stimuli, this interference has been attributed to the nontarget "priming" a competing response. The present study found that with tactile stimuli presenting the nontarget after the target produced more interference than presenting it before the target, a result that suggests that priming is not the sole explanation for the effect.

\section{SYMPOSIUM I: BRAIN IMAGING AND ITS IMPACT ON COGNITIVE PSYCHOLOGY \\ Palladian Room, Friday Afternoon, 1:00-3:30}

Chaired by Walter Schneider, University of Pittsburgh

1:00-1:05 (74)

Introductory Remarks. WALTER SCHNEIDER, University of Pittsburgh-In the last ten years there have been major advances in brain imaging that provide psychologists the ability to look into the brain to identify the biological processes underlying cognition. There are multiple techniques, each with different advantages to map out processing. What is the current state of the art of brain imaging? How do we integrate animal and human data? What type of information processing operations can be monitored? How will it impact our theories of cognition? 1:05-1:25 (75)

Memory and Attention at the Neuronal Level. ROBERT DESIMONE, National Institute for Mental Health-The activity of individual neurons can be recorded in awake, behaving monkeys, performing many of the same tasks that have been used in human studies. These studies are beginning to reveal some of the neuronal bases of many cognitive phenomena, including spatially selective attention, working memory, recognition memory, and visual search. Although some of these effects might be correlated with overall changes in cortical activity at the millimeter levels, others may not be detectable with imaging techniques, given current limitations in spatial and/or temporal resolution.

\section{1:30-1:50 (76)}

Neurophysiological and Neuroimaging Studies of Cognition. GREGORY McCARTHY, Yale University-Electrical recordings made from within the human brain during behavioral performance have provided information about its functional anatomy. Studies will be described in which event-related potentials were recorded from the occipital lobe, inferior and medial temporal lobe, and hippocampus in patients performing language processing, attention, and memory tasks. Complementary studies in which brain areas were electrically stimulated during task performance will also be described. Recent attempts to integrate these neurophysiological results with neuroimaging studies will be addressed. 1:55-2:15 (77)

Anatomy and Circuitry of Cognition: Converging PET and ERP Methods. MICHAEL I. POSNER, University of Oregon-Studies of blood flow (PET, FMRI) suggest a functional anatomy of brain activity during information processing. We use high density electrical recording to indicate the scalp signatures of brain generators active in the same language tasks studies by PET. These electrical recordings show when specific activity occurs in visual, phonological, and semantic areas. Attention serves to amplify these activations and program their organization to conform to task instructions. Specific changes in brain activity are also observed as a result of learning and of development. Taken together, cognitive and imaging approaches provide support for theories distinguishing automatic and control processes.

$$
\text { 2:20-2:40 (78) }
$$

Functional Magnetic Resonance Imaging (FMRI): Mapping the Visual System With Millimeter Resolution. WALTER SCHNEIDER, University of Pittsburgh-FMRI allows noninvasive mapping of cortical function with millimeter resolution allowing comparison of cortical activation across many conditions within subject. FRMI results relating to: mapping visual spatial topology, selective attention, attention 
switching, color and motion perception, motor control, and working memory will be described. Availability and limitations of the methodology will be discussed. The impact of millimeter mapping of cortical function to the development of models of cognition will be commented upon.

\section{2:45-3:05 (79)}

Lexical Processing as Revealed by PET Activation Studies. KARALYN E. PATTERSON, MRC Cyclotron Unit, London, DAVID HOWARD, CATHY PRICE, University of London, \& RICHARD WISE, Charing Cross Hospital, London-Following on from the seminal work of the St. Louis group, we have conducted a series of PET activation experiments to examine processing of single spoken and written words by normal subjects performing various tasks (silent listening/viewing; repeating/reading aloud; lexical decision). Most of the results suggest left temporal activation associated with lexical processing, which accords with our interpretation of lesion data. These temporal regions are, however, only critical components of more complex networks. New methods of analysis of rCBF data across tasks may provide insights into the functional connectivity of brain language areas.

$$
\text { 3:10-3:25 (80) }
$$

Commentary: The Promise of Functional Imaging. JAMES L. MCCLELLAND, Carnegie-Mellon University-Functional imaging techniques show great promise for further constraining cognitive theory and for helping us shed light on the neural basis of cognition. However, these techniques have several limitations, only some of which can be overcome through further developments of brain imaging technology. Ultimately, progress toward a deeper understanding of the neural mechanisms of intelligence will depend on combining functional imaging with other behavioral, physiological, and computational approaches.

\section{ATTENTION II}

Diplomat Room, Friday Afternoon, 1:00-3:20

Chaired by MaryLou Cheal, University of Dayton Research Institute

1:00-1:10 (81)

Attention Shifting and the Simon Effect. DANIEL J. WEEKS \& ROMEO CHUA, Simon Fraser University-Stoffer (1991) proposed a unified model of spatial stimulus-response (S-R) compatibility in which S-R compatibility effects proper and the Simon effect are reconciled by appealing to attentional operations. Of particular importance is whether attention is directed toward the imperative stimulus by lateral shifts or zooming. The present experiments call into question whether such attentional operations are functionally involved in the formulation of spatial codes that can produce compatibility effects.

$$
\text { 1:15-1:25 (82) }
$$

Semantically Primed Words Are Selected Even With Spatial Precues. VERONICA J. DARK, Iowa State University-Two masked 100 -msec targets were preceded at 1000 - and 250 -msec SOAs by a prime related to one or neither. A 50-msec arrowhead "precued" one target's location. Both targets were reported on $15 \%$ or fewer trials, usually following related primes. At both SOAs, report of just one target occurred most often for targets related to the preceding prime, suggesting selective attention via priming. The arrowhead enhanced report of the precued target only at the $1000-\mathrm{msec}$ SOA.

$$
\text { 1:30-1:45 (83) }
$$

Automatic and Voluntary Attention in Young and Elderly Adults. JAMES F. JUOLA, HIDEYA KOSHINO, C. BRUCE WARNER, MONTIE MCMICKELL, TODD FIORI, \& MATT PETERSON, University of Kansas - Young ( 24 yrs) and elderly ( 70 yrs) adults searched for a target character in a 4-item display. On each trial, both a central cue (arrow at fixation) and a peripheral cue (abrupt onset of one item) could indicate the target's position. Both young and elderly adults were equally adept at using the central cues, but costs plus benefits in the elderly were much larger for the abrupt onset cues.

$$
\text { 1:50-2:00 (84) }
$$

Attending to Leaves in the Trellis-Visual Search With Naturalistic Stimuli. JEREMY M. WOLFE, Harvard Medical School-Most visual search experiments involve highly artificial stimuli: isolated items placed on homogeneous backgrounds. Do conclusions derived from such experiments generalize to the world of continuous stimuli on complex backgrounds? Natural stimuli make experimental manipulations such as random placement of targets and distractors difficult. We have developed continuous, naturalistic stimuli that can be systematically manipulated. Results support and extend conclusions based on more artificial stimuli (e.g., efficient conjunction search is still possible).

$$
\text { 2:05-2:20 (85) }
$$

A Response Selection Account of the Effect of Number of Alternatives on Dual-Task Processing. MARK VAN SELST \& PIERRE JOLICOEUR, University of Waterloo (read by Pierre Jolicoeur)-Karlin and Kestenbaum (1968) report an attenuation of the RT difference between simple RT and a two alternative discrimination task with increasing temporal overlap in processing for a preceeding two alternative discrimination. We replicate these findings but found additive effects of the number of alternatives in the discrimination task and a go/no-go procedure. These latter results are consistent with models postulating a processing bottleneck at response selection.

\section{2:25-2:40 (86)}

Auditory Spatial Facilitation of Visual Search Performance: Serial or Parallel Processing? THOMAS Z. STRYBEL, California State University, Long Beach, \& DAVID R. PERROTT, California State University, Los Angeles-Auditory spatial facilitation of visual search performance was measured under conditions which approximated visual serial and parallel processing. Visual search times were lower overall in the parallel search condition, and were less affected by the number of distractors and distance from fixation in this condition. The presence of an auditory spatial cue reduced search times below the levels obtained when either an auditory nonspatial cue or no sound cue was used. 2:45-2:55 (87)

Retention of Skilled Search After Nearly A Decade. NANCY J. COOKE, New Mexico State University, FRANCIS T. DURSO, University of Oklahoma, \& ROGER W. SCHVANEVELDT, New Mexico State University-Retention of skilled search after nine years of nonuse was investigated in two tasks. The consistently mapped task involved search for a letter target among one to three distractor letters. The partially consistent task required subjects to indicate the largest digit among one to three other digits. Results indicated minimal loss of speed and no loss of search rate. Also, savings were equivalent for the two tasks in spite of the consistency difference.

3:00-3:15 (88)

Automatic Activation of Object Representations Through Analysis of Form Information. MURIEL BOUCART, University Paris $V$, CNRS, \& GLYN HUMPHREYS, University of Birmingham, U.K.Semantic interference occurs when subjects are asked to attend to a physical property of the form of objects (Boucart \& Humphreys, 1992; 1993). Experiments were designed to investigate the mechanisms responsible for this effect. We manipulated ISI, exposure time, and practice to the task. None of these manipulations eliminated semantic interference. The results suggest that computation of global form information activates automatically object representations and that interference occurs at the level of decision.

\section{3-D/MOVEMENT PERCEPTION II}

Hampton Room, Friday Afternoon, 1:00-3:00

\section{Chaired by Geoffrey P. Bingham, Indiana University}

\section{1:00-1:10 (89)}

What Does It Mean to Be Sensitive to Biological Motion? MAGGIE SHIFFRAR, SHEBA HEPTULLA, MICHAEL O'SHAUGHNESSY, Rutgers University, \& JENNIFER J. FREYD, University of Oregon-We previously reported that at long SOAs, perceptual knowledge of biological motion overrides the shortest path constraint in apparent motion. In a new series of experiments, observers viewed two photographs of a human body interacting with inanimate, solid objects. Is biological motion sensitivity specific to the ways in which biological bodies move relative to themselves or does it generalize to the ways in which bodies move relative to nonbiological objects? 


\section{1:15-1:30 (90)}

Perception of Heading in the Presence of Moving Objects. WILLIAM H. WARREN, Brown University-Most models of heading from optic flow assume a stationary environment, but we typically guide locomotion in the presence of independently moving objects. Simple spatial averaging would yield systematic heading errors. Alternatively, moving objects could be segregated on the basis of dynamic occlusion, relative motion, or inconsistency with global flow, and heading determined from background flow. Experiments examine translation toward a fronto-parallel plane and manipulate the size, number, and direction of moving objects.

\section{1:35-1:50 (91)}

Detection of Heading From Global Velocity. BRIAN P. DYRE, University of Illinois, \& GEORGE J. ANDERSEN, University of California, Riverside (read by George J. Andersen)-Several sources of information, which use the trajectory of velocities in the flow field, have been proposed for determining the direction of heading from optical flow. We investigated an alternative source of information for determining heading based on differences in the magnitude of velocities in regions of the visual field. Our results suggest that heading judgments are influenced by differences in global velocity and are not based solely on element trajectories.

\section{1:55-2:10 (92)}

Time to Perceive Shape Varies in a Linear 3-D Gradient With Orientation. LAWRENCE PARSONS, University of Texas at AustinTime to perceive and compare two abstract objects that are always at the same relative orientation varies in a 3-D gradient as that orientation varies with respect to the observer. It is slowest when objects' masses are vertical, moderate when transverse horizontal, fastest when line of sight, and varies linearly in between. The RT gradient can be quite steep when the mass is concentrated on one object axis, and slighter as it is distributed across parts.

\section{2:15-2:30 (93)}

Sensitivity to Rotational and Translational Components of Motion Parallax. MARY K. KAISER, NASA-Ames Research Center, MICHAEL MONTEGUT, University of California, Santa Cruz, \& DENNIS R. PROFFITT, University of Virginia-Motion parallax can be decomposed into two components: observer relative rotation (loca to each object) and observer-relative translation (resulting in relative motion among objects). Each component fully specifies objects' relative depths, but may differ in utility to human observers. We found that a moderate degree of rotational distortion was required for detection (50\% detection required $85 \%$ distortion; thresholds increased with target distance). Sensitivity to rotational distortion will be compared to that for translational distortion.

\section{2:35-2:55 (94)}

Principles of Predictive Catching in 6-Month-Old Infants. CLAES vON HOFSTEN, Umea University, Sweden, ELIZABETH S. SPELKE, PETER VISHTON, Cornell University, \& QI FENG, Umea University, Sweden-Principles of predictive catching were studied in 6-monthold infants. They were presented with an object moving on a display on four trajectories with equal frequency: two linear trajectories that intersected at the center of a display and two trajectories containing a sudden turn at the point of intersection. The attempts at catching this object showed that young infants' predictive reaching is guided by the principle that a linearly moving object continues in a linear motion.

\section{LETTER/WORD PROCESSING II \\ Blue Room, Friday Afternoon, 1:00-2:50}

Chaired by Louisa M. Slowiaczek, University at Albany-SUNY

1:00-1:15 (95)

Neighborhood Competition in Visual Word Recognition. KENNETH PUGH, Dartmouth College and Haskins Laboratories, KARL REXER, MIRA PETER, University of Connecticut, \& LEONARD KATZ, Haskins Laboratories (read by Leonard Katz)-Neighborhood effects on visual word recognition were investigated by delaying one letter in a target relative to its other letters. Delaying a letter which would have given the target a neighbor was more costly than delaying a letter which yielded no neighbors. This effect was strongest for words with higher frequency neighbors and was reduced for words with a large friendly to unfriendly neighbor ratio and when nonword neighborhoods were small

\section{1:20-1:35 (96)}

Modeling Neighborhood Effects in Lexical Decision. JONATHAN GRAINGER, CNRS, Paris, \& ARTHUR JACOBS, CNRS, MarseilleAn IA model of the lexical decision task is described that simulates both positive and negative RT means and distributions, percent error to word and nonword stimuli, and the means and distributions of miss and false alarm RTs in a number of new experiments on neighborhood effects. In these experiments both the number and the frequency of the orthographic neighbors of word and nonword stimuli are shown to influence subjects' performance.

\section{1:40-1:50 (97)}

Orthographic Redundancy in Word Recognition: Orthographic Neighborhood or Orthographic Context. GERY D'YDEWALLE \& TOM AUWERS, University of Leuven-The Interactive Activation Model (IAM) and Fuzzy Logical Model of Perception (FLMP) both explain the word-superiority effect as a function of orthographic redundancy. In IAM, redundancy is defined by the "neighborhood" which is the number of "friends" (words sharing the same letters, except one, with the letters of the word containing the target letter). FLMP stresses the orthographic "context": the word similarity with its lexical representation. Two experiments provide more support for neighborhood effects.

\section{1:55-2:05 (98)}

Visibility of Linguistic Symbols During Retinal Stabilization. ALBRECHT INHOFF \& RICHARD TOPOLSKI, SUNY at Binghamton-A visible stimulus, when stabilized on the retina, fades from vision. Preliminary data from stabilized letters indicate that loss of letter visibility is preceded by loss of feature information. Stabilized word units, consisting of compound (cowboy) and pseudocompound words (napkin) generally faded via a periphery to center fragmentation. Occasional loss of center letters, however, revealed generally a morphemic unit. Supplementary studies indicated that the morphemic bias can neither be attributed to guessing nor to memory.

$$
\text { 2:10-2:25 (99) }
$$

Name/Rhyme Similarity Effects on Category Decision: A Developmental Study. PATRICIA SIPLE, JASON ANTHONY, \& ANNE MARIE CWIKIEL-GLAVIN, Wayne State University-In a previous study, we demonstrated that similarity of objects' names slowed both positive and negative responses to word pairs in a category decision task. We attributed these results to processing characteristics of the lexicon. In the present study, we examined the development of these processes. Word pairs, varying in name similarity and category relatedness, were presented to second- and fifth-graders for category decision. A developmental process related to work frequency/familiarity was observed. 2:30-2:45 (100)

Both Response Requirements and Level of Analysis Affect Redundancy Phenomena. D. J. K. MEWHORT \& J. G. BRAUN, Queen's University-We studied RT for single-letter, target-and-distractor, and redundant-target conditions in two-alternative and yes-no paradigms under FC and GNG conditions. A consistent distractor increased RT in the FC conditions, not in the GNG conditions. Redundant targets decreased RT in the GNG conditions, not in the FC conditions: coactivation occurred in the yes-no GNG paradigm, but statistical facilitation occurred in the 2A-GNG paradigm.

\section{ANIMAL COGNITION/MEMORY} Empire Room, Friday Afternoon, 1:00-2:50

\section{Chaired by H. S. Terrace, Columbia University}

1:00-1:20 (101)

Response Strategies of Clark's Nutcrackers in an Operant Spatial List Task. JENNIFER A. BASIL, Boston Unversity, DEBORAH J. OLSON, ALAN C. KAMIL, University of Nebraska, \& RUSSEL P. BALDA, Northern Arizona University (read by Alan C. Kamil)Two groups, one required to match and one to nonmatch, were tested in an operant spatial task during which sequential list presentation was 
followed by binary choice. Once acqusition was complete, the groups performed equally well with 1-6 list items, showing recency and delay effects. However, only the stay group showed a primacy effect, and the shift group was more affected by the spatial configuration of list items. These differences suggest group differences in coding information.

\section{1:25-1:40 (102)}

A Differential Outcome Effect With Nonhedonic Differential Outcome. JANICE N. STEIRN \& JANICE E. WEAVER, Georgia Southern University-Pigeons were trained on delayed matching to sample with the hue of the hopperlight either correlated or uncorrelated with the sample hue and sample line orientation. Delay performance on both hue and line-orientation samples was at a higher level for pigeons in the correlated group than for those in the uncorrelated group. Thus a differential outcome effect can be demonstrated without manipulation of the hedonic aspects of the outcomes.

1:45-2:00 (103)

Can a Pigeon Simultaneously Process Temporal and Numerical Information? WILLIAM A. ROBERTS \& STEPHEN MITCHELL, University of Western Ontario-Pigeons were trained to discriminate between sequences of light flashes that varied in both total duration and number of flashes. Subsequent tests for number and time control showed that birds simultaneously processed temporal and numerical information. Pigeons also learned to respond accurately to ambiguous flash sequences in which time and number indicated different responses. The use of postsequence cues to disambiguate these sequences indicated the selective retrieval of time and number information from working memory.

2:05-2:25 (104)

How Dolphins Represent Objects. HEIDI E. HARLEY, Rollins College, HERBERT L. ROITBLAT, \& PAUL E. NACHTIGALL, University of Hawaii (read by Herbert L. Roitblat)-Using a matching-tosample technique, a dolphin was trained to recognize objects in two modalities-echolocation and vision. The dolphin could successfully use either modality. In addition she matched visually samples that were presented through echolocation and matched echoically samples that were presented through vision. Performance improved when both modalities were available simultaneously.

\section{2:30-2:45 (105)}

Strategies for List Execution by List-Sophisticated Monkeys. KARYL B. SWARTZ, Lehman College of CUNY, SHARON HIMMANEN, Hunter College of CUNY, \& H. S. TERRACE, Columbia University-In our previous studies of list learning by monkeys, the location of each item was varied to prevent learning of fixed motor sequences. In this experiment, list-sophisticated monkeys were trained on novel lists in which the location of the first item, or all items, was kept constant. These manipulations systematically affected trials to acquisition and the latency of responding to the first but not subsequent items. Implications for strategies of executing a list are discussed.

\section{PROBLEM SOLVING \\ Ambassador Room, Friday Afternoon, 1:00-3:05 \\ Chaired by Miriam Bassok, University of Chicago}

1:00-1:15 (106)

How Does Calculator Use Change Mathematics Learning in Early Grades? PATRICIA BAGGETT, University of Michigan, \& ANDRZEJ EHRENFEUCHT, University of Colorado-After using calculators for at least one semester, first through fourth grade children were tested for skills and for solving word problems using calculators. The difficulty of word problems does not disappear. When hand calculations are mixed with calculator use, each medium preserves its own characteristic errors. Children's cognitive skills are above their arithmetic skills; therefore children who have learned how to use calculators can solve problems above their grade level.

$$
\text { 1:20-1:40 (107) }
$$

A Mental Model for Early Arithmetic. JANELLEN HUTTENLOCHER, SUSAN LEVINE, University of Chicago, \& NANCY JORDAN, Rutgers University -We examine young children's ability to solve nonverbal calculation problems where they determine how many items are in a hidden array after items are added or taken away from it. Existing studies show that infants are sensitive to number and number transformation, but not whether they represent number exactly. Our studies indicate that children reliably solve nonverbal calculation problems only after age two. We argue that exact number representation depends on use of a mental model.

\section{1:45-2:00 (108)}

Mental Models for the Electronic Classroom: Designing HyperCourseware. KENT L. NORMAN, University of Maryland-Mental models of education were elicited from university students for use in designing a software environment called "HyperCourseware" for the electronic classroom of the future. Students outlined the typical script of a class, listed typical tools and materials of education, and listed types of classroom interaction. The mental models conveyed by HyperCourseware were found to represent successfully the conventional models and objects of instruction (syllabus, lecture notes, discussion) but in electronic form with enhanced capabilities.

2:05-2:20 (109)

The Ineffability of Insight. JONATHAN W. SCHOOLER \& JOSEPH MELCHER, University of Pittsburgh-In a prior study, concurrent verbalization disrupted insight but not noninsight problem solving. We extend this research by examining subjects' problem solving protocols. Noninsight problems elicited more logical arguments, whereas insight problems provoked more pauses, impasses, and statements of the difficulty of verbalizing relevant thoughts. Furthermore, logical argument usage was exclusively predictive of success on noninsight problems. These findings suggest that insight problem solving may be uniquely vulnerable to verbalization because of its reliance on nonreportable processes.

$$
\text { 2:25-2:40 (110) }
$$

Assessing Students' Knowledge and Use of Symbolic Representations in Problem Solving. LAURA R. NOVICK \& MELISSA FRANCIS, Vanderbilt University-We assessed (a) college students' familiarity with four types of symbolic representations (hierarchy, matrix, node-link network, parts and wholes) by having them generate examples of situations for which those representations could be used to organize information, (b) their ability to select the appropriate one of these representations for various word problems, and (c) their ability to use a specified type of representation to solve a word problem. Relations among these three tasks were explored.

$$
\text { 2:45-3:00 (111) }
$$

An Experimental Test to Distinguish Between Style and Ability. GEIR KAUFMANN \& ERLING SVENSEN, University of Bergen, Norway - An experimental test designed to distinguish between style and ability in problem solving is described. An experiment is reported where the procedure is applied to a standard measure purportedly measuring stylistically based preferences for "adaptive" versus "innovative" strategies in problem solving (KAI). The results strongly suggest that the KAI is a measure of ability rather than style. General implications of the findings are discussed.

\section{HUMAN MEMORY II}

Palladian Room, Friday Afternoon, 3:40-5:15

\section{Chaired by Margaret Jean Intons-Peterson, Indiana University}

\section{3:40-3:55 (112)}

The Temporal Course of Verbal Transfer. NORMAN J. SLAMECKA, University of Toronto-Transfer in paired-associates learning was examined as a function of the interval between the two lists; immediate, three weeks, six weeks. Results showed that the magnitudes of positive (A-B, A-B), negative (A-B, A-Br), and nonspecific (A-B, C-D) transfer tended to remain constant over time, while recall of the first list declined substantially. Apparently, memory of a prior experience is irrelevant to the subsequent influence of that experience.

$$
\text { 4:00-4:15 (113) }
$$

Acquisition and Transfer of Skilled Performance: Are Visual Discrimination Skills Stimulus Specific? STEPHANIE M. DOANE, University of Illinois, DAVID L. ALDERTON, Center for Disease Control, JAMES W. PELLEGRINO, Vanderbilt University, \& YONG WOO 
SOHN, University of Illinois-In acquiring visual discrimination skills, does initial task difficulty influence discrimination strategies and skill transfer? We find the degree of transfer to novel stimuli depends on the difficulty of initial discrimination learning during training. Greater stimulus-specific performance occurs when initial discrimination training is easy, and asymptotic training performance takes place earlier under these conditions. Transfer to novel stimuli occurs with initial difficult training, but at the cost of slower acquisition of asymptotic training performance.

\section{4:20-4:35 (114)}

Memory Psychophysics: Context and Acquisition Effects. WILLIAM M. PETRUSIC, Carleton University, JOSEPH V. BARANSKI, DCIEM, \& DEREK HARRISON, Carleton University-In two experiments, subjects learned to associate labels with visual extents and then these labels were used as standards in the method of constant stimuli. Weber fractions for the remembered standards exhibited end-point effects and systematically varied with set size, range, and acquisition conditions. In contrast, Weber fractions with perceptual standards did not depend on these global contextual factors; rather, they were sensitive to local dependencies arising from variations in presentation order.

\section{4:40-4:50 (115)}

Chinese-English Differences in Recall Span and Articulation Rate. HIM CHEUNG \& SUSAN KEMPER, University of Kansas (read by Susan Kemper)-Recall spans and articulation rates for English and Chinese words were obtained for English monolinguals, Chinese monolinguals, and Chinese-English bilinguals. Regressing recall on articulation rate across word length yielded steeper slopes for Chinese than for English words regardless of linguistic proficiency. These results were partially replicated in a loaded recall task involving concurrent retention of digits for English monolinguals and Chinese-English bilinguals. Differences in phonological structure appear to affect immediate verbal recall span.

$$
\text { 4:55-5:10 (116) }
$$

Feedback Frequency Effects on Motor Learning. GABRIELE WULF, Max-Planck Institute for Psychological Research, Munich, TIMOTHY D. LEE, McMaster University, \& RICHARD A. SCHMIDT, UCLA-The effects of a reduced feedback frequency on motor learning were examined. The results indicate that learning of the fundamental movement pattern (generalized motor program) is enhanced by a reduced feedback frequency, whereas parameterization learning tends to be degraded by less frequent feedback. The results also provide evidence for an empirical dissociation of generalized motor program and parameterization processes.

INFORMATION PROCESSING Diplomat Room, Friday Afternoon, 3:30-5:10

\section{Chaired by Dale Dagenbach, Wake Forest University}

\section{3:30-3:50 (117)}

Variations on Parallel Processing. G. NOZAWA \& H. C. HUGHES, Dartmouth College (read by H. C. Hughes)-We identify the processing architecture involved in performing two tasks. In the OR task, correct responses depend on detection of either one of two targets, whereas the AND task requires detection of both targets. The results from a suprathreshold RT experiment and a near-threshold signal detection experiment are compared with predictions based on several models of selfterminating and exhaustive parallel processing, including coactive models. Unifying relationships between these tasks are developed.

$$
\text { 3:55-4:15 (118) }
$$

Stroop Process Dissociations. D. STEPHEN LINDSAY, University of Victoria, \& LARRY L. JACOBY, McMaster University-Jacoby's "process dissociation procedure" was used to estimate the contributions of word-reading and color-naming processes to Stroop performance. Results demonstrate that these processes can operate independently to determine performance: A manipulation that reduced color naming did not affect word reading, and a manipulation that reduced word reading did not affect color naming. We explain why interference is typically greater than facilitation. The influence of automatic processes cannot be measured as differences from baseline.

\section{4:20-4:40 (119)}

Multiple Feature Discrimination Faster Than Single Feature Discrimination Within the Same Object? LISA R. FOURNIER \& CHARLES W. ERIKSEN, University of Illinois (read by Charles W. Eriksen)-Feature discrimination and the number of features to discriminate within an object varied. Specific feature(s) were judged as present or absent. Results showed, judging the presence of 2 or 3 features was faster than judging the less discriminable of these 2 or 3 features alone. Evidence suggests partial transmission of feature information to response mechanisms influences response times. Thus, RT measurements of mental operations may be contaminated by response priming and inhibiting processes.

\section{4:45-5:05 (120)}

Broadening the FLMP. DOMINIC W. MASSARO, University of California, Santa Cruz-The fuzzy logical model of perception (FLMP) has been successful in describing the integration of multiple sources of information in a variety of domains, including speech perception, reading, visual perception, and judgment. We have extended the model to capture the dynamics of processing by predicting performance across processing time. The model has also been elaborated to describe reaction times. We discuss the model and these extensions and compare it to other extant models.

\section{VISION I}

Hampton Room, Friday Afternoon, 3:10-5:10

\section{Chaired by Bruno G. Breitmeyer, University of Houston}

$$
\text { 3:10-3:30 (121) }
$$

Masking of a Pattern by Parts of Itself. VINCENT DI LOLLO \& PETER DIXON, University of Alberta-We report a new type of masking. A $4 \times 4$ array of randomly oriented Landolt Cs was displayed briefly, with one $C$ cued by four surrounding dots. When array and cue were simultaneous, observers reported the orientation of the cued $\mathrm{C}$ accurately. But if the cuing dots remained visible after array offset, the cued location appeared empty and accuracy plummeted. This masking occurs with zero SOA, extends over long periods, and probably involves attentional processes.

$$
\text { 3:35-3:55 (122) }
$$

Concurrent Measurement of Visual Detection and TargetLocalization Performance. RICHARD G. SWENSSON \& KAREN H. CHAN, Harvard Medical School, and Brigham and Women's Hospital-A new visual detection model describes an observer's ability to find and report targets in gray-scale image backgrounds. It relates the ROC curve, for discrimination between target and nontarget images, to the "Localization Response"' (LROC) curve, which measures the conjoint ability to detect and correctly localize actual targets within images. A maximum-likelihood procedure fits both the ROC and LROC curves, concurrently, by estimating two model parameters from image-ratings scored for target-localization.

\section{4:00-4:20 (123)}

A Remarkable Developmental Deficit in Visual Perception. MICHAEL McCLOSKEY, Johns Hopkins University-AH, a successful university student, is severely impaired in localizing objects from vision, although her visual object recognition is normal. Thus, AH may report that an object on her left is on her right (or vice versa), and reach in the wrong direction when trying to touch it. The deficit affects, in addition to object localization per se, AH's reading and spelling. Implications of the impairment for understanding of vision and developmental dyslexias are discussed.

$$
\text { 4:25-4:40 (124) }
$$

The Perceptual Basis for Evolution of Partial Decussation in the Visual System. LEONARD MATIN \& WENXUN LI, Columbia University-Some dimensions of egocentric spatial localization and orientation require identical processing of bilaterally symmetric visual input in order to be perceptually useful whereas others require opposite treatment. This demands anatomical separation of cortical input from the two hemiretinas ("partial decussation"). We explicate these requirements and demonstrate their realization with psychophysical experiments, showing that bilaterally symmetric pitched-from-vertical lines exert iden- 
tical influences on the elevation of visually perceived eye level but exert opponent influences on the orientation of visually perceived vertical. 4:45-5:05 (125)

Selective Adaptation Effects on the Perception of Bistable Patterns. HOWARD S. HOCK, Florida Atlantic University, \& GREGOR SCHÖNER, Ruhr Universitatt Bochum-When an unbiased, bistable stimulus (two percepts are possible) is presented following adaptation to a biased version, the nonadapted percept is more likely to be perceived. This affect has been attributed to the satiation or fatigue of the adapting percept and/or the requisite processing mechanisms. Adaptation effects are reported for which satiation/fatigue can be ruled out. It is argued instead that adaptation effects may result from the adapting percept decreasing in stability.

\section{PSYCHOLINGUISTICS}

Blue Room, Friday Afternoon, 3:00-5:25

Chaired by Alexander Pollatsek, University of Massachusetts

3:00-3:15 (126)

Lexical Ambiguity Resolution: Evidence From an Eye Movement Priming Paradigm. SARA C. SERENO \& KEITH RAYNER, University of Massachusetts (read by Keith Rayner)-Ambiguous words were presented as primes to targets in short passages of text during the initial $35 \mathrm{~ms}$ of the target region fixation. Priming was measured by comparing fixation times on targets preceded by semantically related versus unrelated ambiguous primes. The type of preceding context (Consistent versus Inconsistent), type of ambiguous prime (Biased versus Balanced), and strength of instantiated meaning (Dominant versus Subordinate) all affected priming. Results are discussed in terms of models of ambiguity resolution.

\section{3:20-3:40 (127)}

Brain Potentials and Parsing During Language Comprehension. COLIN M. BROWN \& PETER HAGOORT, Max Planck Institute for Psycholinguistics, Nijmegen (sponsored by Phillip J. Holcomb)-Eventrelated brain potentials (ERPs) provide a continuous neurophysiological record of language comprehension. We will present ERPs-data from three on-line language comprehension experiments, two in the visual modality, and one using connected speech. In all three experiments sentences were presented containing different kinds of grammatical errors. The ERPs to the errors indicate that syntactic and semantic processes have different neurophysiological manifestations. We will discuss the implications of the data for models of the syntax-semantics interface. 3:45-3:55 (128)

A Model of Homograph Meaning Resolution. LESLIE C. TWILLEY \& PETER DIXON, University of Alberta (read by Peter Dixon)We describe a simple quantitative account of virtually all of the available data on the processing of lexical ambiguity. The model subsumes as parametric variations the Selective-Access Model, the ExhaustiveAccess Model, the Ordered-Access Model, and more recent contextsensitive models.

$$
\text { 4:00-4:15 (129) }
$$

Perceptual Organization of Linguistic and Musical Meters. CAROLINE PALMER, TIMOTHY M. WALKER, Ohio State University, \& MICHAEL H. KELLY, University of Pennsylvania-Analyses of metrical accent structure in song compositions indicated that composers align iambic and trochaic verse with duple musical meters, and dactylic and anapestic verse with triple musical meters. Experiments showed that listeners prefer word/music combinations in which linguistic and musical meters are aligned. Also, listeners more easily perceived and remembered the musical and linguistic meters when they aligned, suggesting that the two metrical structures reinforce each other in song. 4:20-4:40 (130)

Investigating the Structure of Semantic Memory Using ERPs. JOHN KOUNIOS, Tufts University-In recent years, the measurement of event-related (brain) potentials (ERPs) has proven to be a useful technique for analyzing the time-course of cognitive processes. In particu- lar, we discuss an interpretation of additivities and interactions in ERP component amplitudes in semantic tasks that forms a basis for understanding semantic memory structure, in particular, the relationship between context-dependent and context-independent word meanings. This approach is illustrated by empirical examples.

$$
\text { 4:45-5:00 (131) }
$$

Syllable Structure in Speech Production. CHRISTINE A. SEVALD, GARY S. DELL, \& JENNIFER COLE, University of Illinois (read by Gary S. Dell)-What's in a syllable? There are three in "syllable" and only one in "word" but there the consensus ends. Sequences like "per perfen" or "perf perften" with shared first syllables are easier to produce than sequences like "per perften" or "perf perfen," without shared structure. This advantage also holds for sequences like "kil perfen." Syllable boundaries fall where linguistic theory predicts they will. They are stored in an abstract frame, not in the stored segments.

5:05-5:20 (132)

Backward Priming in Picture Naming: A Time Course Study. MARY C. POTTER, MIT-Levelt (1989) and others have proposed that, in speaking, we retrieve a word in two stages: first the lemma, which specifies meaning and syntax, and then the lexeme, which specifies phonology and orthography. Subjects named a pictured object. Incidental, superimposed words appeared $0-960 \mathrm{~ms}$ after picture onset: they were related semantically or phonologically to the picture name, or were unrelated. The lemma-lexeme distinction was supported in part.

\section{ANIMAL LEARNING/CONDITIONING I Empire Room, Friday Afternoon, 3:00-5:30}

\section{Chaired by Leon R. Dreyfus, Vassar College}

\section{3:00-3:15 (133)}

Proactive Effects of Surprising Reward Omissions on Autoshaping With Rats. MAURICIO R. PAPINI \& R. THOMAS DUDLEY, Texas Christian University-The frustration effect (FE) refers to the facilitation of performance that follows surprising reward omissions and it illustrates, according to frustration theory, the motivational properties of primary frustration. Demonstrations of the FE is double runway and Skinner box situations produce ambiguous results, because experimental and control conditions are not typically equated in the number and distribution of rewards. We found evidence of a FE in autoshaping with rats, under equated conditions of reinforcement across groups.

$$
\text { 3:20-3:35 (134) }
$$

Competitive Motivation and Reinforcement in a Social Analog of Instrumental Conditioning. ROBERT FRANK WEISS, STEPHNEE BRUNKEN, LISA CLORE, JULIE SON, \& NICHOLAS B. MCDONALD, University of Oklahoma-People will learn an instrumental response, the reinforcement for which is the cessation of competition, and the strength of this escape conditioned response can be measured by its speed. We now show in 5 experiments that increasing the number of competitors in "a war of all against all" is analogous to increasing the strength of electric shock, and that an instrumental response can be reinforced by a reduction in the number of competitors.

3:40-3:55 (135)

Temporal Encoding in Pavlovian Learning: Trace Conditioning. ROBERT P. COLE, ROBERT C. BARNET, \& RALPH R. MILLER, SUNY at Binghamton (read by Ralph R. Miller)-Rats were exposed to S1 - US pairings with either a 0-s or 5-s ISI followed by "backward" second-order pairings $(\mathbf{S} 1 \rightarrow \mathbf{S} 2)$ with a 0 -s ISI. A trace conditioning deficit was seen in less responding to $S 1$ trained with the 5-s relative to the 0-s ISI. However, S2 elicited more second-order responding based on S1 trained with the 5-s than the 0 -s ISI. Thus, variation in the S1 $\rightarrow$ US interval had opposite effects on first- and second-order conditioning. The data challenge the view that trace conditioning deficits, at least for short ISIs, arise from a learning failure and suggest that animals learn temporal relationships between events.

$$
\text { 4:00-4:20 (136) }
$$

Isolating Food Density From Elapsed Session Time on Simple Interval Schedules. JAMES D. DOUGAN \& LAURA S. CAMPBELL, 
Illinois Wesleyan University-Experiments examining the function relating response rate to reinforcement rate on interval schedules have typically confounded elapsed session time with the number of reinforcers earned. Two experiments isolated the influence of these factors. In Experiment 1 , session time was held constant and reinforcer density was manipulated. Increased reinforcer density resulted in an increasingly bitonic function. In Experiment 2, reinforcer density was held constant and session time was manipulated. Session time had no systematic effect on the function.

\section{4:25-4:45 (137)}

The Microstructure of Matching. TERENCE A. MARK \& C. R. GALLISTEL, UCLA (read by C. R. Gallistel)-When scheduled rates of reward change frequently, matching behavior on concurrent VI schedules depends primarily on the last few interreward intervals. We report determinations of the patch-leaving probability as a function of the current stay duration and ratios or differences in the most recent interreward intervals or in the most recent profitabilities (rewards/time on side). We discuss the implications of these data for models of the decision process that generates matching behavior.

$$
\text { 4:50-5:10 (138) }
$$

Mapping Time Onto Space: The Peak Choice Procedure. J. GREGOR FETTERMAN, Indiana University and Purdue University at Indianapolis, \& PETER R. KILLEEN, Arizona State University-Pigeons timed a triplet of intervals concurrently. Responses to one key could be reinforced after a short time, to a second key after an intermediate time, or to a third key after a long time. The durations of the intervals and the probability of reward at the end of each trial were varied across conditions. These manipulations were assessed with respect to predictions of Scalar Expectancy Theory (SET) and the Behavioral Theory of Timing (BeT).

$$
\text { 5:15-5:25 (139) }
$$

Duration Effects for Signals of Noncontingent Reinforcement. BEN A. WILLIAMS, University of California, San Diego-Rats learned to approach a light that signaled food when food only occurred after the CS, but did not approach the light when food was equally probable regardless of light. When food unpaired with the light was preceded by a short signal, little learning was evident as well, but when the unpaired food was preceded by a longer signal, approach to the CS was learned.

\section{CATEGORIZATION}

Ambassador Room, Friday Afternoon, 3:15-5:20

\section{Chaired by James T. Townsend, Indiana University}

$$
\text { 3:15-3:30 (140) }
$$

Category Optimality and Category Learning. MONICA L. DASHEN \& JAMES E. CORTER, Teachers College, Columbia University (read by James E. Corter)-The category utility hypothesis (Gluck \& Corter, 1985) holds that people tend to learn and use more informative ("basic") categories, and that category informativeness increases with category validity $(P(F \mid C))$ and category base rate $(P(C))$ and decreases with feature base rate $(P(F))$. In three new learning experiments using fuzzy categories, these predictions were confirmed. Implications of the results regarding the underlying assumptions of the category utility model (and of Anderson's (1990) "rational" model) are discussed.

\section{3:35-3:50 (141)}

Attribute Inheritance From a Point of View. JAMES A. HAMPTON, City University, London-When conflicting concepts are combined, the new concept may possess emergent attributes not possessed by either concept individually. A proposed source for these attributes is background theories of the domain. Background theory was manipulated by asking subjects to adopt a particular point of view in generating and rating the appropriateness of attributes for combined social categories. Point of view had a marked effect on the pattern of attributes observed for the conjunctive concepts.

\section{3:55-4:10 (142)}

Causal Models and the Acquisition of Category Structure. MICHAEL R. WALDMANN, University of Tübingen, KEITH J. HOLYOAK, \& ANGELA FRATIANNE, UCLA-In contrast to recent proposals that category learning is solely guided by associationist principles or by domain-specific knowledge, causal model theory contends that people are also sensitive to the underlying causal structure of the learning task. In our experiments, different causal models were imposed on learning tasks in which cue/category relations and content domain were held constant. The difficulty of learning varied with the causal model. These findings cast doubt on the sufficiency of domain-specific and associationistic accounts.

$$
\text { 4:15-4:30 (143) }
$$

Comparing Models of Prior Knowledge Effects on Category Learning. EVAN HEIT, Northwestern University-Two categorization models made distinct predictions for experiments that manipulated prior expectations about new categories and observed category membership within the experimental context. According to the integration model, new categories are initially filled with prior examples from other, established categories. In the weighting model, exemplars of a new category are learned better to the extent that they are congruent with prior expectations. The results supported the integration model and provided no evidence of selective weighting.

\section{4:35-4:55 (144)}

Rule-Plus-Exception Model of Classification Learning. ROBERT M. NOSOFSKY, THOMAS J. PALMERI, \& STEPHEN C. MCKINLEY, Indiana University-A rule-plus-exception model of classification learning is formalized and tested. According to the model, people learn categories by forming simple logical rules and then storing occasional exceptions to those rules. Complete exemplars are virtually never stored. The model accounts for fundamental category learning phenomena such as prototype effects, effects of specific exemplars, and the difficulty of learning different classification problems. The model also gives good predictions of distributions of individual subject generalization patterns.

\section{5:00-5:15 (145)}

Issues in the Multiple Representation of Social Groups. JOHN ROACH \& DORRIT BILLMAN, Georgia Institute of Technology (read by Dorrit Billman)-In thinking about members of a social group, people may draw on multiple representations-the cultural stereotype, the best-known person, a media image. Rather than one dominant representation (e.g., the stereotype), different representations may be used in different circumstances. Experiment 1 assessed content, uniformity, and distinctiveness of five possible representations of African-Americans (e.g., best-known individual, stereotype, media images). Later experiments assessed relative context independence and test-retest stability. 


\section{POSTER SESSION I \\ Regency Ballroom, Friday Evening, 5:30-7:00}

(146)

Influence of Subject Biases on Scaling of Suprathreshold Auditory Stimuli. DONALD FUCCI, Ohio University, DANIEL HARRIS, Healthcare Rehabilitation Center, Austin, LINDA PETROSINO, Bowling Green State University, \& MOLLY BANKS, Ohio University-The purpose of this study was to determine the effect of subject bias for a complex stimulus (rock music) on magnitude estimation scaling behavior. Two groups of young adults, 20 who liked rock music and 20 who did not like rock music, were employed. Results indicated a difference between group performances. Subjects who liked rock music provided lower mean numerical responses than subjects who did not like rock music for all suprathreshold intensity levels employed.

(147)

Are Mental Clocks Amodal? GEOFFREY L. COLLIER, South Carolina State University-Researchers in the timing literature have asserted that mental clocks are amodal. If this is true then the often observed differences among modalities might be of peripheral origin. A psychophysical adjustment paradigm was used to estimate the means and standard deviations of visual and auditory isochronous and simpleratio pulse trains. Analyses of variability did not support the peripheral hypothesis, but in contrast, biases in both modalities mirrored those observed in production, favoring the amodal hypothesis.

(148)

Phonological and Visuo-Spatial Processing in Working Memory: An Interference Analysis With Temporal Estimation. CLAUDETTE FORTIN \& RICHARD BRETON, Université Laval-The present study integrates recent developments in the field of short-term memory in a psychophysical theoretical framework by combining working-memory tasks with temporal production. In Experiment 1, a rhyming-judgment task lengthened brief temporal intervals produced simultaneously. In Experiment 2, temporal intervals were not affected by the amount of processing in mentally rotating alphanumeric characters. These results suggest that a phonological subsystem of working memory would contribute to time estimation, while visuo-spatial working memory would not be involved.

(149)

Rotation Component of SAE Similar to Linear MAE. MAURICE HERSHENSON, Brandeis University-Total duration and decay time constant increased and decay rate decreased in a similar fashion as a function of inspection duration $(30,60,90,120,150, \& 180 \mathrm{sec})$ for linear motion aftereffects and for the rotary component of 90 - and 120deg spirals.

Protan Observers' Sensitivity to Longwavelength Light Cannot Predict Differences in Rayleigh Matching. CHARLES B. WOODS, Austin Peay State University-Recent studies have found poor agreement between the cone photopigment genes, middle and longwavelength cone spectral sensitivities, and the resulting color vision of anomalous trichromats. Protan observers' sensitivity to red $(632 \mathrm{~nm})$ increments to white backgrounds was compared to individual Rayleigh match means and ranges. As expected, large inter-subject differences were observed for protan but not color-normal observers. There was poor correlation, however, between increment thresholds and Rayleigh match means and match range sizes.

Spatial Summation of Widely Separated Visual Stimuli: Neural or Probabilistic? C. A. MARZI, University of Verona, M. PRIOR, University of Padua, \& C. MARTINI, University of Verona (sponsored by $M$. A. Goodale)-We carried out four reaction time experiments to test whether spatial summation of widely separated visual stimuli relies on a probabilistic or a neural mechanism. In Exps. 1 and 2 we manipulated stimulus size and found a summation effect which was in keeping with a probabilistic mechanism but only for large stimuli. In Exps. 3 and 4 we manipulated allocation of implicit spatial attention and found that summation occurs not only in attended but also in unattended locations.

Illusory Conjunctions Between Real and Imagined Stimuli. CATHERINE CRAVER-LEMLEY \& MARTHA E. ARTERBERRY, Gettysburg College-Illusory conjunctions, the incorrect recombination of stimulus features, can occur when attention is overloaded (Treisman \& Schmidt, 1982). Subjects were tachistoscopically presented with two digits, three objects (shape, color, and "fill" were varied) and asked to imagine the fourth object. The "distracting" task was to report the digits, the secondary task to describe a cued object. Subjects' reports indicated illusory conjunctions occur with imagery. These findings are related to perceptual equivalence (Finke, 1989) and assimilation (Segal, 1971).

\section{(153)}

Perceptual Microgenesis of the Ponzo Illusion. LLOYD L. AVANT \& TIM J. WOJAN, lowa State University-Subjects were presented either the vertical diverging lines or the two horizontal target lines of the Ponzo illusion, for either 100 or $50 \mathrm{msec}$., followed by the other illusion component. Across trials, the second input was presented in an ascending series of $1-\mathrm{msec}$. steps until subjects reported seeing the illusion. As exposure duration of the second component increased, subjects consistently reported seeing two equal target lines before they saw two unequal lines. The illusion appeared at briefer exposures if the first input was for 100 , rather than 50 , msec. Control presentations of the complete figure produced the same result.

\section{(154)}

Binaural Localization of Simultaneous Sounds: Across-Frequency Effects. LAURIE M. HELLER, University of Connecticut Health Center, \& VIRGINIA M. RICHARDS, University of PennsylvaniaThe localization of simultaneously presented sounds was investigated by applying (via headphones) interaural disparities in time or intensity to a narrow-band signal (the target), but not to another, spectrally remote signal (the distractor). The distractor interfered with listeners' sensitivity to changes in the target position. Both discrimination performance and position judgments indicate that the distractor position influenced the perceived position of the target, possibly reflecting a weighted combination of interaural information across frequencies.

(155)

Surface Orientation Affects Haptic Depth Perception. DRAGANA BARAC-CIKOJA, CESPA, University of Connecticut, \& MICHAEL T. TURVEY, Haskins Laboratories and CESPA, University of Connecticut (sponsored by Laurie B. Feldman)-Two visually occluded surfaces were probed with a hand-held rod in order to discuss their relative distance. They formed gaps that extended diagonally across the transverse plane, to the side of the sagittal plane. Manipulated were: gap size, distance from gap center to the observer, and gap orientation. Haptic depth perception depended on the direction of the gap's tilt relative to the sagittal plane regardless of which hand did the probing and how it was reported.

\section{(156)}

Intersensory Conflict and Texture Perception: Evidence for Tactual Capture. LINCOLN G. CRATON, Trinity University, \& EMILY W. BUSHNELL, Tufts University-An intersensory conflict paradigm was used to study how sight of the exploratory hand affects subjects' weighing of visual and tactual information. Subjects chose roughness matches for abrasive papers that appeared to be unitary surfaces but actually emanated from two sources differing in roughness. The results indicated tactual capture when the hand was visible; results for the handoccluded condition depended on the direction of the discrepancy. Implications for theories of intersensory bias are discussed.

(157)

The Effect of Shape and Location on Temporal Masking of Vibrotactile Patterns. DAVID T. HORNER, University of WisconsinOshkosh-Identical spatial patterns presented to separate locations on a fingerpad often feel like different patterns. Tactile temporal masking studies show little interference identifying a pattern when an identical 
masker is presented to the same location. In the current study, subjects identified patterns followed by same-shape or different-shape maskers presented to the same location or a different location. The hypothesis was that same-shape maskers at different locations would behave like different-shape maskers.

\section{(158)}

Tactile Agnosia: An Analysis of Processing Deficits. CATHERINE L. REED, University of Pennsylvania, \& RICHARD J. CASELLI, Mayo Clinic, Scottsdale-Tactile agnosia is a modality-specific disorder of tactile object recognition in the absence of more basic somesthetic dysfunction. A tactile agnosic with a small left inferior parietal infarction underwent detailed testing to assess what stage of tactile object processing was disrupted, including simple shape perception, complex shape perception and tactile object memories. Results suggest that tactile agnosia can arise from faculty higher-level perceptual processes, especially those involved in the processing of complex shape information.

Ingestive Behavior in the Egyptian Spiny Mouse (Acomys cahirinus). GARY M. BROSVIC, NICHOLAS KOLODIY, SHERYL LOEFFLER, SCOTT BLOSZINSKI, \& AMY HARRON, Rider CollegeThe ingestive behavior of Acomys cahirinus during normal and acute to chronic states of water and bodily sodium deficiency is reviewed. Relative to the ingestive behavior of Long-Evans rats (Rattus norvegicus), Acomys demonstrates few taste preferences and readily adapts to and recovers from physiological challenge.

Effectiveness of an Image Similarity Metric. FRANK M. MARCHAK \& JACOB D. GOLDSTEIN, TASC-Previous efforts described a metric that captures the preattentive visual similarity of images of natural scenes. The metric is based on measures that characterize features of the texture (fractal dimension, contrast, correlation distance) and color (hue, variability) of the scene. Here, reaction time of same-different judgments were used to determine the relative importance of individual metric components and differentially weight elements of a vector description of these measures. A standard distance metric describes similarity.

Visual Intensities and Duration Discrimination of Intermodal Intervals. SIMON GRONDIN, Laurentian University, RICHARD B. IVRY, \& ELIZABETH A. FRANZ, University of California, Berkeley-People have difficulty timing events bounded by signals from different modalities. To explore this phenomena, we studied the timing of two types of intervals: visual-auditory (VA) and auditory-visual (AV). In Experiment 1, the intervals varied around a standard duration of $250 \mathrm{msec}$ and the intensity of the visual signal was varied. Discrimination improved when the visual signal was made more intense and this effect was true for both VA and AV intervals. Results will be presented from a second experiment in which these comparisons are made over a range of standard durations.

(162)

Combining Recalibration and Learning Accounts of Contingent Aftereffects. FRANK H. DURGIN \& DENNIS R. PROFFITT, University of Virginia (presented by Dennis R. Proffitt)-A visual aftereffect of one perceptual dimension can sometimes be made contingent on another. Such contingent aftereffects may be conceived either mechanistically, as learned visual responses, or functionally, as recalibrations of perception. We will describe aftereffects of texture density contingent on (1) color of surround, (2) texture type, and (3) temporal sequence. We suggest that these various contingent aftereffects may reflect processes that normally accomplish the functional goals of recalibration by means of contingency learning.

Apparent Gravitational Direction in Erect and Supine Observers. ARNOLD E. STOPER, KAREN MONTAN, JUSTIN RANDLE, \& MARCELLA SPENCE, California State University, Hayward-Twelve Ss were instructed to set a luminous target level with eye, navel, and knee while standing erect, and vertically above eye, navel, and knee while lying supine. In the erect condition errors for all three judgments were small. In the supine condition the average settings for "above navel" and "above knee" were $19^{\circ}$ and $27^{\circ}$ high (toward the head; this is the "Aubert illusion" in the pitch dimension). The "above eye" judgment, however, showed no significant bias.

$$
\text { (164) }
$$

Size Scaling Depends Upon Information About Environmental Size. DAVID BENNETT, University of Pennsylvania-Previous studies have found that reaction time increases with increases in size ratio in a simultaneous same-different task. When retinal and environmental size ratios are distinguished by placing random forms at different depths within a computer generated hallway, information about environmental size influences reaction time, with the strength of the effect depending upon the size information available.

\section{(165)}

Prism-Generated and Real Pitch Influence Egocentric Localization Similarly; Prism-Generated and Real Slant Don't. WENXUN LI \& LEONARD MATIN, Columbia University-Visually perceived eye level (VPEL) changes linearly with either real or prism-generated (base-up or down) pitch of a visual field consisting of only two isolated vertical lines in darkness. Moreover, effects of the prism and real pitch are additive. Prism-generated (base-left or right) slant of a horizontal 2-line stimulus influences visually perceived straight ahead (VPSA) systematically; however, a slanted-from-frontal horizontal 2-line stimulus has no effect on VPSA, although the optical effects are the same.

Periscopically Shifted Eye Height Affects Perceived Object Size. ULRIC NEISSER \& M. J. WRAGA, Emory University-Rectangular wooden panels, $4.7 \mathrm{~m}$ away, were viewed through a periscope that raised/lowered effective eye height (EH). In Experiment 1, subjects judged object height. Lowered EH produced substantial overestimates compared to a non-periscope control; raised EH led to smaller underestimates. In Experiments 2 and 3, subjects judged width. Lowered EH again led to overestimation; raised EH had little effect. These data partially support the hypothesis that EH provides a scaling metric for object size.

\section{(167)}

Accenting and the Perception of Timing, Intensity, and Pitch in Pure Tone Sequences. HASAN GÜRKAN TEKMAN, Middle East Technical University-Manipulation of the intensity and pitch structure of pure tone sequences led to changes in the perception of timing and intensities, respectively, of the tones. Manipulation of timing structure did not influence the perception of pitches. Sensitivity to deviations on one of these dimensions was more affected by the regularity or irregularity of deviations on another dimension than the mere presence or absence of those deviations.

\section{(168)}

Involuntary Shifts of Visual Attention Caused by Orientation Gradients. JULIAN S. JOSEPH \& LANCE M. OPTICAN, National Eye Institute, $\mathrm{NIH}$-We report data from three experiments providing evidence that involuntary shifts of visual attention can result from an orientation gradient within $100 \mathrm{msec}$ of its onset. Preceding the probe stimulus, we presented a display of oriented bars containing either a noninformative orientation oddball or no oddball. We observed that accuracy in trials with a valid orientation oddball was significantly greater than in trials with no oddball. Therefore, these attentional shifts rapidly follow preattentive texture processing.

(169)

Inhibition of Return: Effects of Multiply-Cued Spatial Locations. JAY PRATT \& RICHARD A. ABRAMS, Washington University (presented by Richard A. Abrams)-Inhibition of return refers to a bias against attending to visual stimuli at recently attended locations. In a series of experiments, we studied the effects of multiple attentional cues on the phenomenon. Our findings indicate that the cueing of distractor locations differentially affected response latencies depending on whether it occurred before or after cueing of the target location. Responses to multiply-cued locations and singly-cued locations were also examined. (170)

Spatial Attention in Searching for Features and Feature Conjunctions. MIN-SHIK KIM \& KYLE R. CAVE, Vanderbilt University (presented by Kyle R. Cave)-Spatial attention was measured in both con- 
junction search and feature search tasks using a probe technique. Contrary to predictions from Feature Integration Theory (Treisman, 1988), spatial attention was allocated to the target location in a feature search under some conditions. In the conjunction search, attention was allocated to locations occupied either by the target or by distractors with one of the target features. Spatial attention is apparently allocated according to the presence of target features.

Inhibition of Return of Visual Attention to Multiple Location Cues. RICHARD D. WRIGHT \& CHRISTIAN RICHARD, Simon Fraser University-Inhibition-of-return is the inhibition of processing at a particular cued location that occurs after attention is shifted to another cued location. Our results suggest that processing can be inhibited at more than one location if the first cue is replaced by simultaneous multiple cues. We argue that a spatial index is allocated to each cued location and remains assigned to the location to serve as an inhibitory tag after attention is shifted away.

\section{(172)}

Attentional Mode and Gap Effects in Stimulus Detection Task. VICTOR I. BELOPOLSKY, Russian Academy of Sciences (sponsored by George W. McConkie)-To be detected in uncertain spatial positions a visual target must be caught by the attentional focus. Spatiotemporal properties of the attentional focus were studied in choice reaction time experiments, where the size of the preattentional field and the delay between the fixation box's offset and the target stimulus' onset were used as the variables. The results are interpreted as a demonstration of different strategies of attentional dynamics.

(173)

Electrophysiological Substrates of Visual Selective Attention to Spatial Frequency. ALICE MADO PROVERBIO, University of California, Davis, ALBERTO ZANI, Istituto di Psicologia del CNR, \& GEORGE R. MANGUN, University of California, Davis (sponsored by Patrizia Bisiacchi)-Visual event-related brain potentials (ERPs) and reaction times were recorded to gratings of different spatial frequency. Multichannel recordings (64 channels) were obtained while subjects performed different selective attention tasks: target count, motor response, and passive viewing tasks. Current Source Density (CSD) topographical analysis showed attention effects at early latency level $(80-120 \mathrm{msec}$ poststimulus).

An Auditory Analogue to Feature Integration. MICHAEL D. HALL \& RICHARD E. PASTORE, SUNY at Binghamton (presented by Richard E. Pastore)-Feature Integration Theory was evaluated for audition using standard search tasks for cued features (musical timbres or pitches) or feature conjunctions (timbre/pitch combinations) in arrays of objects with distinct locations, pitches, and timbres. Conjunction search RTs increased, and accuracy decreased, with increasing stimulus complexity, reflecting analogue movement of attention. Incidence of illusory conjunctions was comparable to rates for visual stimuli. Results also suggest that instrument timbre may represent feature conjunctions.

Negative Priming for Spatial Locations: Identity Mismatching, Not Distractor Inhibition. JOOYONG PARK \& NANCY KANWISHER, UCLA (presented by Nancy Kanwisher)-Negative priming (NP) is commonly thought to occur because distractor inhibition is necessary for target selection. Contrary to this account, target selection is shown to be neither necessary (Experiment 1) nor sufficient (Experiment 2) for NP in a target localization task modeled after Tipper, Brehaut, and Driver (1990). Experiments $3 \& 4$ provide further evidence against the "inhibition" account and support an alternative "mismatching" account: Spatial NP results from a change in the symbol bound to a given location.

(176)

Stimulus-Driven Capture and Attentional Set. JAN THEEUWES, TNO Institute for Perception (sponsored by A.F. Sanders)-Previous research suggests that attentional capture is contingent on strategically alterable control settings. In the present study, subjects searched multielement displays in which a color singleton and an onset singleton were simultaneously present. Subjects were asked to either search for the color singleton or for the abrupt onset singleton. The results indicate that, irrespective of the attentional set of the observer, attention was captured by the most salient singleton.

The Direction of Attention by Spatially Correlated Precues Independently of Eye Movements. ROSE M. ROBERTS \& DAVID R. PERROTT, Califormia State University, Los Angeles (presented by David R. Perrott)-Visual and auditory spatial precues were examined in a brief presentation task with two ranges of stimulus onset intervals (SOAs) which did or did not allow eye movements (100-200 ms versus 0-50 ms). Three distances were tested: near (four degrees from fixation), intermediate (nine degrees) and far (sixteen degrees). At each distance, combined, visual, and auditory precues improved performance. In the Intermediate condition improvements were found with SOAs of 0-50 ms, indicating direction of attention prior to eye movements.

$$
\text { (178) }
$$

Specific and Nonspecific Transfer Effects in Training for Vigilance. AMI B. BECKER, JOEL S. WARM, WILLIAM N. DEMBER, \& STEVEN R. HOWE, University of Cincinnati (presented by Joel S. Warm)-Previous studies of training for vigilance have led to the conclusion that such training is primarily nonspecific in nature-subjects learn general skills to improve monitoring efficiency, not skills localized within a particular task. This study tested that conclusion by comparing training with knowledge of results in simultaneous (comparative judgment) and successive (absolute judgment) type vigilance tasks. Specific transfer effects were observed in terms of both the overall level of performance and the vigilance decrement.

(179)

Synesthesia of Lightness, Pitch, and Melodic Interval. TIMOTHY L. HUBBARD, University of Arizona-When subjects rated how well various visual lightnesses and auditory pitches "fit together," lighter stimuli fit best with higher pitches and darker stimuli fit best with lower pitches. When subjects chose which lightnesses "fit" single pitches, most chose lighter stimuli for higher pitches. When subjects chose which lightnesses "fit" melodic intervals, lighter stimuli were chosen for ascending intervals while darker stimuli were chosen for descending intervals. Larger melodic intervals produced more extreme (lighter or darker) choices.

\section{(180)}

Production and Interpretation of Pictures of Houses by the Blind. MORTON A. HELLER, Winston-Salem State University, \& JOHN M. KENNEDY, University of Toronto, Scarborough Campus-Blind people were exposed to a 3-dimensional model of a house and were asked to draw it using a raised-line drawing kit. Independent groups of early and late blind subjects were told to identify the vantage point of tangible pictures of the model, including "side-views," "views" from above, and "views" involving linear perspective. The ease or difficulty of picture interpretation depended upon the nature of the tangible drawing, with much better performance for "views" from the side.

(181)

Coding of Information in the Somatosensory System: Evidence From Neuropsychology. MORRIS MOSCOVITCH, University of Toronto, \& MARLENE BEHRMANN, Carnegie-Mellon University (presented by Marlene Behrmann)-To determine the reference frame within which neglect operates in the somatosensory system, patients with right parietal damage were touched simultaneously on the left and right sides of the wrist of one hand. The hand was tested in both the palm up and palm down position. Patients neglected the stimuli on the side of space contralateral to the lesion regardless of hand position. These results indicate that point-localization in the somatosensory system is accomplished with respect to a spatially defined frame-of-reference and not strictly with respect to somatotopically defined coordinates.

(182)

Spatial Effects on Cognitive Function in Patients With Parietal Damage. H. BRANCH COSLETT, Temple University School of Medicine, MYRNA SCHWARTZ, \& GARY GOLDBERG, Moss Rehabilitation Hospital-Motor, sensory and language tasks were administered to 30 patients with unilateral stroke, once each on the right and left sides. Ten patients, all with parietal lobe lesions, performed significantly worse 
in the contralesional side on one or more tasks. We suggest that all cognitive operations (including language) are maintained in registration with systems mediating spatial representation and attention; disruption of the parietal lobe mediated spatial system impairs performance in the contralesional hemispace.

Effects of Learning Equations on Transfer in Mathematical Domains. RICHARD CATRAMBONE, Georgia Institute of TechnologyWhile experts generally take a conceptual approach, novices prefer to use provided equations when solving problems, even though this often hinders transfer from examples to novel problems. In this study, subjects studied conceptually-structured worked-out probability examples. For half of the subjects, the examples also included the standard equation form. Subjects who studied examples illustrating both the conceptual and equation-based approaches transferred less successfully to novel problems than the other subjects.

\section{(184)}

On Putting Bottles Into Apples: Effects of Word Knowledge on Problem Solving. MIRIAM BASSOK, University of Chicago-Problem solving depends on inferences about possible scenarios triggered by knowledge about the specific variables. For example, subjects always divide books per shelves rather than vice versa, but they divide either people per watermelons (eating scenario) or watermelons per people (unloading a truck scenario). Moreover, when the two variables are known to play similar roles (e.g., boys and girls) subjects add the two sets of elements (i.e., children) and ask about relative proportions.

(185)

Evaluating Multiple Hypotheses With a Diagnostic Strategy and Maximally Different Hypotheses. ERIC G. FREEDMAN, Michigan Technological University, \& ROOP JAYARAMAN, Michigan State University-The evaluation of multiple hypotheses was investigated by encouraging either use of a diagnostic strategy (i.e., tests which were an instance of one hypothesis and not an instance of another hypothesis) or generating maximally different hypotheses. Employing a diagnostic strategy improved performance although generating maximally different hypotheses did not. Using a diagnostic strategy decreased positive tests and confirmation and increased negative tests, diagnostic tests and disconfirmation. A diagnostic strategy appears to facilitate the elimination of incorrect hypotheses.

\section{(186)}

Analogical Problem Solving: The Facilitative Effects of Procedural Similarity on Applying Process. ZHE CHEN, University of KentuckyA series of studies were conducted to examine the importance of the executing process of analogical transfer. Subjects viewed a schematic model and then attempted to solve an analogous problem. While the general solution principle was held constant between source and target problems, the concrete procedures were manipulated. The studies demonstrate that the level of similarity in implementation procedure between source models and target problems determines the ease with which a solution is utilized.

Acquisition and Retention of Concrete Operations. VALERIE MALABONGA, ROBERT PASNAK, \& CHARLENE HENDRICKS, George Mason University (presented by Robert Pasnak)-Eight kindergartners lagging in cognitive development were taught unidimensional classification, unidimensional seriation, and number conservation via a learning set procedure. Seven control children were taught the alphabet, numbers, shapes, colors, coin values, time, printing, phonics, and rudiments of addition and subtraction. Tests three months later showed significant superiority only in classification for children taught the concrete operations. A more complete mastery of concrete operations via instruction would be necessary to maximize cognitive and academic gains.

(188)

The Role of Causal Structure in Graph Interpretation. MERIDETH GATTIS LEE \& KEITH J. HOLYOAK, UCLA (presented by Keith J. Holyoak)-Graphs can be considered a conceptual mapping of cause and effect relations. Our experiments demonstrate that graph interpretation is constrained by causal structure and axes placement. By ma- nipulating the causal direction between variables, we show that accurate identification of the change in a variable depends on whether subjects consider the variable to be a cause or an effect.

(189)

Analogical Reasoning In Vivo: Different Goals Dictate the Use of Different Types of Analogy. KEVIN DUNBAR, McGill University-Scientists in four leading molecular biology laboratories were investigated over a one year period. Weekly lab meetings were taped and interviews conducted. This presentation will focus on the scientists' use of analogy. Three different classes of analogies were used: Local Analogies were from the same domain, and were used to solve experimental problems. Regional Analogies, where a whole system of relationships from a similar domain was mapped onto the target domain, were used to plan experiments and interpret results. Long-Distance Analogies, where a concept is mapped from a very different source domain, were used to highlight features when explaining a theory.

\section{(190)}

Effects of Instructional Style on Students' Processing of Classroom Events. CLEA FERNANDEZ \& JAMES W. STIGLER, UCLA (presented by James $W$. Stigler)-In this study children viewed one of two mathematics lessons which covered the same material. One lesson was teacher directed, the other less so. Next, all subjects performed an online recognition task while viewing a common second tape covering related material. Those who first viewed the less directive lesson were better and faster at recognizing information discussed during the second tape, suggesting that these students were forming a more integrated representation of what they were watching.

Evaluating Informal Arguments. VICTORIA F. SHAW \& PHILIP N. JOHNSON-LAIRD, Princeton University (presented by Philip N. Johnson-Laird) - We have investigated how individuals evaluate and raise objections to informal arguments. Subjects were more likely to object to the truth value of the assertions in an argument than to the logic of the argument. They also tended to focus on the information explicitly presented in the argument, and rarely referred to other relevant information. We discuss the results in terms of the mental model theory of reasoning.

(192)

Strategy Change With Practice in a Mental Animation Task. MARY HEGARTY \& J. MITCHELL FERGUSON, University of California, Santa Barbara-When asked to determine the motion of a component in a mechanical system, most novice subjects step through the causal chain, mentally animating each component in turn and ending with the component in question. Response times, verbal protocols, and eye fixations suggest that with practice, subjects develop strategies based more on rules than on this mental stimulation approach. Using these rules, subjects can determine the motion of a component by mentally animating only that component.

\section{(193)}

Why Is Space Complex? Relational Versus Absolute Spatial Descriptions. CAREN M. JONES, University of Massachusetts, \& BARBARA TVERSKY, Stanford University (presented by Barbara Tversky)-Data from two experiments suggest that part of the difficulty subjects have with spatial information is its relational nature. Subjects read descriptions of objects and their features or their locations. When locations were described in relative terms, subjects were slow to establish a representation. When locations were described in absolute terms, there was no difference in time to establish spatial and nonspatial representations. However, when relational rather than absolute questions were asked, subjects were slowed.

(194)

Memory for Route and Survey Space Representations. CESARE CORNOLDI \& FRANCESCA PAZZAGLIA, University of Padua-It has often been observed that mental maps may be built starting from route or survey descriptions. However it is not clear whether the two descriptions produce common or different representations. A series of experiments will show that, when the map is not overlearned, the two descriptions have specific different memory effects: verification time 
depends on the correspondence between description and characteristics of the test item; memory varies according to the quantity of the to-beremembered material.

\section{(195)}

The Emotional Distinctiveness of Odor-Evoked Memories. RACHEL S. HERZ, University of British Columbia-Two experiments tested whether memories evoked by odors were more emotional than memories evoked by word cues. In an incidental learning procedure subjects smelled 8 odors, and were told to imagine 8 odors (word cues) while viewing 16 different emotionally evocative paintings. Forty-eight hours later memory for paintings and associated emotional responses were tested by cued recall. Results of both experiments revealed that odor-evoked memories were significantly more emotional than memories recalled by words.

\section{(196)}

Repetition Effects in Validating Falsehoods. ALAN S. BROWN \& LORI A. NIX, Southern Methodist University-Prior research has shown that repeated exposure can enhance credibility of trivia statements, regardless of the item's actual veracity. None of these studies provided correct feedback concerning the items, while the present study did. Repeated true statements were rated truer than new true statements at one week and one month, while repeated false statements were rated less credible than new false statements at one week, but more credible at one month.

\section{(197)}

Effects of Increased Effort on Recall of Bizarre Images. VIRGINIA A. LANG, Wichita State University-An effort hypothesis to explain and predict the inconsistency of the bizarre imagery effect has been postulated, but never fully investigated (Einstein \& McDaniel, 1987). This set of experiments investigated the recall effects of increased resource allocation during the encoding of bizarre and common images. Namely, an increased number of to-be-remembered items over previous experiments was used in the formation of images into bizarre and common contexts. Preliminary results do not support an effort hypothesis.

(198)

The Role of Anomalous Data in Theory Change. WILLIAM F. BREWER \& CLARK A. CHINN, University of Illinois-We propose a theoretical framework, based on evidence from history of science and cognitive psychology, for understanding how individuals respond when they encounter data contradicting their current theories about the physical world. We postulate that there are seven responses to anomalous data, only one of which leads to theory change. In addition, we provide experimental evidence on the factors that influence which forms of response will be adopted and which factors lead to successful theory change. (199)

Does Reading Serve as Practice in Maintaining Word Processing Skill? SUZANNE MANNES \& SHELLI M. HOYES, University of Delaware-Efficient methods of practice are always being sought. In this study, subjects first performed word-processing tasks. After a week, some practiced by either reading about or re-doing the learned tasks. Two weeks later, all subjects completed the original and new tasks. Results indicate that those who re-did the tasks for practice were better than subjects who did not practice, but only for the original tasks. Interestingly, subjects accurately predicted their performance, regardless of practice condition.

\section{(200)}

Training for Across-Domain Transfer of Diagnostic Skill: A First Study. ADRIENNE Y. LEE, New Mexico State University, \& NANCY PENNINGTON, University of Colorado-Transfer of diagnostic skill across domains has been found in subjects with advanced levels of diagnostic skill (Lee \& Pennington, 1993). This study examined diagnostic skill training, to control such factors as self-selection and type of training. Undergraduates were trained in diagnosis or an unrelated domain. Experimental subjects learned more than controls, but did not show more transfer. More training may be necessary for subjects to reach advanced levels of the skill and thereby show transfer.

(201)

Evaluating the Influence of Depressive Self-Schema on Memory with Forced Recall Methodology. LAURA A. MURRAY \& WAYNE
G. WHITEHOUSE, Temple University (presented by Wayne G. Whitehouse)-Dysphoric and nondepressed subjects were tested for recall of a series of trait adjectives, varying in relevance to depression, which were presented as part of a self-description task. With the exception of a possible instance of self-reference bias, a forced-recall assessment found little evidence for the operation of a negative self-schema in producing depressive deficits in recall. Rather, the findings suggest that dysphoric subjects were less willing than nondepressed individuals to report recollections with confidence.

Effects on Retroactive Interference of Providing Information at Retrieval About the Interpolated List. SLATER E. NEWMAN \& JOHN DAVID RANDLE, North Carolina State University-Bower and Mann (1992) have reported that (1) providing category information at retrieval about items on the interpolated list reduced retroactive interference and that (2) uninformed subjects who became aware of such category information prior to retrieval, recalled more first-list items than did unaware subjects. The present experiment replicated the second finding but not the first. Possible bases for failure to replicate the first finding will be discussed.

\section{(203)}

The Role of Surprise in Mediating the Bizarreness Effect. GILLES O. EINSTEIN, PAUL C. BRADY, Furman University, \& MARK A. MCDANIEL, Purdue University-A robust finding is that bizarre images are better recalled than common images in mixed lists. One explanation for this finding is based on surprise reactions to bizarre sentences. In three experiments, we varied surprise reactions to bizarre and common sentences and found that (a) attenuating surprise reactions to bizarre sentences did not reduce the magnitude of the bizarreness effect and (b) increasing surprise reactions to sentences did not increase recall for those sentences.

\section{(204)}

Stalking the Effect of Bizarre Imagery on Memory. PETER G. KEPROS \& ANNE L. ISRAELI, University of New Brunswick-It remains to be demonstrated whether the bizarre imagery effect on memory is merely an artifact of procedures and/or materials, or a legitimate phenomenon. Subjects from psychology courses were asked to form images to lists of normal, bizarre, or mixed (normal and bizarre) sentences. Immediate or delayed memory tests (recall, recognition, stem completion or fragment completion) were given to each subject. The results showed that list-differences in memory depend primarily upon test-type. (205)

Retrieval of Geographical Knowledge. HOLLY R. STRAUB, PATRICIA A. MACK, \& SUZANNE D. TULLY, University of South Dakota-Previous research demonstrated that males outperform females when asked to identify U.S. states on a blank map, and performance appears to be influenced by retrieval strategy. Reported here is a series of experiments, utilizing the map paradigm, which assesses the relationship between gender and demand characteristics, and the effects of retrieval strategies and task demands on recall of state names and locations. Suggestions are made for use of the map paradigm in memory research.

\section{(206)}

Covert Mediation in the Development of Direct Memory Retrieval Processes. ROBERT J. CRUTCHER, University of Illinois at ChicagoThe role of mediation in memory retrieval processes was explored using an interference paradigm. After learning vocabulary pairs (cabra-goat) using keyword mediators $(c a b)$, followed by extended vocabulary retrieval practice, new keyword associations (cab-hospital) were learned. Retesting of vocabulary pairs showed reliably longer latencies after learning new keyword associations, even when the pairs could be directly accessed in a single working memory step, suggesting the possibility of covert mediational processes (e.g., semantic priming).

(207)

The Influence of Unattended Dimensions on Symbolic Distance Effects. RICHARD L. MARSH, University of Georgia-Symbolic distance effects arise when people must choose which of two objects has more or less of some property. Earlier investigations focused almost exclusively on repeated testing of a single dimension (of what are natu- 
rally multidimensional stimuli). These experiments demonstrated that latency to decide that one object exceeds another on some queried attribute is influenced by the pair's relationship on another attribute that is irrelevant to the current question.

$$
\text { (208) }
$$

The Effect of Source Credibility and Delay on Eyewitness Suggestibility. KAREN L. CHAMBERS \& MARIA S. ZARAGOZA, Kent State University (presented by Maria S. Zaragoza)-Subjects who have been exposed to misleading suggestions about an event they have witnessed sometimes come to believe they remember seeing items that were merely suggested to them, an error we refer to as source misattribution errors. This experiment examined the role of source credibility and retention interval on source misattribution errors. Source credibility influenced performance immediately but not after a delay, thus supporting the hypothesis that source memory decays faster than fact memory. (209)

Geon Differences During Recognition are More Salient Than Metric Differences. ERIC E. COOPER, University of Minnesota, \& IRVING BIEDERMAN, University of Southern California (presented by Irving Biederman)-Subjects judged whether a pair of sequentially presented object images had the same name when the objects could differ either in a viewpoint invariant contrast (geon change) or in the length of one of the parts (metric change). Responses were faster and more accurate for the metric changes, even though the metric differences were greater according to a representation based on the direct output of V1 simple cells. The high saliency of geon differences for object recognition likely emerges from subsequent processing.

Mere Exposure for Possible and Impossible Three-Dimensional Figures. JOHN G. SEAMON \& PEPPER WILLIAMS, Wesleyan University-Previous studies of implicit memory show priming for possible but not impossible figures following global but not local encoding (Cooper \& Schacter, 1992). We used the mere exposure paradigm to measure implicit memory for 3-D figures. Subjects demonstrated sig nificant affective preference for possible and impossible target stimuli after global and local encoding. This implies that past findings are specific to certain forms of implicit memory, and that other types of implicit memory for objects exist.

\section{(211)}

Mental Imagery in Written and Oral Autobiographical Accounts. ALBERT N. KATZ \& CORINNE S. ENRIGHT, University of Western Ontario-Most autobiographical memory studies have looked exclusively at written accounts. A study was conducted comparing the reported imagery of oral autobiographical, written autobiographical and white lie control accounts. The results indicate that clarity of imagery is greater during oral compared to written accounts. Further, imageability tends to decrease over retellings for autobiographical accounts, but increase over retellings for white lie accounts. Practical and theoretical implications of this finding are discussed.

Is the Brain Response to Syntactic Anomaly Language-Specific? LEE OSTERHOUT, University of Washington-Previous work has shown that syntactic anomaly elicits a positive-going event-related brain potential (P600). The present study was designed to determine whether the P600 is distinct from another ERP component, P300. P300 amplitude is known to vary with the probability and task-relevance of the eliciting event. Subjects read sentences containing an agreement violation, a word in upper-case letters (known to elicit P300), or a word that contained both types of anomaly. Responses to agreement violations ( P600) and upper-case words (P300) were similarly affected by manipulations to task relevance and probability-of-occurrence. However, words that contained both types of anomaly elicited a response equal to the summation of the response to each anomaly type in isolation, indicating that the $\mathrm{P} 600$ and $\mathrm{P} 300$ are independent.

$$
\text { (213) }
$$

Priming Effects on Tip-of-the-Tongue States for Names. NUSHA ASKARI \& DENA ATHANASIOU, University of San FranciscoTip-of-the-tongue (TOT) states were induced in subjects via auditory descriptions of proper and common nouns. On some trials, the descrip- tion was followed by a semantically related, phonologically related, unrelated, or no prime, or the initial letter of each word/name. Subjects had more TOTs for proper than common nouns, and correctly retrieved more targets with initials and phonological primes. These findings are consistent with previous claims regarding transmission deficits in TOT states.

The Representation of Syllable Structure: Evidence From Priming. CRISTINA ROMANI, University of Birmingham, U.K.-A priming paradigm was exploited to gather some insight into the phonological representations involved in speech production. Results show priming effects for segmental units corresponding to single phonemes and for suprasegmental, structural units corresponding to word prosody and syllable templates. No priming effects specific for segmental syllable units, however, are found. These results are consistent with production models that, along the lines of autosegmental phonology, represent phonological content and the phonological structure through distinct units.

A Linguistic Decision Model for Rhyming Tasks. DORIS AARONSON, JENNIFER THOMAS, New York University, MICHAEL PALU, Yeshiva University, SUSAN VOGEL, \& PETER SPARKS, New York University-In a YES/NO rhyme-detection task, when spelling and sound are either similar or dissimilar (flight, slight; shoe, crop), fast RTs and absence of word frequency effects implicate decisions based only on orthographic and phonemic processing. But, when word-pairs have conflicting orthography and phonology (prize, guise; cough, bough), RT and error patterns implicate strategic control, deeper semantic processing, and a complex decision making procedure. Our interactive modular theory is consistent with some recent connectionist approaches.

Prosodic Effects on Naming Bisyllabic Words. CHRISTOPHER T. KELLO \& ALAN H. KAWAMOTO, University of Califormia, Santa Cruz (presented by Alan H. Kawamoto)-This study examined the role of prosodic information in reading. Subjects read three bisyllabic words silently, and then named a fourth bisyllabic word. The context words were all weak-strong or all strong-weak. The targets varied in stress (WS or SW), grammatical category (nouns or verbs), and frequency (high or low). These variables were fully crossed, and naming latencies, durations, and errors were measured. Results suggest that prosodic information interacts with frequency and grammatical category. (217)

Verbal Learning Revisited: Natural Prosody Increases Memorability of Nonsense-Word Strings. PHYLLIS L. KOENIG \& LETITIA R. NAIGLES, Yale University (presented by Letitia R. Naigles)Enhanced memorability of syntactically inflected over uninflected nonsense-word strings supports the psychological reality of syntax (Epstein, 1961). We propose that prosodic structuring may also account for this finding. Memorability of written strings with varied stress indications and either no inflections, English inflections, or novel inflections are compared. Results suggest that subjects assign a prosodic stress pattern to inflected strings and that, independently of syntax, natural stress patterns increase memorability while unnatural ones decrease it

$$
\text { (218) }
$$

A Longitudinal Process Approach to Understanding Writing. SARAH RANSDELL, New College of University of South Florida, \& MICHAEL LEVY, University of Florida-A longitudinal experiment assessed the dynamics of college writers' mental models about writing over a 12-week period during which they generated thinking-aloud protocols and word processed essays. Real-time records of the time and effort devoted to planning, translating and editing subtasks revealed changes in writing efficiency, point-of-utterance revision, and quality corresponding to increased automaticity of generating concurrent protocols. Results are discussed in terms of current models of written composition

Environment Features Influencing Spatial Description Perspective. HOLLY A. TAYLOR, Texas Christian University, \& BARBARA TVERSKY, Stanford University-What determines the perspective used to describe an environment, survey, route, or a mixture of both? We systematically varied features of environments hypothesized to influ- 
ence perspective choice: number of paths, landmarks on a single or several size scales, enclosed or open, and overall scale. Subjects studied four maps, and wrote descriptions from memory. Survey descriptions dominated, but the presence of a single path and of landmarks on a single scale encouraged route descriptions.

$$
\text { (220) }
$$

The Effect of Focus on Lexical Access During Reading. ROBIN K. MORRIS \& JOCELYN L. REPPERT, University of South Carolina-Readers are faster to read words when the message level context is related to the target word than when it is unrelated. Gaze duration and naming time measures were used to measure lexical access of unambiguous nouns when the semantic relationship between the focus of the context and the target word was varied. The lexical content of the sentence was held constant across conditions. Implications for models of word processing during reading will be discussed.

(221)

How Do Movies Elicit Predictive Inferences? JOSEPH P. MAGLIANO, University of Chicago, ROLF A. ZWAAN, \& KATIHKA DIJKSTRA, Memphis State University-We investigated when viewers made predictive inferences about upcoming events in a movie. We collected verbal protocols as viewers watched a movie. When viewers made a prediction, they stopped the movie, wrote down the prediction, and identified the information source which supported the prediction. Our analysis shows that multiple information sources converge to support predictive inferences in movies. These information sources include general knowledge about actions and movie genre, foregrounding, and music.

Generalization During Reading. ROBERT F. LORCH, JR., University of Kentucky, JERRY HAUSELT, Southern Connecticut State College, \& W. ELLIOT INMAN, University of Kentucky-College students read texts with either a general or specific theme. The fourth sentence (target) of each text was consistent with the general theme but inconsistent with the specific theme. If readers did a word recognition test immediately after each text, target reading times were slower on the inconsistent than consistent text. If no immediate test was given, there was no difference. Results show that adults make generalizations during reading if encouraged to read carefully.

Recovery From Garden-Pathing in Sentences Containing Ambiguous Words. SUSAN A. DUFFY, ALEXANDRA G. GORMAN, AMY L. GRAGG, \& SARAH E. KIDD, Amherst College-The time course of recovery from instantiation of the unintended meaning for an ambiguous word was investigated. Sentences contained biased ambig uous words in clause 1 that were disambiguated toward their subordinate meaning in clause 2. A moving window sentence presentation preceded target word naming. Neither meaning for the ambiguous word was primed immediately after sentence offset; both were primed one second later. Results are discussed in terms of lexical re-access and message level processes.

Children's Inferences About Ambiguous Events: Sensitivity to Story Clues and Context. MARK A. CASTEEL, Pennsylvania State University-York Campus-Second- and fourth-graders heard stories with ambiguous outcomes that contained clues and biasing context (near, far, or neutral). The clues either supported the biasing context or were neutral, and clue order was manipulated. The results showed a distinct recency effect, where the last clue tended to bias the initial interpretation, especially if it supported the biasing context. Surprisingly, there were few grade or context nearness differences. Implications of the results are discussed.

\section{(225)}

The Role of Working Memory in Writing Fluently. ROBERT MADIGAN, JOHN HOLT, \& JENNIFER BLACKWELL, University of Alaska, Anchorage-Working memory has been implicated in a variety of reading and writing skills and may be a fundamental ability underlying language skill in general. The present study examined the role of working memory in the writing process. College freshmen wrote essays on assigned topics while their moment to moment progress was monitored. Students with large working memory capacities paused less between words and wrote essays judged to be higher in overall quality. (226)

Flexible Perspective-Setting in Conversation. PAMELA STELLMANN \& SUSAN E. BRENNAN, SUNY at Stony Brook (presented by Susan E. Brennan)-When pairs of people referred to objects repeatedly, they minimized their collective effort over 4 trials (measured by decreasing time, words, turns, and errors). Then they switched partners with another pair that had done the same task. Trial 5 resembled Trial 1; despite task experience, people set new perspectives with new partners. For Trials 9-12, people returned to their original partners; they continued where they left off in Trial 4. Perspectives are set not autonomously, but jointly, with particular partners.

(227)

Sequential and Coordinative Processing Dynamics From Childhood to Old Age. ULRICH MAYR, REINHOLD KLIEGL, \& RALF TH. KRAMPE, Max Planck Institute for Human Development and Education, Berlin (sponsored by Neil Charness)-Our previous research suggested processing speed and error-proneness of information coordination as two distinct sources of adult age differences. In this experiment we determined time-accuracy functions for two sequentially and two coordinatively complex figural transformation conditions in nine-year old children, young and old adults. Developmental differences in processing rates replicated the dissociation between speed and coordination with children being less affected by coordinative demands than old adults.

Aging, Suppression, and Visual Selective Attention. S. LISA CONNELLY \& DAVID J. MADDEN, Duke University Medical CenterOlder and younger adults indicated the presence or absence of targets under feature or conjunction search conditions (e.g., Treisman \& Gelade, 1980). Negative priming for the spatial location of distractors was assessed. Under feature search conditions, search time was independent of distractor set size, and negative priming did not obtain. Under conjunction search conditions, search appeared serial and self-terminating, and negative priming was found. This pattern of results was equivalent across younger and older subjects.

\section{(229)}

Stimulus-Dependent Distractibility in Infancy. DONALD J. TELLINGHUISEN \& LISA M. OAKES, University of Iowa (presented by Lisa M. Oakes)-Infants' attention during object exploration was investigated by measuring latencies to orient toward auditory, visual, or auditory + visual distractors. Seven- and 10-month-olds' latencies were longer during examining than non-examining attention for all distractor conditions. However, infants were more easily distracted by auditory + visual distractors than either visual or auditory distractors. Distractibility appears to be related to distractor complexity as well as level of object-directed attention.

The Roles of Inhibitory Processes and Working Memory Capacity in Cognitive Aging Effects. JULIA D. GRANT, Pennsylvania State University, \& DALE DAGENBACH, Wake Forest University (presented by Dale Dagenbach)-The role of working memory capacity and inhibitory processes in deficits associated with cognitive aging was explored by collecting measures of each, along with performance on a discourse processing task, for a college sample and a sample of elderly adults. The elderly subjects showed significant negative priming effects, impaired working memory capacity, and impairment in discourse processing. Patterns of correlations suggest that neither working memory capacity nor efficiency of inhibition adequately explains cognitive aging effects.

The Development of Metaconceptual Understanding in Children. BEATE SODIAN, University of Munich (sponsored by Susan Carey)Lack of metaconceptual knowledge is one important potential source of across-domain cognitive limitations in children. In this paper, I explore 7- to 13-year-old children's understanding of the notions of "hypothesis," "experiment," and "theory." The results of three experiments and an interview study indicate that children acquire a basic 
understanding of the logic of hypothesis testing earlier than was previously thought but that they fail to understand the function of empirical tests in the construction and revision of theories.

(232)

Memory Span and Stategy Choices in Chinese and American Children. DAVID C. GEARY, University of Missouri-Columbia, LIU FAN, China Central Institute for Education Science, C. CHRISTINE BOWTHOMAS, University of Missouri-Columbia, \& ROBERT S. SIEGLER, Carnegie-Mellon University-Chinese and American kindergarten children were administered a numerical memory span measure, and an addition strategy assessment. The strategy assessment provided information on the types of strategies used to solve addition problems. When addition facts could not be retrieved from long-term memory, then the Chinese children tended to count verbally, whereas the American children tended to count on their fingers. The national difference in the relative use of finger and verbal counting appeared to be related to a 2.6 digit memory span advantage for the Chinese children. The results are related to Baddeley and Hitch's (1974) working memory model.

Age Differences in Memory for Performed Activities. JULIE L. EARLES, VICKY E. COON, \& ANDERSON D. SMITH, Georgia Institute of Technology (presented by Anderson D. Smith)-Two studies assessed the relationship between age, perceptual speed, working memory, and word recall as predictors of memory for performed cognitive tasks. Perceptual speed, as an index of processing efficiency, was associated with a large portion of the age-related variance in memory for performed activities, but some age-related variance in performance remained. The control of a verbal memory measure also greatly reduced the age-related variance in activity memory.

Aging and Interference: Evidence From Direct and Indirect Memory Tests. MARILYN HARTMAN \& JEFFERY DUSEK, University of North Carolina at Chapel Hill-Three experiments examine age differences in the effects of interference on memory, using indirect and direct memory tests. On the indirect test, older adults showed equal retention of target and non-target stimuli; younger adults showed retention of only the targets. In contrast, on direct memory tests both age groups were more accurate for targets than non-targets. Results are discussed in terms of age-related increases in interference, without concomitant increased elaborative rehearsal of task-irrelevant stimuli.

(235)

Aging and Retrieval-Induced Forgetting. MICHAEL C. ANDERSON, UCLA, TAMARA ABOUSLEMAN, \& DEBORAH BURKE, Pomona College (presented by Deborah Burke)-Using a retrieval practice paradigm, we tested hypothesized inhibitory deficits in old age. Young and older adults studied eight categories (e.g., Fruit-Orange) and then received retrieval practice on some category examples (e.g. Fruit-Or__ (_) Retrieval practice facilitated recall of practiced examples, but impaired recall of remaining unpracticed items (e.g., FruitBanana) relative to baseline items from unpracticed categories. This retrieval-induced inhibition effect was larger for older adults, suggesting unimpaired inhibitory processes.

\section{(236)}

Priming Item Information and Decision Processes in a Category Verification Task. JENNIFER A. MANGELS \& ARTHUR P. SHIMAMURA, University of California, Berkeley (presented by Arthur P. Shimamura)-Cross-trial priming effects were observed for category verification judgments when test items from one trial were the same or related to those present on the subsequent trial (e.g., animaldollar; animal-cat). Priming effects were often greater for repeated categories than for repeated exemplars, however this effect depended on the truth value of the prior decision. These findings suggest that priming effects in category verifications can occur for both item information and decision processes.

\section{(237)}

Negative Priming for Spatial Location: A Methodological Critique. KELLY FRAME, JOHN CHRISTIE, \& RAYMOND KLEIN, Dalhousie University (presented by Raymond Klein)-Many studies of negative priming for spatial location (cf. Tipper, Brehaut \& Driver) have used unbalanced designs in which the prime trial configuration can be used by the subject to predict where the target (and distractor) may appear on the probe trial, thus contaminating measures of interference. Using a balanced design which eliminates this possibility we found interference at the previous distractor location, and both interference and facilitation at the previous target location, and more.

Elaborative Processing Effects on Conceptual Priming: A Process Dissociation Analysis. MARY JACIW \& MARY PAT MCANDREWS, University of Toronto (presented by Mary Pat McAndrews)-A level of processing manipulation was used to evaluate conceptual priming on a traditional indirect memory test of category exemplar generation in comparison with estimates of conscious and unconscious influences of memory derived from the process dissociation procedure (Jacoby, 1991). Results indicated an effect of study elaboration on both the indirect test and on the estimate of conscious influences; the estimate of unconscious memory processes did not show this effect.

(239)

Effects of Levels of Processing on Implicit and Explicit Tasks. ANJALI THAPAR \& ROBERT L. GREENE, Case Western Reserve University (presented by Robert L. Greene)-Challis and Brodbeck (1992) reported that larger levels-of-processing effects are obtained in fragment completion when the processing conditions are presented in block fashion than when they are mixed. This finding is replicated here and is extended to priming in perceptual identification and questionanswering. Explicit tasks (recognition, free recall, cued recall) show equivalent levels-of-processing effects in blocked and mixed designs. (240)

Process Dissociations of Directed Forgetting: Recognized and Unrecognized Retrieval. SCOTT W. ALLEN \& JOHN R. VOKEY, University of Lethbridge-Directions either to remember or forget words in a training list resulted in better memory for remember items on both direct and indirect memory tests, the latter result having previously been taken as support for a suppression/inhibition hypothesis. However, consistent with a simple encoding account, application of Jacoby's (1991) process dissociation procedure showed that the superior memory for remember items on both types of test was primarily due to explicit rather than implicit processes.

\section{(241)}

Directed Forgetting Effects in Explicit and Implicit Memory. TERRENCE M. BARNHARDT, University of Illinois, \& JOHN F. KIHLSTROM, University of Arizona-Three directed forgetting (DF) experiments were conducted. Intraserial cuing was used. In Experiment 1, a DF effect was observed only in the intentional study condition in exclusive stem-cued recall. In Experiment 2, a DF effect was also found in the incidental study condition. A DF effect was not observed in the stem completion tests. In Experiment 3, a DF effect was found in an exclusive recognition test. DF appears to affect retrieval processes dependent upon contextual information.

(242)

The Effects of Frequency on Recognition and Lexical Decisions. PATRICIA L. TENPENNY \& GAVIN S. LEW, Loyola University of Chicago-The yes/no recognition task and the lexical decision task both require a binary choice in response to a single stimulus, and both may involve an assessment of familiarity. However, they are affected differently by frequency. I compared the effects of frequency on the RN and LD tasks plus an intermediate task that required a recognition judgment but included nonwords. The results suggest how RN and LD might be explained within a common framework.

(243)

Optimal Defensive Hand Positioning to Limit Basketball Shooting Accuracy. MICHAEL K. McBEATH, Kent State University, \& PHILIP J. KELLMAN, UCLA-This study examines if putting a hand in a basketball shooter's face provides more effective defense when it is waved around with fingers open, or held stationary with fingers closed. Surveyed undergraduates strongly favored the waved-hand strategy, independent of their basketball experience, but results supported the stationary-hand strategy. People appear to assume that the added complexity of motion increases distractibility, whereas the findings support 
that motion can enhance visibility through a partially-occluding surface such as a hand.

Adaptive Function Allocation Enhances Pilot Monitoring Performance. INDRAMANI L. SINGH, Banaras Hindu University, India, ROBERT MOLLOY, Catholic University of America, JOHN E. DEATON, Naval Training System Command, \& RAJA PARASURAMAN, Catholic University of America (presented by Raja Parasuraman)-This study examined whether adaptive function allocation reduces the degree of automation-induced monitoring inefficiency. Twenty-three pilots monitored an automated engine-monitoring system for occasional automation failures, during three 30-minute sessions. Two methods of adaptive logics (model- and performance-based) were used by introducing a single manual block in the middle of an automated session. Both adaptive groups showed detected significantly more automation failures than a nonadaptive control group.

\section{(245)}

The Acquisition and Structure of Music Sight-Reading. K. ANDERS ERICSSON, ANDREAS C. LEHMANN, \& JACK A. TAYLOR, Florida State University-The sources of individual differences in sightreading performance for expert musicians are theoretically intriguing in that sight-reading is rarely deliberately practiced. Performance data (MIDI) of 15 accompanists and solo performers were recorded, while they accompanied pre-recorded flute solos. From biographic interviews the pianists' past and current amount of practice and accompanying experience was quantified and related to sight-reading performance. Furthermore, hypothesized component skills were measured and related to past experience of sight-reading and current performance level.

(246)

Evidence for Action-Based Representations of To-Be-Ignored Objects in a Selective Reaching Task. DANIEL V. MEEGAN \& STEVEN TIPPER, McMaster University (presented by Steven Tipper)-Previous selective reaching studies have shown that attention accesses action-based internal representations. In other words, the action a distracting object affords will determine how strongly it competes for the control of action. The present study directly manipulates the complexity of the required reach to a particular location to see if the interference produced by a distractor at that location is influenced. The data to be reported support the action-based model.

(247)

The Fast and the Slow of Skilled Bimanual Movement Timing. RALF TH. KRAMPE, REINHOLD KLIEGL, \& ULRICH MAYR, Max Planck Institute for Human Development and Education, Berlin (sponsored by K. Anders Ericsson)-Fifteen professional pianists and 15 amateurs were tested with two tasks requiring the production of either isochronuous or polyrhythmic bimanual movements. In the course of six sessions a large range of tempi was examined. Accuracy of timing was modeled with two-parameter time-accuracy functions (TAF's) capturing biomechanical constraints and the variability of internal timing mechanisms, respectively. Effects of expertise on performance can be related to past amounts of deliberate practice.

\section{(248)}

Localizing Sequential Effects in Choice RT With Two-to-One Mappings. ERIC SOETENS \& JOHAN HUETING, University of Brussels-Locus of automatic facilitation and subjective expectancy in choice RT is investigated by means of two-to-one mappings, with stimuli presented in a square, and keys were left-right. Relevant stimulus dimension was left-right in Experiment 1, and up-down in Experiment 2. Similar to two-choice tasks, the dominating mechanism of sequential effects is determined by interaction of response-stimulus interval and compatibility. Automatic facilitation is present at both stimulus and response side, whereas expectancy is response located, and left-right oriented, even if this dimension is irrelevant.

(249)

Research Support From the National Science Foundation. FRED STOLLNITZ \& JOSEPH YOUNG, National Science Foundation. 


\section{HUMAN MEMORY III \\ Palladian Room, Saturday Morning, 8:00-9:55}

Chaired by Robert A. Bjork, UCLA

8:00-8:15 (250)

Frequency Memory for Actions Presented in Lists, Scripts, and Stories. DEBORAH A. CONNOLLY \& WILLIAM E. HOCKLEY, Wilfrid Laurier University (read by William E. Hockley)-Incidental memory for the frequency of action statements was compared for different presentation contexts. Frequency estimates were equally accurate for atypical actions presented in a list or embedded in a set of scripted routines (Exp. 1), but judgments were more accurate for atypical actions presented within scripted routines than within stories (Exp. 2), and more accurate for atypical actions than typical script actions (Exp. 3 ). The findings provide novel support for the schema pointer plus tag model.

\section{8:20-8:35 (251)}

Evidence for Exemplar Retrieval and Strength Theories of Category Frequency Estimation. DARRYL BRUCE, Saint Mary's University, \& HEATHER J. FAULKNER, McMaster University-When individuals judge the frequency with which examples of taxonomic categories occurred in a list, reliance on exemplar retrieval appears to be particularly strong when cued recall of exemplars precedes frequency estimation, moderate when it does not, and minimal if categorization of the exemplars takes place during list presentation. As exemplar retrieval accounts for less of the variance, we assume by default that some version of strength theory plays more of a role.

\section{8:40-8:55 (252)}

Estimation Strategies and the Judgment of Event Frequency. NORMAN R. BROWN, University of Alberta-The processes underlying judgments of event frequency were investigated in a series of studies Verbal protocols and response times indicate that people use a variety of frequency estimation strategies and that strategy selection is determined, in part, by the nature of the target item. Specifically, when the instances of a target event are highly distinctive, enumeration-based responses are very common; when they are not, responses based on "general impressions" and/or availability predominate.

$$
\text { 9:00-9:10 (253) }
$$

Working Memory and Calculation Strategies in Running Addition. RICHARD A. CARLSON \& MELANIE CARY, Pennsylvania State University-Subjects in three experiments performed running addition tasks varying in calculation and working-memory demands, while providing talk-aloud protocols. Selection of calculation proceduresmemory retrieval or counting-was influenced by placekeeping and other task demands, but not by priming or relative speed. Subjects used articulatory strategies for maintaining goals and intermediate results, for placekeeping, and to monitor performance. Results suggest individuals control fluent cognitive performances by placing process-control elements in working memory.

$$
\text { 9:15-9:25 (254) }
$$

Memory Scanning of Verbal and Visual Information in Working Memory. LINDA W. DUKE, EDWARD J. RICKERT, TERRI HOAR, \& APRIL LOGGINS, University of Alabama in Birmingham-Reaction time increased linearly with increasing memory set size in a verbal Sternberg task, while in a visual/spatial task reaction time to an intermediate set size was slower than to a smaller or larger memory set. Instructions to retain the positive set as presented versus instructions to retain the negative set, rather than the largest positive set, resulted in different RT functions. Results appeared consistent with flexible, modality independent, retrieval mechanisms in working memory.

$$
\text { 9:30-9:50 (255) }
$$

Parameter Variation in Retrieval-Independence Theories of Memory. WILLIAM H. BATCHELDER, University of California, IrvineHintzman and others have raised concerns about the interpretation of memory data aggregated over subjects and items. These concerns are especially strong in paradigms that involve two successive memory tests on the same items (e.g., MMFR, RTT, and the Tulving-Wiseman function). This paper utilizes methods and recent results in mathematical statistics and item-response theory to understand better the role of subjectitem parameter differences in retrieval-independence theories for such paradigms.

Diplomat Room, Saturday Morning, 8:00-9:50

Chaired by Harold Pashler, University of California, San Diego

8:00-8:20 (256)

Toward a Resolution Theory of Visual Attention. YEHOSHUA TSAL \& NACHSHON MEIRAN, Tel Aviv University-We propose that preattended information produces a coarse representation by automatically stimulating a detector that responds to a range of similar features. Attending to a given location improves the resolution of features by computing the relative activation of overlapping detectors. A review of the literature suggests that the proposed distinction is supported by diverse effects of target-background similarity, background homogeneity, conjunctive search, illusory conjunctions, global precedence, shape discrimination, detection of signals, and categorical search.

8:25-8:40 (257)

Why Does Selective Attention Fail? ROBERT D. MELARA, JEFFREY R. W. MOUNTS, \& NORIKO YAMAGISHI, Purdue University-We present a change-detection model of selective attention. A bank of perceptual channels, based on the primacy of stimulus dimensions, directs attention according to the nature, importance, and degree of environmental change. The model captures a host of experimental results including: (a) Garner interference in classification; (b) Stroop interference to color/word stimuli; (c) performance differences between same-different and single-interval tasks; (d) the traditional dichotomy between interacting and separable dimensions; (e) contextual effects of stimulus discriminability.

\section{8:45-9:00 (258)}

Selectivity in Attentional Capture by Featural Singletons. CHARLES L. FOLK, Villanova University, \& ROGER W. REMINGTON, NASA-Ames Research Center-Previous research suggests that if looking for a featural singleton, irrelevant featural singletons will capture attention regardless of the dimensions or values over which those singletons are defined. We report new evidence that when looking for a singleton in one color, singletons in a different color do not produce attentional capture. We conclude that attentional control settings can be adopted for specific color values. We argue that previous results reflect nonspatial distraction effects.

$$
\text { 9:05-9:25 (259) }
$$

Attention, Spatial Frequency, and Parietal Function in Humans. LYNN C. ROBERTSON, University of California, Davis, \& ROBERT EGLY, University of Oregon-Two previous studies showed that attentional allocation to global and local levels of hierarchically formed stimuli was disrupted in patients with left inferior parietal damage. Data are presented suggesting that the disruption is a loss of normal costs associated with switching from one spatial frequency value to another across successive trials. Left parietal damage affects an attentional record left by the spatial frequency of the target most recently selected for processing.

\section{9:30-9:45 (260)}

A Visual "Cocktail Party" Effect: Seeing Your Name Without Attention. ARIEN MACK \& JONATHAN KATZ, New School for Social Research-Under conditions of inattention, neither grouping, texture segregation, nor shape are perceived. One's own name is. Sixty subjects were tested; for 20 the inattention stimulus was their own name; for 20 it was someone else's and for 20 it was a common noun. $30 \%$ saw the noun. $50 \%$ saw someone else's name. $95 \%$ saw their own name. These results are consistent with the view that perception entails attention and only what captures attention is perceived unless searched for

\section{COGNITION}

Hampton Room, Saturday Morning, 8:00-10:05 
8:00-8:20 (261)

A Resource Theory of Spatial Ability. MARCEL ADAM JUST \& PATRICIA A. CARPENTER, Carnegie-Mellon University-Spatial ability can be construed as the resource pool that supports both computations and representations in spatial reasoning, as supported by three converging approaches. First, pupillometric studies show larger effects for lower ability individuals if the task requires more processing. Second, age-related changes in spatial performance are greater if the task requires such resources. Finally, a simulation model with a parameterized resource pool accounts for the differences among individuals in a mental rotation task.

\section{8:25-8:40 (262)}

The Effect of Visual Field Restriction on Spatial Knowledge Acquisition. JEANNE SHOLL, Boston College-Previous research indicates that landmark interrelations are encoded in the form of route knowledge when a path is traveled under a cognitive load and survey knowledge, otherwise. The present study examines whether cognitive load affects the type of spatial knowledge acquired because of (a) decreased central capacity for encoding spatial information or (b) a constriction of visual attention to the central visual field. The results support the latter alternative.

$$
\text { 8:45-9:05 (263) }
$$

A Nearest Neighbor Account of Analogy Solution. EDWARD J. SHOBEN, University of Illinois, \& DANIEL D. SADLER, Indiana University of Pennsylvania-We propose a nearest neighbor heuristic for solving analogy problems of the form A:B:C:?. According to this heuristic, one picks a solution by determining which is closer to $\mathrm{A}, \mathrm{B}$, or $\mathrm{C}$ ? If $\mathrm{B}$ is closer, then the solution is the alternative that is the nearest neighbor of $\mathrm{C}$. Two experiments, using two distinct domains, provided data that favored this heuristic over the parallelogram rule. We discuss limitations and possible extensions of this finding.

\section{9:10-9:25 (264)}

Information Processing During Saccadic Eye Movements. DAVID E. IRWIN \& LAURA A. CARLSON-RADVANSKY, University of Illinois-Do people think while they are moving their eyes? We know that visual input is suppressed during saccadic eye movements; some (e.g., van Duren, 1993) have suggested that cognitive activity is suppressed as well. We examined whether a prime viewed in one fixation exerts a larger influence on a target viewed in a second fixation when a long vs. short saccade separates their viewing; such an effect would imply that processing occurs during saccades.

$$
\text { 9:30-9:45 (265) }
$$

Cognitive Factors in Automated Instruction for Individuals and Groups. WAYNE SHEBILSKE, JEFFREY A. JORDAN, \& WINFRED ARTHUR, JR., Texas A\&M University-We tested factors that contribute to a $100 \%$ increase in training efficiency yielded by a dyadic protocol for training complex skills. Dyadic protocols reduce hands-on practice, but cognitive and social theories predict factors that could offset this reduction. These factors were isolated and tested for college students operating Space Fortress, a video game like research tool, for $10,1 \mathrm{hr}$ sessions of 8 practice and 2 test games. Results suggested the importance of observational learning for acquisition and automatization.

\section{9:50-10:00 (266)}

Directions to Remember and Forget in Short-Term Recognition Memory. RICHARD S. CIMBALO \& KIMBERLY A. FERRITER, Daemen College-Research investigated effects of instructions to remember and forget a particular word on recognition memory for twelve 5-word matrices. When told to "remember this word" subjects remembered word better than no-instruction control but not the "forget this word condition." "Remember this word" causes poorer performance for other words of the matrix. Instructions at beginning or end of study period made no difference. Memory implications for directed forgetting and the von Restorff Effect are discussed.

\section{LANGUAGE/DISCOURSE PROCESSING I} Blue Room, Saturday Morning, 8:00-9:55

\section{Chaired by Murray Singer, University of Manitoba}

\section{8:00-8:15 (267)}

The Availability of Protagonists' Goals in 2nd Versus 3rd Person Narratives. AMY R. BRIGGS \& CHARLES R. FLETCHER, University of Minnesota (read by Charles $\mathrm{R}$. Fletcher)-A naming task was used to assess the availability of protagonists' goals during narrative comprehension. Results suggest that: (a) Goals remain active while the protagonist is the discourse topic and engages in a sequence of potentially goal-directed actions. (b) Goals become inactive when a second character becomes the topic. (c) When the protagonist becomes the topic once again, goals are reinstated if the text is written in second person, but not if it is written in third person.

8:20-8:40 (268)

Text Comprehension as Function of Feedback Type and Amount. PHILIP LANGER, VERNE KEENAN, \& MISSY SCHREINER, University of Colorado-A spatial or linear-route description of the same town was presented one sentence at a time. Feedback provided was either (1) limited access to a map, (2) limited opportunities to review previously scanned sentences, or (3) presentation of the entire text after completion. Comprehension was indexed by propositional recall and inferential reasoning. The differential effects on version comprehension of feedback type and amount are explained in terms of our complementarysupplementary model.

\section{8:45-9:05 (269)}

Testing the Primacy of Comparison in Metaphor Processing. DEDRE GENTNER \& PHILLIP WOLFF, Northwestern University-Match-then-map models of metaphor comprehension assume an initial process of comparison. Map-first models postulate an initial process of abstraction from the base followed by mapping to the target. We recorded subjects' time to interpret metaphors when preceded by either the base, target, both, or neither. In Experiments 1 and 2, we failed to find a base advantage in processing time. In Experiment 3, a base advantage was found, but only for high conventional bases.

$$
\text { 9:10-9:30 (270) }
$$

A Comparison of Measures of Calibration Accuracy for Deeply and Shallowly Processed Text. RUTH H. MAKI, North Dakota State University-Level of processing of text was manipulated by having subjects indicate whether probe sentences were identical to or had the same meaning as text sentences. Subjects predicted the number of questions they would get correct on a test and they estimated the number they actually got correct following the test. Various measures of calibration accuracy that emphasize the absolute accuracy of judgments and the relationship between judgments and performance were compared in the two processing conditions.

\section{9:35-9:50 (271)}

Verbal Commitments and Gestures: Exploring the Connection. PAUL C. AMRHEIN \& BRENDA MARTINEZ, University of New Mexico-Subjects chose photographs of emblematic gestures (e.g., handshake, hand on heart, shrug) perceived to accompany the utterance of quasi-performative verbs (e.g., promise, agree, plan, suppose) occurring in verbal commitments. Results indicated three gesture types: selfreference (e.g., hand on heart), external reference (e.g., handshake), and composite (e.g., shrug) which correlate to speaker intentions/beliefs conveyed by the committing verbs. Findings are related to the role of emblematic gestures in biasing speaker intention/belief relevance in verbal commitments.

\section{PICTURE MEMORY/PROCESSING}

Empire Room, Saturday Morning, 8:00-9:50

Chaired by Matthew J. Sharps, California State University, Fresno

$$
\text { 8:00-8:10 (272) }
$$

Verbal and Visual Processes in Mental Construction. TORE HELSTRUP, University of Bergen, \& RITA E. ANDERSON, Memorial University-The results of a series of experiments suggest that visual con- 
struction and verbal interpretation are distinct processes in the visual construction task. Interpretational constraints were provided early in each trial or were delayed, with or without use of verbal, visual, or neutral suppression trials. Being able to explore the ways the parts can be combined before having to interpret the construction enhances task performance.

\section{8:15-8:35 (273)}

Representational Differences Between Pictures of Objects and Pictures of Scenes. CARMELA V. GOTTESMAN \& HELENE INTRAUB, University of Delaware (read by Helene Intraub)-Tested immediately, memory for scenes yields extension of picture boundaries. Following delay, close-up views yield extension and wide-angle views restrict. Intraub (1992) proposed that initially, activation of a perceptual scene schema pushes boundaries outward; over time, memory normalizes toward the average view. We presented pictures without scene structure (object alone) and the normalization pattern occurred immediately. When the same objects were presented within a scene structure, boundary extension occurred, thus supporting the perceptual schema hypothesis.

\section{8:40-9:00 (274)}

The Effects of Naming on a Visual Manipulation Task. MARGARET JEAN INTONS-PETERSON, Indiana University-Brandimonte, Hitch, and Bishop (1992) reported that naming the outcome of an imaginal subtraction task was facilitated when articulatory suppression presumably reduced phonological recoding of visual information into long-term memory. This result is replicable when subjects name the output of the subtraction task, but not when subjects recognize, reproduce, or both name and describe the outcome of the task. In the latter cases, articulatory suppression interferes with performance.

$$
\text { 9:05-9:20 (275) }
$$

Classifying Faces by Sex: Human and Neural Network Performance. DOMINIQUE VALENTIN, KAREN R. MCKEE, HERVÉ ABDI, \& ALICE J. O'TOOLE, University of Texas at Dallas (read by Hervé Abdi)-Faces can be classified by sex using the first few eigenvectors of an autoassociative memory made of male and female face images. These eigenvectors remain stable even with very small numbers $(<20)$ of faces. We showed that the projections of a face on these eigenvectors predict reaction times for human subjects classifying faces by sex. The patterns of prediction, however, are affected by the sex of the subject and the sex of the face.

\section{9:25-9:45 (276)}

Shape Recognition Processes Operate Before Figure-Ground Organization. M. A. PETERSON, University of Arizona, \& BRADLEY S. GIBSON, Johns Hopkins University-It has been assumed that figureground segmentation must precede shape recognition processes. We showed observers brief masked exposures of figure-ground stimuli (14$100 \mathrm{~ms}$ ) and manipulated (1) the symmetry of two regions competing for a figure-ground contour, (2) their denotivity (roughly, meaningfulness), and (3) their orientation (and hence, the time taken to complete reference-frame dependent shape recognition). Our results demonstrate that shape recognition processes operate before initial figure-ground organization and influence that organization.

\section{ANIMAL LEARNING/CONDITIONING II}

Ambassador Room, Saturday Morning, 8:00-9:55

\section{Chaired by William A. Roberts, University of Western Ontario}

\section{8:00-8:20 (277)}

Novelty Versus Retrieval Cue Value of Visual Contextual Stimuli in Pigeons. SPENCER K. MORRISON \& DAVID R. THOMAS, University of Colorado (read by David R. Thomas)-Pigeons keypeck-trained in the presence of a (red or blue) houselight responded substantially more, in extinction testing, when the training color and not the alternative color was present. No such preference developed when exposure to the houselight color preceded or followed but did not accompany training. Thus contextual stimuli present during training can help retrieve memory of that training, as demonstrated by a strategy which controls for the novelty of the nontraining context condition.

\section{8:25-8:40 (278)}

Retrieval of Extinction Attenuates Spontaneous Recovery and the Renewal Effect. DOUGLAS C. BROOKS \& MARK E. BOUTON, University of Vermont (read by Mark E. Bouton)-A cue from extinction attenuates spontaneous recovery when presented during testing. The cue also attenuates the "renewal" of responding that occurs when a $\mathrm{CS}$ is tested in the conditioning context after extinction in another context. The cue's effect is not due to generalization decrement, unconditional disruption of responding, or the acquisition of demonstrable inhibition or excitation. Spontaneous recovery and renewal may result from a failure to retrieve extinction outside the temporal or physical extinction context.

\section{8:45-9:00 (279)}

Interactive Effect on Learned Helplessness of Shock Duration and Chronicity of Signaled Shock Preexposure. PHILIP J. BERSH, PAUL E. NEUMAN, Temple University, STEPHEN C. MEISTER, Veterans Administration, MICHAEL F. STROMBERG, University of Pennsylvania, WAYNE G. WHITEHOUSE, Temple University, \& DONNA MONGELUZZI, SUNY at Albany-Further evidence is provided on the interactive effect on learned helplessness of shock duration and chronicity of preexposure to signaled shock. Under some conditions, animals preexposed to signaled escapable shock manifest subsequent shockescape impairment; under other conditions, animals preexposed to signaled inescapable shock fail to show later shock-escape impairment. 9:05-9:25 (280)

Contextual Representation Formation in Fear Conditioning: An NMDA-Mediated Process in the Hippocampus. MICHAEL S. FANSELOW, STACEY L. YOUNG, \& BEATRICE M. DE OCA, UCLAContext preexposure sometimes enhances contextual fear conditioning. Perhaps this occurs because during exploration the individual stimulus elements of a context become integrated into a unitized representation. This integration is performed by NMDA-mediated processes in the hippocampus but the representation is stored in the neocortex. Supporting this view, NMDA antagonists and hippocampal lesions prevented both habituation of exploration and contextual fear conditioning. Additionally, context preexposure protected rats from the detrimental effects of hippocampal lesions.

\section{9:30-9:50 (281)}

Taste Intensity Influences Retrieval of Interelement Associations in Potentiation of Visual Aversions. JOSEPH J. FRANCHINA \& BARRY A. GARST, Virginia Polytechnic Institute-Chicks received brief access to compound CSs of red water or red $1.0 \%$ or $4.0 \%$ vinegar, followed seven hours later by conditioning in which clear water or clear $1.0 \%$ or $4.0 \%$ vinegar was paired with $\mathrm{LiCl}$ injection. Testing with red water showed that potentiation increased reliably the higher the vinegar concentration at conditioning. Results suggested that potentiation of visual aversions depended more on taste-illness associability than on the association between compound CS elements.

\section{RECOGNITION/RECALL I}

Palladian Room, Saturday Morning, 10:05-11:50

\section{Chaired by Murray Glanzer, New York University}

\section{0:05-10:25 (282)}

Conjunctions and Superimposed Composites in Face Recognition. JANET METCALFE, Dartmouth College-Several experiments explored recognition memory for faces. Old and new faces were called old and new, respectively. Conjunctions (eyes and nose came from one studied face; background from another), and Superimposed Composites (two studied faces superimposed each with 50\% transparency) were called old with intermediate frequency, with Composites sometimes being higher than Conjunctions. Results from five computational models (CHARM, TODAM, Competitive Learning, MINERVA, and Back Propagation) relate these data to "cognitive binding" in explicit memory. 10:30-10:40 (283)

Separating the Effects of Prior Knowledge From Recollection. COLLEEN M. KELLEY, Macalester College, \& LARRY L. JACOBY, McMaster University_Jacoby's (1991) process dissociation procedure 
was used to separately estimate the contributions of memory and general knowledge to performance on a memory test. Subjects read a list of general knowledge questions paired with correct or incorrect answers, and then attempted to recall the presented answer when cued with the question. The results of two studies support the hypothesis that memory and general knowledge can act as independent sources to determine responses on a memory test.

$$
\text { 10:45-11:05 (284) }
$$

Action Slips, Proactive Interference, and Probability Matching. LARRY L. JACOBY \& JANINE HAY, McMaster University-Action slips arise from the opposition of habit and current intentions as does proactive interference. Traditionally such interference effects have been examined separately from facilitative effects. In contrast, we investigated the two types of effect together so as to separate the contributions of habit and current intentions. Estimated effects of habit showed probability matching. Process dissociations were found and interpreted as reflecting effects in memory tasks that are akin to Stroop effects in perceptual tasks.

\section{1:10-11:25 (285)}

Effects of Feedback on Human Interval Timing. SEAN C. HINTON, Columbia University, JOHN GIBBON, Columbia University \& New York State Psychiatric Institute, BRIAN C. RAKITIN, \& WARREN H. MECK, Columbia University (read by Warren H. Meck)The effects of feedback on timing short intervals (5-30s) in a peak-interval timing procedure were assessed. Successive trials $(n=4)$ since feedback (TSF) showed systematic rightward drift of peak time. The relative magnitude of this drift decreased linearly with increasing signal duration. The contribution of memory (versus response threshold) variance was greater for longer signal durations. Variability decreased from the first to the second TSF, and the magnitude of this effect diminished with increasing signal duration.

$$
\text { 11:30-11:45 (286) }
$$

Extending the Fuzzy Logical Model of Perception to Episodic Memory Tasks With Direct and Indirect Retrieval Instructions. DAVID G. PAYNE \& MICHAEL J. WENGER, SUNY at BinghamtonMassaro, Weldon, and Kitzis (1991) demonstrated that Massaro's Fuzzy Logical Model of Perception (FLMP) accounts for the effects of integrating orthographic and semantic cues in a semantic memory task. We extended this work in an episodic memory task and also under direct vs. indirect retrieval instructions. Our results assess (a) the utility of the FLMP approach to theoretical issues in memory and (b) the ability of the basic FLMP formalism to account for performance in various memory tasks.

\section{ATTENTION IV}

Diplomat Room, Saturday Morning, 10:00-11:50

\section{Chaired by Richard B. Ivry, University of California, Berkeley}

10:00-10:15 (287)

Illusory Conjunctions Without a Brief Exposure or Diverting Attention. WILLIAM PRINZMETAL, DEBORAH HENDERSON, \& RICHARD B. IVRY, University of California, Berkeley-Illusory Conjunctions are the incorrect combination of correctly perceived features, such as colors and shapes. Treisman and others have found illusory conjunctions with briefly presented stimuli when attention was diverted The present experiments demonstrate that Illusory Conjunctions can occur with long exposure durations ( 1.5 seconds) and without diverting attention.

\section{0:20-10:35 (288)}

Object Continuity in Motion Perception and Attention. STEVEN YANTIS, Johns Hopkins University-On each trial of a visual search task, one element was briefly flickered off and back on. The flickering element captured attention with increasing efficiency as the duration of the flicker increased from 0 to $100 \mathrm{~ms}$. This mirrors the timecourse of motion perception in a bistable apparent-motion (Ternus) display, which also depends on the duration of the blank interval between successive frames. Both phenomena reflect the creation of a new perceptual object by the temporal gap.

\section{0:40-11:00 (289)}

Perceptual Learning and the Representation of Complex Objects. NANCY LIGHTFOOT \& RICHARD M. SHIFFRIN, Indiana University (read by Richard M. Shiffrin)-Subjects searched for initially novel, complex, visual objects. We found unprecedented improvements in search performance, attributable to a process of perceptual unitization. We used transfer tasks to investigate factors affecting the nature and rate of perceptual unitization, including the roles of featural processing, redundancy, similarity, and task constraints. The results have important implications for understanding the nature of, and changes in, complex object representation.

11:05-11:25 (290)

Symmetry Detection, Part Decomposition, and Object-Based Visual Attention. GORDON C. BAYLIS, University of California, San Diego, \& JON DRIVER, University of Cambridge-Mach (1885) observed that symmetry is easier to detect than repetition. We suggest that usually symmetrical but not repeated contours have matching partdescriptions, according to Hoffman and Richards' minima rule. We manipulated figure-ground assignment so that repeated but not symmetrical contours now had matching part-descriptions. Under these conditions the Mach effect reverses. These data show that contours automatically undergo figure-ground assignment, with resulting partdescription according to the minima rule.

\section{1:30-11:45 (291)}

Visual/Auditory Capture of Auditory/Visual Attention. LAWRENCE M. WARD, University of British Columbia-Moving visual stimuli easily capture auditory localization, viz. ventriloquists and cinema. Does such attention capture involve the polymodal covert orienting mechanisms identified by others? Experiments in which abrupt set visual and/or auditory orienting cues precede visual and/or auditory targets that must be detected, discriminated, or localized are reported. The results constrain theories of covert attention orienting and also suggest ways in which polymodal attentional mechanisms might differ from unimodal ones.

\section{3-D/MOVEMENT PERCEPTION III Hampton Room, Saturday Morning, 10:15-11:55}

Chaired by Bennett I. Bertenthal, University of Virginia

$$
\text { 10:15-10:30 (292) }
$$

Time-Distance Relations in Visual, Auditory, and Tactile Apparent Motion. STEPHEN LAKATOS \& ROGER N. SHEPARD, Stanford University (read by Roger N. Shepard)-Stimuli were sequentially presented at different rates at $3,4,6$, or 12 equally spaced locations around a circle-by LED's in the frontal plane (visually), speakers around the head (auditorally), or mechanical stimulators on the palm or airpuff nozzles around the head (tactually). In all cases, minimum SOA yielding $75 \%$ accurate discrimination between clockwise and counterclockwise sequences increased with angular distance between successive stimuli in accordance with Korte's third law of apparent motion. 10:35-10:55 (293)

Motion Coherence Is Perceived as Information Entropy. DAVID L. GILDEN, University of Texas at Austin, ERIC HIRIS, \& RANDOLPH BLAKE, Vanderbilt University-Information theory has played two separate roles in the development of cognitive psychology. Its primary application and success was in the measurement of channel capacities. Information theory also guided inquiry into descriptions of pattern perception. Here the theory content was never substantively used. We present a stimulus domain where information theory is descriptive; the judgment of coherence in dynamic visual noise appears to be based on an explicit encoding of the Shannon-Wiener information entropy. 11:00-11:15 (294)

Perceived Rigid Rotation in Depth From Constant Flow Fields. JAMES T. TODD, VICTOR PEROTTI, \& J. FARLEY NORMAN, Ohio State University-In most natural contexts, the optical flow fields produced by moving objects deform systematically over time. Our research has examined how the absence of such deformations influence observers' perceptions of structure from motion. Although our displays 
have no possible rigid interpretation when analyzed over multiple views, the results reveal that they are often indistinguishable from rigid rotations in depth. This finding is consistent with the theoretical analysis of affine structure from motion proposed by Todd \& Bressan (1990). 11:20-11:35 (295)

Circumventing Mental Rotation. ASHER KORIAT, University of Haifa-The processing of stimuli is generally impeded when they appear in unusual orientations. The size of the rotation effect, however, differs markedly for different tasks, supposedly because of different "rates of mental rotation." Evidence supporting an alternative view that distinguishes between different ways of interpreting disoriented stimuli will be presented. For example, it will be shown that left-right discriminations, normally associated with strong orientation effects, can sometimes be performed relatively independent of disorientation.

\section{1:40-11:50 (296)}

Comparison of Two Indicators of Perceived Distance Under Fulland Reduced-Cue Conditions. JOHN W. PHILBECK \& JACK M. LOOMIS, University of California, Santa Barbara (read by Jack M. Loomis)-Under both full-cue and reduced-cue conditions, we compared two response measures of perceived egocentric distance: verbal report and open-loop walking (where the observer walks without vision to a previewed target). Both measures showed little systematic error under full-cue conditions but substantial systematic error under reduced-cue conditions. The mapping between the two measures was essentially constant across contexts, indicating that the two measures are controlled by the same variable, obstensibly perceived egocentric distance.

LETTER/WORD PROCESSING III

Blue Room, Saturday Morning, 10:05-12:00

\section{Chaired by Stephen J. Lupker, University of Western Ontario}

10:05-10:25 (297)

The Effect of Meaning on Letter Detection. JULIA E. MORAVCSIK \& ALICE F. HEALY, University of Colorado (read by Alice F. Healy)-We examined whether familiarity of word meaning affected letter detection. Fewer errors occurred for "the" when it had an unusual meaning, was contrastive, or had an ambiguous referent. Fewer errors occurred for less common meanings of "in" and "it" even when "it" took on less semantic content and was a function word. These experiments suggest that uncommon meanings of words are accessed slowly and that letter processing occurs during a late stage of semantic accessing. 10:30-10:40 (298)

Phonological and Orthographic Priming Effects in Auditory and Visual Word Recognition. MARTHA W. BURTON, Pennsylvania State University, ALLARD JONGMAN, \& JOAN SERENO, Cornell University (read by Allard Jongman)-A series of experiments investigated the role of phonological and orthographic priming effects in word recognition. Priming effects were evaluated in both the auditory and visual modalities using lexical decision and naming tasks. Conditions in which there was overlap of both phonological and orthographic information, overlap of phonological information only, and overlap of orthographic information only were compared to unrelated conditions. The results will be discussed in terms of current theories of word recognition.

\section{0:45-11:05 (299)}

Phonological Priming in Spoken Word Recognition is Not Strategic. LOUISA M. SLOWIACZEK \& MARYBETH HAMBURGER, University at Albany-SUNY-While Slowiaczek and Hamburger (1992) argue that facilitatory and inhibitory phonological priming effects are the result of two distinct processes in the word recognition system, Goldinger, Luce, Pisoni, and Marcario (1992) suggest that these effects are strategy induced. The current study manipulates relatedness proportion and interstimulus interval to determine whether strategies induce phonological priming effects. Facilitatory and inhibitory phonological priming was obtained in all conditions supporting the position that these effects reflect basic operations in the word recognition system.

\section{1:10-11:30 (300)}

Syllable Structure and Orthographic Form-Priming in High Density Neighborhoods. KENNETH I. FORSTER, University of Arizona, \& MARCUS TAFT, University of New South Wales-Previous work suggests that form-priming effects (e.g., mature-NATURE) are postive only in low-density neighborhoods (i.e., when the target word is low N). Using a masked priming paradigm, it is shown that this is no longer true when neighborhood density is defined in terms of all syllabic units rather than individual letters. The results are interpreted in terms of a recording mechanism that attempts to maintain all even density throughout lexical space.

$$
\text { 11:35-11:55 (301) }
$$

On the Processing of Ambiguity With a PDP Model: Unsettled Issues. STEVE JOORDENS \& DEREK BESNER, University of Waterloo (read by Derek Besner)-PDP models assume different meanings of a word are represented across a common set of nodes. Our intuition is that multiple meaning words would be slower to identify than single meaning words because the different meanings compete when attempting to instantiate their pattern. Since humans are faster to identify multiple meaning words, the stage is set for a confrontation between data and model.

\section{DEVELOPMENT/AGING I \\ Empire Room, Saturday Morning, 10:00-11:55}

Chaired by Susan Kemper, University of Kansas

10:00-10:15 (302)

Notational Disparity and Numerical Competence: U.S./Chinese Comparisons. DAVID R. PAREDES, Texas A\&M University, \& KEVIN F. MILLER, University of Illinois (read by Kevin F. Miller)Whether cognitive abilities are mediated by specific "surface" notations has been a continuing controversy. Children must master at least two mathematical notational systems: Arabic numerals and their language's number words. The disparity between "word" and numeral notations is larger for English than for Chinese. U.S. and Chinese children solved addition problems in both "word" and numeral notations. Chinese children were more likely to apply "numeral" strategies to "word" problems, resulting in a specific pattern of errors.

\section{0:20-10:35 (303)}

Problem Solving Strategies of Deaf and Hearing Children. MARC MARSCHARK, RIT/National Technical Institute for the Deaf, VICTORIA S. EVERHART, \& JULIA COMFORT, University of North Carolina at Greensboro-Problem solving strategies of deaf and hearing children (aged 7-14) were examined using a form of the " 20 Questions" game. Deaf children required more qustions to solve the problems and used more item-specific guessing than hearing peers. Hearing children were more likely to employ hierarchically constraining questions and systematically test constraint-consistent hypotheses. Those strategies were more "efficient" in eliminating alternative problem solutions. Problem solving strategies were related to reflectivity-impulsivity scores on the Porteus Mazes.

\section{0:40-10:50 (304)}

Developmental Changes in Concepts of Mental Verbs of Knowing. WILLIAM V. FABRICIUS, Arizona State University, PAULA J. SCHWANENFLUGEL, University of Georgia, JOYCE ALEXANDER, Indiana University, \& CAROLINE R. NOYES, University of GeorgiaThe developing organization of mental verbs was examined using similarity judgments obtained from 2 nd and 4 th graders, and adults. Schwanenflugel et al. (1993) had suggested that adults organize mental verbs along a naive information processing conception of mind and along a constructive continuum. Both of these aspects were found to develop from second grade to adulthood. In Experiment 1, young children were found to weight the constructive aspects of mental processes less than adults in their similarity judgments. In Experiment 2, adults organized verbs along three clusters: a memory, a processing, and an input cluster. Fourth graders possessed a memory and processing cluster, but second 
graders possessed little of the adult organization of mental verbs of knowing.

10:55-11:05 (305)

A Cross-Linguistic Study of the Comprehension of Superordinate Category Terms. M. MICHAEL AKIYAMA, University of MichiganDearborn-Forty Japanese-speaking 1- and 2-year-olds and 18 Englishspeaking 1- and 2-year-olds were tested on the comprehension of superordinate category terms (i.e., animal, vehicle, food, and clothing). They were tasked to select 3 items out of 6 . Despite differences on how terms are expressed in the two languages, all children find animal and vehicle terms easier to comprehend than food and clothing terms. These results suggest that categories are formed prior to and independent of language. 11:10-11:30 (306)

Symbolic Development in Young Children: Honey, I Shrunk the Room. JUDY DELOACHE, KEVIN F. MILLER, KARL ROSENGREN, \& NICOLE BRYANT, University of Illinois-Two studies tested the dual representation hypothesis about very young children's symbol use. In both studies, $21 / 2$ and 3 -year-old children performed poorly in a task in which there was a representational or symbolic relation between two entities (a scale model and a room), but they were successful in a task that was structurally similar but in which there was no representation relation. The results provide strong support for the hypothesis.

\section{1:35-11:50 (307)}

Melody Identification at Fast and Slow Tempos by Young and Old Listeners. W. JAY DOWLING, JAMES C. BARTLETT, University of Texas at Dallas, ANDREA HALPERN, Bucknell University, \& MELINDA ANDREWS, University of Texas at Dallas-Listeners 18 to 85 years of age heard recycling familiar melodies that started fast and slowed down, or started slow and speeded up. Identification thresholds in fast and slow conditions were affected by musical expertise but not by age. Detailed rhythmic information was more useful at slow tempos than at fast. Inclusion of a temporal gap marking the beginning of fast melodies was used effectively only by older listeners of high musical experience.

ANIMAL COGNITION/MEMORY II Ambassador Room, Saturday Morning, 10:05-11:55

Chaired by Janice N. Steirn, Georgia Southern University

10:05-10:20 (308)

Pigeons Differentially Observe Drawings That Differ Only in Spatial Organization. EDWARD A. WASSERMAN, K. KIRKPATRICKSTEGER, G. C. ODEN, University of Iowa, \& IRVING BIEDERMAN, University of Southern California-Four pigeons were trained to discriminate four different drawings that contained the same four components by pecking a different key in the presence of each drawing. Three exhibited patterns of observing behavior, measured with touch technology, that differed to the four different drawings. This spatial differenti- ation increased toward the end of the Fixed Ratio observing requirement. Superimposed on this trend was a propensity for pigeons to jump from one region of the display to another.

\section{0:25-10:40 (309)}

Discrimination of Relative Positions of Natural Visual Landmarks by Pigeons. DONALD F. KENDRICK, Middle Tennessee State University-Location discrimination by pigeons seems to require identification of visual landmarks and their relative positions in three-dimensional space. White Carneaux pigeons were trained to discriminate outdoor pictures of a left $20^{\circ}$ arc-area from a right $20^{\circ}$ arc-area. Generalization gradients, covering a $220^{\circ}$ arc-area, indicated that pigeons learn leftright relative positions of visual landmarks. Additional experiments indicated that pigeons also learn near-far relative positions. Stimulus features controlling learning are discussed.

10:45-11:05 (310)

Memory for Space Versus Color in Food-Storing and Nonstoring Birds. DAVID R. BRODBECK, University of Western Ontario, \& SARA J. SHETTLEWORTH, University of Toronto (read by Sara J. Shettleworth)-Food-storing birds may have adaptively specialized spatial memory. In one test, food-storing black-capped chickadees and nonstoring dark-eyed juncos matched to sample with trial-unique location + color compounds. Tests with the spatial element, the color element, and the compound occurred randomly. Chickadees' performance was controlled almost completely by spatial cues while juncos' was controlled about equally by space and color. Further experiments asked whether these results reflect species differences in memory, attention, and/or hemispheric asymmetry.

\section{1:10-11:25 (311)}

Crypticity as a Determiner of Searching Image. CYNTHIA M. LANGLEY, University of California, Berkeley, ALAN B. BOND, University of Nebraska State Museum, \& DONALD A. RILEY, University of California, Berkeley (read by Donald A. Riley)-Selective attention to visual features of a prey may account for improved detection following successive encounters (searching image). In this experiment, pigeons searched multicolored or gray gravel trays on which grains were cryptic or conspicuous, respectively. Following exposure to one grain type, birds showed a stronger selection bias for that grain on probe trays when both setting and probe were multicolored, than when either was gray, indicating crypticity to be a determiner of searching image. 11:30-11:50 (312)

Numerical Competence in an African Grey Parrot. IRENE M. PEPPERBERG, University of Arizona-A parrot, Alex, trained to enumerate homogeneous collections, correctly enumerated, without further training, targeted subsets of heterogeneous collections. Trials had different numbers of items varying in color and object categories (e.g., blue and red keys and trucks); Alex enumerated items uniquely defined by conjunction of color and object category. Under such conditions, humans count rather than subitize (Trick \& Pylyshyn, 1989). I discuss Alex's accuracy $(83.3 \%)$ in terms of human numerical competence, particularly counting ability. 
POSTER SESSION II

Regency Ballroom, Saturday Noon, 12:00-1:30

(313)

The Interaction of Object and Relational Similarities in Comparisons. ARTHUR B. MARKMAN, Columbia University, \& DEDRE GENTNER, Northwestern University-Two experiments examined the role of object similarity in structural alignment. Subjects verified whether two arrays had the same configuration. For arrays made of rich objects (e.g., houses), subjects were faster to say the configurations were the same if the objects were the same than if the objects were different. This difference was not obtained for arrays made of sparse objects (e.g. squares). Implications bear on the interplay of object similarity and relational similarity in processing comparisons.

(314)

The Effect of Expertise on the Confirmation Bias. JOSEF F. KREMS \& CHRISTOF ZIERER, University of Regensburg-The dependency of the confirmation bias on the level of expertise in diagnostic reasoning was investigated in the medical domain. Subjects with varying degrees of experience were first given a diagnosis followed by successively presented symptoms. Their fit to the given diagnosis or to alternative explanations had to be rated. Experts developed more coherent pathophysiological explanations and modified hyptheses more flexibility. The confirmation tendency decreases with expertise which indicates that domain-knowledge can overcome cognitive biases.

(315)

Does Water-Level Representation React to Introspective Reporting and Stimuli Realism? PAULINE MORIN \& MICHÈLE ROBERT, Université de Montréal (presented by Michèle Robert)-With the longrange purpose of discovering how the water-level task is conceptualized, this study examined whether a think-aloud procedure facilitates or hinders proficiency. Standard (on a table) and realistic (hand-held) stimuli were used. Results show no think-aloud effect. Realistic stimuli were detrimental only to women who were always outperformed by men. Mastery correlated with RFT scores (uninfluenced by think-aloud requirements). Discussion includes information obtained in other physical tasks.

(316)

Task Interruption and its Effects on Memory. MARK B. EDWARDS, Pacific Bell, \& SCOTT D. GRONLUND, University of Oklahoma (presented by Scott D. Gronlund)-The memorial effects of interruptions were examined by training subjects to retrieve a set of items from specific locations. During training, one group retrieved the items in a fixed sequence and the other group retrieved the items in an arbitrary sequence. During the last training session, subjects were unknowingly interrupted. As shown previously, similarity between the main and interruption tasks was detrimental for the arbitrary group, but this effect did not hold for the fixed group.

Modeling Textual Coherence With Latent Semantic Indexing. PETER W. FOLTZ, University of Pittsburgh, WALTER KINTSCH, University of Colorado, \& THOMAS K. LANDAUER, Bell Communications Research-Creating propositional models to determine textural coherence can require much effort. We used an automatic statistical method, Latent Semantic Indexing (LSI), for evaluating textural coherence. LSI provides quantitative measures of the degree of semantic overlap between adjoining text sections. Comparisons of LSI analyses with hand-crafted propositionalization indicates that the coherence predictions are similar. We describe the approach of using LSI for measuring coherence and applying it to text structuring and modeling readers' comprehension.

(318)

When Discredited Information Affects New Inferences. HOLLYN M. JOHNSON, COLLEEN M. SEIFERT, \& JULIE K. BUSH, University of Michigan (presented by Colleen $M$. Seifert)-Information previously integrated into memory may influence new inferences and judgments, even when more recent information discredits it. Several experiments examine how the causal relationship of the discredited information to the surrounding text affects the success of correction. The results show that causal explanation, rather than any heightened avail- ability from its mention, is responsible for the continued influence of the discredited information. A final study examines factors determining the viability of potential causes.

\section{(319)}

Accuracy of College Students' Predictions of Academic Test Performance. MARGARET D. ANDERSON \& PETER A. HORNBY SUNY at Plattsburgh (presented by Peter A. Hornby)-Subjects estimated their test performance immediately prior to taking a test (prediction) and immediately after taking the test (postdiction). Data from 104 subjects for 15 tests over a one semester period support laboratory based findings regarding higher accuracy for postdiction than prediction. However, contrary to such studies, a tendency to underestimate rather than overestimate test performance was found. Additionally, accuracy of both prediction and postdiction was unrelated to ability (average test performance) or to experience (number of previous tests taken)

(320)

Recall in a Different Context: The Role of Directed Attention to the Learning Environment. ANGEL FERNANDEZ, Universidad de Salamanca, \& MARIA A. ALONSO, Universidad de La LagunaBefore studying a word list, subjects either drew the study room (Directed Contextual Processing) or copied a print (Casual Contextual Processing). One week later, they were tested for free recall in a different room. Without specific retrieval instructions, subjects in the Directed Processing group showed better memory than those in the Casual Processing group, replicating a previous finding. Context reinstatement instructions at retrieval failed to affect recall, making spontaneous reinstatement of context an unlikely explanation.

\section{(321)}

Measuring Distinctive and Relational Processing: Item Gains and Losses in Hypermnesic Recall. DANIEL J. BURNS, Union College, TANYA K. BRUBAKER, \& DINA R. LINARDUCCI, Lafayette College-Recent research has led to the hypothesis that item gains (new items recalled on a later test that were not recalled on an earlier test) and item losses (items forgotten on a later test that were recalled earlier) are good measures of distinctive and relational processing, respectively. In each of four experiments, amount of distinctive or relational processing was manipulated and gains and losses were measured. The results supported the hypothesis.

\section{(322)}

Memory Can Improve Over Time Without Repeated Testing: Spontaneous Recovery Revisited. MARK A. WHEELER, Rotman Research Institute of Baycrest Centre-Two experiments confirm the existence of spontaneous recovery, or memory improvement over time without repeated testing. While this phenomenon had been previously studied within the verbal learning tradition, evidence for its existence had been disputed. In both experiments, retention of an initial list was reduced by retroactive interference. Over time, first-list retention showed an absolute recovery from the interference. The proposed explanation involves retrieval inhibition, and its subsequent dissipation, as the processes underlying recovery.

\section{(323)}

Inhibitory Consequences of Selecting One of Two Competing Lists for Recall. LAURA A. DA COSTA, ROBERT A. BJORK, \& THOMAS D. WICKENS, UCLA-Two experiments examined whether selecting one of two alternative lists for recall involves inhibiting or suppressing access to the other list. Evidence that initiating recall of one list of words impaired subsequent recall of the other list was obtained in both experiments: In fact, simply initiating the recall process provided as much output interference as completing that process. The results of experiment two suggest that such inhibition is list-wise, rather than item-specific.

Do People Understand the Relation Between Retrieval Difficulty and Subsequent Recall? BENNETT L. SCHWARTZ, Florida International University, \& ROBERT A. BJORK, UCLA-Ease or speed of recall is one index people use to assess "strength" of memory representations (e.g., Kelley \& Lindsay, 1993). Replicating Gardiner, Craik, and Bleasdale (1973), we found that long response times yielded better, not poorer, subsequent free recall of the answers to generalinformation questions. The data pattern changed with retention inter- 
val, however, and subjects were relatively accurate in predicting their own future recall, suggesting that people are sensitive to episodic distinctiveness as a basis for later recall.

(325)

A Modality Effect at Early List Positions in Probed Recall. DENNY C. LECOMPTE, Louisiana State University, \& ALLISON R. MARKS, Yale University-A temporal distinctiveness explanation of the end-oflist auditory advantage for immediate recall predicts that a beginningof-list visual advantage should appear when list items are followed by silent distracting activity. Marks \& Crowder (1992) found this pattern with free recall. The present experiments replicate and extend their finding by showing the same results using probed recall, thereby eliminating the possibility that output order alone can explain these results.

(326)

The Role of Explanations in Symptom-Fault Rule Acquisition. CHRISTOPHER R. HALE, University of Chicago-Expert troubleshooting performance often is based on elaborated associations between symptoms and faults. This research investigated properties of explanations important in facilitating associative elaboration. Within an associative learning paradigm, subjects learned to troubleshoot fictionalized mechanical devices with or without explanations. Explanations increased the rate of rule acquisition, but only when they allowed subjects access to elaborations acquired during system learning. Thus, symptom-fault rule acquisition is more sensitive to background knowledge than frequency theories predict.

Cue Dependency and the Test Effect: Retrieval Route or Trace Enhancement. ERIK T. BERGMAN \& EUGENE WINOGRAD, Emory University (presented by Eugene Winograd)-The act of recall enhances subsequent recall (the "test effect"). Repeated retrieval of the same words using the same or different retrieval cues was compared to performance on a single retrieval. At short intertest delays, the test effect was present regardless of retrieval cue. At longer delays the effect was more cue specific. Subject's strategy was also a factor. The test effect is best regarded as enhancement of the retrieval process rather than trace strengthening.

Delayed Versus Concurrent Motor Reproduction Effects in Observational Motor Skill Learning. DOUGLAS L. WEEKS, University of Montreal, ANDREA K. HALL, \& L. PAUL ANDERSON, Ball State University - The time at which learners motorically reproduced modeled actions was investigated for 26 handshapes of the manual alphabet. A group imitating handshapes concurrent with their demonstration was compared to a group delaying imitation until 3-letter sequences were displayed, and a group practicing under a combination of these conditions. Conditions requiring more effortful processing (Delayed/Combination conditions) were superior for serial recall of handshapes, identifying random 3-letter sequences, and spelling 3-letter words.

Collective Memory: How Does Group Remembering Affect Recollection? MARY SUSAN WELDON \& KRYSTAL BELLINGER, University of California, Santa Cruz-This research explored the nature of group remembering as compared to individual remembering. In Experiment 1, subjects studied pictures and words under either deep or shallow processing instructions, then recalled the items either individually or in groups. In Experiment 2, subjects listened to "The War of the Ghosts," then recalled the story either individually or in groups. Group remembering is governed by similar principles as individual remembering. However, true groups actually remember less than nominal groups (pooled individuals).

(330)

Evidence for Separate Retrieval Processes in Forward and Backward Serial Recall. SHU-CHEN LI \& STEPHAN LEWANDOWSKY, University of Oklahoma (presented by Stephan Lewandowsky)Comparison of the effects of various study manipulations on forward and backward serial recall showed that (i) verbal intra-list distractors impaired forward but not backward recall, (ii) intra-list mental rotation tasks disrupted forward and backward recall, and (iii) manipulations of the visual properties of stimuli affected backward but not forward recall. The data support a dual process account of serial recall, with serial associations underlying forward recall and visuo-spatial attributes dominating backward recall.

(331)

Misattributions of Fame Are Insensitive to Encoding Manipulations and Time Delays. JOHN RYBASH, LAUREN RUBENSTEIN, \& KELLI DELUCA, Hamilton College - Varying the amount of elaborative processing required at study and increasing the length of the studytest interval from 1 day to 4 weeks influenced subjects' ability to recognize nonfamous names, but not their tendency to misjudge previously presented nonfamous as famous. These results illustrate the dissociability of source memory from recognition memory and suggest that similar mechanisms regulate performance on measures of source memory (e.g., Jacoby's False Fame Task) and priming.

Retrieval Effects in Spaced Practice. KELLY BRAUN \& DAVID C. RUBIN, Duke University (presented by David C. Rubin)-To study the effects of retrieval on spaced practice, undergraduates performed either a letter-length or continuous-recognition task. These tasks were performed under either incidental or intentional learning conditions. Both intentional learning and continuous recognition encourage the retrieval of earlier items. Thus, if retrieval of earlier occurrences produces a spacing effect, spacing should be present in all but the incidental-letter-length task. Alternative explanations are considered.

Unconscious Sequence Learning Paradigms: Tests of Two Implicit Assumptions. JONATHAN REED \& PEDER JOHNSON, University of New Mexico (presented by Peder Johnson)-Two methodological issues related to implicit sequence learning were investigated. Experiment 1 examined the effect of a secondary task on indirect measures of learning. Contrary to the prevaviling view, the manipulation of attention influenced performance but failed to influence learning. Experiment 2 tested the assumption that subjects learn probabilistic sequence information embedded in completely deterministic structures. The results showed that subjects learned the less predictive frequency information despite the fact that it provided no unique information.

Hierarchical Organization and Schemata in Reporting the Day of the Week. VINCENT PROHASKA \& LISA J. FELLNER, Lehman College, CUNY-People reported, from memory, the day of the week of eight news events. They also indicated their confidence in their reports and their overall knowledge of each event. Evidence for hierarchical organization of the week into weekday and weekend periods was found. Certain events were never reported to have occurred in one or the other period. Error analyses also indicated the use of general schemata in constructing reports.

\section{(335)}

Mood State and Memory for Places: Disentangling Aware and Unaware Memory. PENNIE S. SEIBERT \& LINDA J. ANOOSHIAN, Boise State University-We used a process dissociation procedure to derive estimates for conscious recollection (aware memory) and sense of familiarity (unaware memory) in the identification of scenes from previously viewed routes of travel. The effects of induced moods (during initial viewing of routes) were reliable for conscious recollection, but not for familiarity. The results paralleled those we obtained earlier for divided attention; happy and sad mood states yielded lower estimates (relative to neutral mood) for conscious recollection.

\section{(336)}

"Weapon Focus Effect": Looking at the Role of Novelty. KAREN J. MITCHELL \& MARILYN LIVOSKY, Pennsylvania State University, Erie (presented by Marilyn Livosky)-Causative factors behind the "weapon focus" effect were investigated. College students were randomly assigned to view one of four videotaped scenes in which a male presented either: his empty hand, a gun (in either a threatening or nonthreatening manner), or celery (novel item). Subjects were tested for their recall of central and peripheral details. Results are discussed in terms of Easterbrook's cue utilization theory and findings from human perception studies of visual fixations.

Differential Hypermnesia Across Tests: A Relational/Individual Item Account. MARK A. MCDANIEL \& HOWARD L. WHITEMAN, 
Purdue University-Sometimes hypermnesia is greater between tests 1 and 2, whereas other times hypermnesia is greater between tests 2 and 3 . These patterns could be understood by assuming that relational processing produces net gains in recall that are more pronounced on early tests than later tests, but that individual-item processing produces greater net gains in recall on later tests than early tests. Two experiments are reported that support this analysis and that detail patterns of reminiscence and intertest forgetting that illuminate the reasons for the effects. (338)

Forced-Choice Judgments of Associative Recognition and Frequency. STEVEN E. CLARK \& ALDEN HORI, University of California, Riverside-Forced-choice associative recognition is better when targets and distractors do not overlap (NOLAP) than when they do overlap items (OLAP). This NOLAP advantage is inconsistent with globalmatching models which predict an OLAP advantage. Clark, Hori, and Callan (1993) have suggested that the NOLAP advantage is due to recalllike retrieval processes. In experiments designed to minimize the contribution of recall (i.e., long lists and frequency discriminations), the NOLAP advantage was eliminated.

Feeling of Knowing in Recall and Recognition. SERGE LAROCHELLE, University of Montreal, MARIE IZAUTE, University of Grenoble, JUDITH MORENCY, University of Montreal, \& GUY TIBERGHIEN, University of Grenoble-Feeling of knowing accuracy was tested against performance in recall, cued recall and recognition. For previously unrecalled items, FOK accuracy was null in a multiplechoice recognition task. When computed over all items, FOK accuracy became virtually perfect in a cued recall task. We argue that traditional multiple-choice recognition tasks provide an inaccurate view of FOK accuracy because the internal memory contents monitored may not allow to choose the externally defined criterion response.

(340)

Narrative Reminding With Far Analogies. CHARLES M. WHARTON, TRENT E. LANGE, MICHAEL C. ANDERSON, THOMAS D. WICKENS, \& ARI SCHINDLER, UCLA (presented by Thomas D. Wickens) - A story might remind a reader of another story with similar themes and similar events (a near analogy) or possibly one with similar themes and dissimilar events (a far analogy). Whether far analogical reminding is a naturally occurring aspect of memory retrieval is an important question for memory models. In three experiments, subjects studied stories and later received near and far analogs as retrieval cues. All experiments demonstrated reliable near and far analogical reminding. (341)

Imagery, Memory, and Transfer-Appropriate Processing. BEVERLY ROSKOS-EWOLDSEN, DAVID R. ROSKOS-EWOLDSEN, University of Alabama, JEFFERY J. FRANKS, Vanderbilt University, JACQUELINE M. BICHSEL, \& SANDRA WILLIS, University of Alabama-The influence of "ease of imagery" judgments on recognition memory was explored. Experiment 1 found that overlapping processing at acquisition and retrieval (i.e., transfer-appropriate processing-TAP) can account for the effect of imagery judgments on memory. Experiment 2 demonstrated that explicit imagery judgments during acquisition are not necessary to obtain TAP effects for high imagery words, indicating that subjects spontaneously judged words for their imageability. Implications for models of imagery and memory are discussed.

(342)

Memory for Inferences. CATHERINE O. FRITZ, ROBERT A. BJORK, \& ROCHEL GELMAN, UCLA (presented by Rochel Gelman)-Information in fables was either implied or explicity stated. Subjects' memory for the inferred or read material was tested in two incidental learning studies. Free recall (cued by the titles) and cued recall (specific questions) measures were used. Retention intervals varied from 15 minutes to 9 weeks. Some subjects were tested twice so that retrieval practice effects could be studied. Responses were analyzed in terms of correctness and style (stated or implied).

(343)

Visual and Auditory Imagery Attenuate Primacy Effects. MATTHEW J. SHARPS, JANA L. PRICE, \& V. MICHAEL BENCE,
California State University, Fresno-Recent research on free recall for verbal and imageric information led to the hypothesis that primacy effects might be attenuated by visual or auditory stimulus imagery. Unrelated items, either the photographs, sounds, or printed names of the same $\mathbf{4 0}$ objects, were presented sequentially in two experiments. Significant primacy effects were observed in the verbal (printed-name) conditions, but were eliminated in all other conditions, consistent with the hypothesis advanced and providing evidence on the stimulus dependency of serial position effects.

(344)

Implicit and Explicit Memory for Overlapping Pictures. ERNEST M. GARCIA \& WILLIAM MARKS, Memphis State University (presented by William Marks)-The present study confirmed that explicit recognition memory for unattended pictures of objects is poor. This pattern held under conditions of semantic and nonsemantic encodings of attended objects. Implicit memory for attended and unattended pictures was also assessed in a perceptual clarification task. Attended pictures were identified faster than unattended ones, which were identified faster than new pictures. These results show that attention does affect both implicit and explicit memory performance.

\section{(345)}

Faces Are Special: A Case of Severe Visual Object Agnosia With Spared Visual Facial Knowledge. PATRICIA A. McMULLEN, Dalhousie University, JOHN D. FISK, \& STEPHEN J. PHILLIPS, Dalhousie University and Camp Hill Medical Center-Visual agnosics may lose the ability to recognize faces ( prosopagnosia) and not objects. Rarely is object recognition lost with spared face recognition. Patient $\mathrm{H}$. $\mathrm{H}$. showed dramatic deficits in processing visually presented shapes and real objects, not found when these objects were palpated. Remarkably, color photographs of famous people were identified and face drawings, with correctly placed features, were sorted from those with scrambled features. These results support cognitive mechanisms that may be unique to faces.

\section{(346)}

Transfer Between Picture Naming and Translation: A Test of Asymmetries in Bilingual Memory. ALEXANDRA SHOLL, University of Massachusetts, JUDITH F. KROLL, Mount Holyoke College and University of Massachusetts, \& ARUNA SANKARANARAYANAN, Mount Holyoke College (presented by Judith F. Kroll)-A transfer paradigm was used to investigate the relations between picture naming and translation. In two experiments English-Spanish bilinguals named pictures and translated from one language to the other. Whereas translation from $\mathrm{L} 1$ to $\mathrm{L} 2$ produced reliable transfer with picture naming, translation from L2 to L1 produced only limited transfer with picture naming. The results support the claim that translation is conceptually mediated from L1 to L2 but lexically mediated from $\mathrm{L} 2$ to $\mathrm{L} 1$.

Activation of Multiple Codes for Simultaneously Presented Words: Modulation by Attention. CHRISTINE CHIARELLO, LISA MAXFIELD, Syracuse University, LORIE RICHARDS, University of Kansas Medical School, \& TODD KAHAN, SUNY at Albany-We investigated the extent to which attention modulates lexical code activations. Vertical and horizontal strings, crossing at the middle letter, were used. Subjects pronounced the word of one orientation, ignoring the other. Distractor type varied: no distractors, random letter strings, pronounceable nonwords, unrelated words, semantically related words, and identical words. Both interference and facilitation resulted, depending on target orientation and distractor type, as predicted by the pathway strength model of Cohen, et al., (1990).

\section{(348)}

Obscuring the Stimulus Obscures the View: More About Context and Degradation. PATRICK BROWN \& STEPHEN J. LUPKER, University of Western Ontario-Stimulus degradation and context influence word naming time interactively; the context effect is larger for degraded targets. Besner \& Smith (1992) claimed the interaction was due to spreading activation, not strategic expectancies. We manipulated context, degradation, and probability of relatedness, with a $200 \mathrm{~ms}$ SOA. Mild degradation produced effects of context and degradation but no interaction. 
Under severe degradation, the context by relatedness interaction appeared only in the high probability condition, supporting a strategic expectancies account.

(349)

The Locus of Orthographic Inhibition Priming. MARIE-JOSÈPHE TAINTURIER, Johns Hopkins University-Priming written words with orthographic neighbors can produce longer lexical decision latencies. The locus of this effect was examined with targets preceded by primes that shared an average of: (a) $76 \%$ letters and $61 \%$ phonemes, (b) $34 \%$ letters and $61 \%$ phonemes, or (c) $4 \%$ letters and $1 \%$ phonemes. The results suggest that the inhibition effect has a phonological component and, more generally, that the phonological forms of words are automatically activated during written word processing.

(350)

Alphabetic Reading Competence and Language Representation in Bilingual Chinese Subjects. BEATRICE DE GELDER, Tilburg University, The Netherlands, \& PAUL BERTELSON, Universite libre de Bruxelles, Belgium (sponsored by Paul Bertelson)-Explicit speech segmentation (initial consonant/syllabic vowel deletion, rhyme judgment) was examined in two groups of Chinese residents in the Netherlands. All could read Chinese characters, but those in the alphabetic group had, unlike those in the nonalphabetic group, also learned to read some Dutch. The results support the hypothesis that competence in a nonphonographic orthography does not promote the expicit analytical representation of the segmental structure of utterances

(351)

Semantic Priming of Conceptual Representations: Manipulating Depth of Processing of the Prime. JENNIFER SHELTON, University of Maryland, \& RANDI MARTIN, Rice University-Automatic priming within a conceptual knowledge network was investigated by having subjects make semantic judgments to words presented in sequential order or by having subjects make a semantic judgment to the prime and name the color of the subsequent target. Facilitation was found only when the word pairs were related and shared the same decision. The effect appears due to the similarity in information used in the decision not spreading activation in a knowledge network.

$$
\text { (352) }
$$

Activation and Inhibition of Phonological Information in Word Naming. GREG B. SIMPSON \& MICHAEL J. CORTESE, University of Kansas -In a word-naming task, targets were primed by words with the first letter deleted (e.g., *ard). When the prime was phonologically ambiguous (e.g. *ome), naming was facilitated for words with the regular pronunciation of the prime (home), but inhibited for words with irregular pronunciation (come), relative to a condition in which prime and target were phonologically unrelated. The results suggest rapid selective activation of phonological information in the absence of complete lexical input.

\section{(353)}

About Re-Explorations of Words During Text Reading. FRANÇOISE VITU, CNRS-Université René Descartes, Paris, GEORGE W. MCCONKIE \& DAVID ZOLA, Beckman Institute (sponsored by Jonathan Grainger)-During reading, the eyes often return to previously fixated words. In our study, we analyzed these cases on fifth grade reading data. We found that re-explorations of words mostly occur when in the first pass words had been explored with a single fixation located at their beginning. Further analyses suggest that these particular cases might result from visuomotor constraints rather than from processing difficulties. Implications for models of eye movements in reading are discussed.

\section{(354)}

The Syllabic Structure of Orthographic Representations. BRENDA C. RAPP, Johns Hopkins University, DAVID ALWAY, National Institutes of Health, \& ALFONSO CARAMAZZA, Johns Hopkins University-Subjects see a picture followed by a letter and are instructed to press a key if the letter occurs in the name of the pictured item. Onesyllable words reveal an increasing RT function across letter positions. Results with two-syllable words indicate a drop at the onset of the second syllable regardless of the position of the syllable boundary or the consonant-vowel status of boundary letters.

\section{(355)}

Rhythmic Effects in Auditory and Visual Sentence Processing. SHARI R. SPEER \& KATHRYN M. DOBROTH, Northeastern University-Three experiments demonstrated comprehenders' sensitivity to rhythmic structure during spoken and written sentence understanding. End-of-sentence comprehension times were measured for auditory sentences containing temporary syntactic ambiguities and natural or composite prosodic patterns. In two follow-up experiments, visual comprehension times were measured for these sentences presented wordby-word, with temporal breaks analogous to those in the spoken sentences. RTs were fastest when rhythmic constituents were consistent with syntactic constituents and slowest when consistent with an inappropriate analysis.

Levels of Planning in Sentence Production. JOHN S. HUITEMA \& CHARLES E. CLIFTON, JR., University of Massachusetts (presented by Charles E. Clifton, Jr.)-A series of experiments investigated effects of referential, syntactic, and phonological complexity on initiation times and pause locations in one-sentence descriptions of simple events presented on a computer screen. The results shed light on the scope of planning at different levels of representation before and during speech, as well as on interactions between different levels.

(357)

Effects of Context on Syntactic Ambiguity Resolution. A. RENÉ SCHMAUDER \& ROBIN K. MORRIS, University of South CarolinaSubjects read two-sentence passages with a word ambiguous as to syntactic category membership included in the second sentence. According to Frazier and Rayner (1987), the parser adopts a delay strategy in the case of category ambiguities, awaiting disambiguating information. MacDonald (1993) suggested that probabilistic information impacts ambiguity resolution and rejected the delay account. The present experiments test different predictions of these two positions. Implications for a theory of sentence comprehension are discussed.

(358)

Syntactic and Thematic Processing During Sentence Comprehension. BRIAN MCELREE \& TERESA GRIFFITH, University of California, Irvine-Time-courses for syntactic and thematic role processing during sentence comprehension were measured with reaction time and speed-accuracy tradeoff variants of a grammaticality judgment task. We found that detections of thematic role violations were delayed by as much as $150 \mathrm{msec}$ relative to detections of syntactic (constituent and subcategorization) violations. These data indicate that the construction of a syntactic representation temporally leads the construction of a more semantically embellished thematic representation.

\section{(359)}

Syntactic Processing as an Automatic Process. STEPHANIE GRAY WILSON, Seton Hall University - It is proposed that syntactic processing is an automatic process in the sense intended by Logan (1988). Using artificial and natural language stimuli, evidence is found to suggest that syntactic processing is both qualitatively and quantitatively similar to automatic processes in general. Syntactic processing may not be a function of the structure of the language processor as many theories suggest. Rather, it may be an automatic process that has developed through experience with a given language.

(360)

Text Coherence, Background Knowledge, and Levels of Understanding in Learning From Text. DANIELLE S. McNAMARA, University of Colorado-Comprehension of one of four versions of a text, orthogonally varying local and global coherence, was examined with three different measures. Low-knowledge readers benefited from coherent text, whereas high-knowledge readers benefited from minimally coherent text. We argue that knowledgeable readers infer the unstated relationships in the low-coherence text. This study also provides evidence that rewards from this compensatory processing are primarily at the level of the situation model, rather than at superficial levels of understanding.

(361)

Recognition of Explicit Targets Involved in Predictive Inferences. REBECCA FINCHER-KIEFER, Gettysburg College-Explicit targets 
involved in predictive inferences were examined within a word recognition paradigm. In Experiment 1, relative inhibition was found for these targets, and Experiment 2 demonstrated that this effect was specific to inference-related explicit targets. In Experiment 3, instructions to respond positively when a target had been read or thought about eliminated the inhibition. These results suggest that predictive inferences are encoded during reading and support a source monitoring explanation for the relative inhibition.

\section{(362)}

Dimensions of Situation Model Construction During Narrative Comprehension. ROLF A. ZWAAN, JOSEPH P. MAGLIANO, ARTHUR C. GRAESSER, \& CHRISTINE MACDONALD, Memphis State University - We investigated the extent to which temporal, spatial, causal, and motivational information are involved in the construction of situation models during narrative comprehension. We analyzed two literary stories. For each story sentence, we determined its degree of temporal, spatial, causal, and motivational relatedness with the prior passage context. We performed multiple regression analyses to determine the extent to which temporality, spatiality, causality, and motivation predicted sentence reading times.

(363)

Sentence Priming Effects on Lexical Access and Post-Access Processes. STEPHEN T. PAUL, Washington University, \& GEORGE KELLAS, University of Kansas-Using sentences biasing homographs toward dominant and subordinate interpretations, context effects were examined before and after target presentation (naming). Results replicated findings demonstrating initial context-sensitive meaning activation. Addtionally, few post-access influences were observed for dominant contexts. Subordinate contexts, however, provided evidence of post-access processing. Comprehension appears to involve post-access strategies for fine-tuning a text interpretation and integrating it with new information. Dependence on these strategies varies with meaning dominance.

\section{(364)}

Situation-Based Inferences and Text Comprehension. DIETER HAENGGI, WALTER KINTSCH, University of Colorado, \& MOR TON ANN GERNSBACHER, University of Wisconsin-Information that was consistent with a story character's movements through a building was inferred more rapidly than inconsistent information. A pairedassociate explanation of this spatial separation effect was ruled out, and consistent information was facilitated even when readers memorized a spatially indeterminate building description. The Construction-Integration model of text comprehension simulated the spatial separation effect in terms of variations in knowledge integration, and inference latencies correlated with spatial imagery and reading comprehension ability.

\section{(365)}

The Role of Perspective in the Accessibility of Goals During Reading. JASON E. ALBRECHT, University of Massachusetts, EDWARD J. O'BRIEN, University of New Hampshire, \& JEROME L. MYERS, University of Massachusetts-Most causal models assume that readers adopt the goals and perspective of the protagonist. In two experiments, we show that readers draw goal-based inferences independent of the goals of the protagonist unless explicitly instructed to read from the perspective of the protagonist. The results are discussed in terms of readerand character-based perspectives and text characteristics that cue perspective taking and perspective shifting.

$$
\text { (366) }
$$

The Use and Interpretation of Backchannel Responses in Conversation. DEANNA WILKES-GIBBS \& ELENA GERTSENZON, Wesleyan University-It has been claimed that gender differences in the use and interpretation of backchannel responses cause big problems in mixed-sex conversation. But in two experiments on interpretation, we found no evidence of the predicted gender effects. Similarly, the "fact" that women are more responsive than men failed to materialize in two additional studies of production. All else being equal, the pragmatics of the backchannel may not play much of a role in male-female miscommunication. (367)

Language Selection in Bilingual Naming and Translation. ROBERT DUFOUR, University of Massachusetts, JUDITH F. KROLL, Mount
Holyoke College and University of Massachusetts, \& KATHERINE MacLENNAN, Mount Holyoke College-We investigated the effects of language uncertainty on bilingual naming and translation performance. English-French bilinguals named and translated words under conditions in which the languages were presented in separate blocks or mixed, and in contexts in which filler words were cognates or not. Language uncertainty produced a significant cost for $\mathrm{L} 1$ but not for $\mathrm{L} 2$ naming and differentially influenced the two directions of translation. The implications for models of lexical representation in bilingual memory will be discussed.

(368)

Invariants Versus Nonaccidental Properties as Information Used in Affine Pattern Matching. JOHAN WAGEMANS, ANDREAS DE TROY, LUC VAN GOOL, University of Leuven, JON R. WOOD, \& DAVID H. FOSTER, Keele University, $U K-$ A series of experiments was performed in which subjects indicated whether two four-dot patterns were the same, although possibly viewed from different directions, or different, paired at random. Analyses of responses times and error rates suggest that the subjects' performance in this affine matching task is based on non-accidental properties such as convexity, parallelism, collinearity, and proximity, rather than on real affine invariants such as the ratio of triangular areas.

(369)

Figural Symmetry Constrains Perceived Vantage, Orientation of Interpreted Objects. DIANE J. SCHIANO, Interval Research Corporation, \& MICHAEL K. McBEATH, Kent State University-Subjects viewed bilaterally symmetric and asymmetric polygons, describing "what the figure looks like" and its orientation. Most were seen as silhouettes of 3D bilaterally symmetric objects, with symmetry affecting perceived vantage. Symmetric figures were systematically interpreted as front or top views; asymmetric figures as profile or oblique views. Demonstrated repeatedly with horizontal symmetry, this latest study confirms these general findings using vertical symmetry, which promoted frontal views of an object "turned sideways."

Judging Colinearity Within and Across Fixations. DALE S. KLOPFER, Bowling Green State University-In a free-viewing situation, subjects judged whether three points were colinear, i.e., whether they fell along a single implied line. When all three points were foveal, accuracy was high and variability low regardless of pattern type. When seeing all three points required making eye movements, accuracy was poorer and variability higher than in the foveal condition, and pattern type still affected neither measure. Results obtained from restricted viewing conditions are also discussed.

\section{(371)}

Effects of Cortical Magnification on Visual Search Tasks. MARISA CARRASCO \& KAREN FRIEDER, Wesleyan University-Relative contributions of spatial resolution and covert attention were studied in a feature search of an orientation asymmetry, in which eye movements were precluded. Both RTs and errors increased as eccentricity increased, more so for tilted than vertical targets. This position effect disappeared when peripheral stimuli were scaled to equate visual acuity (Cortical Magnification Factor). These results stress the role of physiological constraints of the visual system on detection and question the extent of attentional involvement.

Infants' Expectations of Perceptual Correspondences Between Auditory Pitch and Visual Location. RICHARD F. BRAATEN, University of Denver-Six-month-old infants watched a sequence of pictures synchronized with sounds. The pictures randomly appeared either high or low in location. When the sounds were presented in an alternating sequence of high and low pitch, the infants formed expectations for the upcoming pitch. An analysis of visual reaction times showed that the infants also expected a synesthetic match between pitch and location (high pitch with high location, low pitch with low location).

Spatial Organization in the Mental Imagery of Fundamental Solids. JOHN R. PANI \& HONG-GUANG ZHOU, Emory University-The Platonic Solids (the regular polyhedra) are some of the simplest, most 
regular, and commonest forms in nature. Each of them has different geometric structures relative to different axes of the object. In two experiments, it was found that the three simplest Platonics are easy to visualize when they are generalized cones about the vertical but very difficult to visualize when they are antiprismatic. The results are explained in terms of types of geometric simplicity

(374)

Visual Detection of Second-Order Differential Structure in Moving Patterns. JOSEPH S. LAPPIN, Vanderbilt University, ULF B. AHLSTRÖM, Uppsala University, \& WARREN D. CRAFT, Vanderbilt University - What are the spatial primitives for perceiving 3-D structure from motion? Recent theoretical analyses indicate that deformations of 2 nd-order differential structure are necessary and sufficient to specify the qualitative local structure of a smooth surface. We have tested the visibility of two distinct forms of such structural relations when lowerorder relations were masked by random motions. Evidently, vision is sensitive to deformations of 2 nd-order spatial structure.

What is Represented in Representational Momentum? MARGARET P. MUNGER \& LYNN A. COOPER, Columbia University (presented by Lynn A. Cooper)-Representational momentum is a memory distortion for the position of a moving object in the direction of its motion. The physical analogies proposed to underlie this memory distortion predict that properties of objects and their transformations should affect the size of the memory distortion. A series of experiments varied these properties in physically meaningful ways, in order to assess the proposed physical analogies. The experiments generally fail to support predictions made by the physical analogies.

\section{(376)}

Probing Early Visual Representations of Patterns. CHRISTOPHER WOODARD \& THOMAS SANOCKI, University of South Florida (presented by Thomas Sanocki)-We presented primes and targets briefly enough to be integrated, followed by a mask. We measured identification accuracy. Although the primes contained no distinctive features, they (often) facilitated identification, relative to control conditions. We attribute this to early representations established by the primes. By varying the primes' contents, we assessed the importance of global shape, emergent features, low spatial frequencies, target-prime alignment, and depth in the early representations of structurally different patterns.

(377)

The Role of Location Uncertainty in the Face-Detection Effect. ANNETTE R. TASSONE, ALAN L. STEWART, Stevens Institute of Technology, \& DEAN G. PURCELL, Oakland University (presented by Alan L. Stewart)-An observer who shows the Face-Detection Effect (FDE) detects an upright face faster than an inverted face. Simultaneous cueing of two possible locations of stimulus presentation improves detection by $30 \mathrm{msec}$ and eliminates the FDE. This suggests that the FDE is based, in part, on more efficient spatial localization of upright as compared to inverted faces. Cueing minimizes location ambiguity thus facilitating stimulus detection prior to activation of mechanisms responsible for the FDE.

(378)

Is the Object Recognition System Really Colorblind? JAMES TANAKA, Oberlin College, \& LYNN BUNOSKY, Wooster CollegeWhile most object recognition theories stress the importance of shape information, color information might also be a factor in recognition. In categorization and visual search experiments, subjects identified objects that were high (e.g., banana) and low (e.g., lamp) in color diagnosticity. Whereas high diagnostic objects were more impaired by color distortion, low diagnostic objects were more impaired by shape distortion. These findings indicate that both color and shape are used in object recognition.

\section{(379)}

Auditory Memory and Voice Perception. JOHN W. MULLENNIX \& JEROME N. HOWE, Wayne State University-The time course of memory for voice was examined using a same-different voice matching task. A "same voice" advantage was obtained for short ISI's. How- ever, this advantage was eliminated by a noise mask. In another study, auditory words were primed forwards and backwards in time by voice. The voice primes had equivocal effects. Results suggest that selective attention to voice plays an important role in storage of voice information in auditory short-term memory.

(380)

Lexical Competition: The Case of Embedded Words. MARK A. PITT, Ohio State University-Some theories of auditory word recognition conceive of the recognition process as a competition between phonetically similar lexical entries. Cross-modal priming (auditory $\rightarrow$ visual) experiments investigated the conditions in which an entry becomes a competitor of the intended word by measuring whether a prime embedded in a longer word ("win" or "twin") activates its semantic associate ("lose"). Discussion will focus on the constraints these data place on theories of lexical processing.

The Effects of Prosodic Cues on the Perception of Vowel Sequences. MAGDALENE H. CHALIKIA, ROSALEE MEYER, \& ROBIN LINDEMANN, Moorhead State University-Listeners exposed to a repeated sequence of steady-state vowels (of same duration and pitch) report hearing verbal forms. These forms are fairly robust, and can be recognized when the stimuli are presented at a later time. Originally, the duration and pitch of the vowels had been kept constant. Two ex periments investigated the effects of variations in the duration or pitch of individual vowels, on the perceptual forms heard. The results sug gest that listeners can match the altered stimuli with the verbal forms heard with the original vowel sequences.

(382)

The Role of 2-D Information in 3-D Attention Effects. LYNN ZIMBA, CARIDAD BRITO, TERESA NORMAN, \& DION BROWN, University of lowa-Previous research has suggested that apparent 2-D (X-coordinate) offsets might be instrumental in generating endogenous visuospatial attention effects in depth. Results of the present study provide support for this hypothesis by demonstrating that attention effect magnitudes are equivalent under the following three conditions, as long as apparent 2-D offsets exist: 1) both binocular and monocular depth cues present, 2) only binocular depth cues present, and 3) no cues to depth present.

Visual Attention to Locations in Depth From Motion. MARC L. CARTER, University of South Florida-The experiments reported here examine attentional allocation to locations in depth from motion. Subjects performed a standard 2-D spatial-attention task (see e.g., LaBerge, 1983) superimposed on simulated slanted planes undergoing rotation (orthographic projection) or translation (perspective projection). Response time data compared to judgments of slant for the motion displays suggest that the representation of space in which attention is allocated reflects the perceived depth of the target locations in the display.

Inhibition of Return Within a Depth-Rotated Object is Orientation Invariant. BRADLEY S. GIBSON \& HOWARD EGETH, Johns Hopkins University - Inhibition of return (IOR) was used to assess the nature of 3-D object representations underlying a simple detection task. Observers viewed a depicted 3-D brick that rotated in depth between the presentation of cue and target. Based on IOR, we show that (a) the specification of location on a surface of the brick remained invariant across depth-rotation; and (b) this location was more specific than the whole surface.

\section{(385)}

Attentional Set Mediates Distracting Effects of Irrelevant Singletons During Visual Search. WILLIAM BACON \& HOWARD EGETH, Johns Hopkins University (presented by Howard Egeth)Distracting effects of irrelevant-dimension (e.g., color) singletons during visual search for known target shapes may suggest that salience alone drives attention. We replicate such findings, but argue that distraction effects may depend on subjects adopting an attentional set for featural singletons. In subsequent experiments, we discouraged the singleton set 
by adding additional target shapes or unique distractor shapes. Irrelevant singletons no longer interfered, suggesting that top-down featurebased information may also guide attention.

(386)

Evidence for Processing Letters at Uncued Locations. PAULA GOOLKASIAN, University of North Carolina at Charlotte-The sequential cuing procedure introduced by Eriksen, Webb, \& Fournier (1990) was used to study the processing of stimuli presented at uncued locations of a multielement display. These studies differed from the previous one by varying target/distractor similarity. A second and third experiment investigated the effect of task difficulty and the presence of the first cue. The results are consistent with Duncan and Humphreys (1989) revised late selection theory.

Eye Movements in Feature and Conjunction Search Tasks. DIANE E. WILLIAMS, MORRIS MOSCOVITCH, University of Toronto, MARLENE BEHRMANN, Rotman Research Institute, \& EYAL REINGOLD, University of Toronto (presented by Morris Moscovitch)Subjects performed feature and conjunction search tasks while eye movements were monitored. Number of eye movements (EM) increased with display size on positive and negative trials in the conjunction search condition, but increased only slightly on negative trials in the feature search condition. Response-time data indicate that subjects processed conjunction search displays serially and feature search displays in parallel. This correspondence between EM and response times suggests that eye movements and attention are linked.

\section{(388)}

The Effects of Spatial Cues on Visual Attention, Response Selection, and Spatial Compatibility. BERNHARD HOMMEL, Max-Planck Institute for Psychological Research, Munich-Location cues preceding a stimulus have been assumed a) to facilitate stimulus processing, b) to prime corresponding responses, and c) to influence spatial stimulus coding. In a series of Simon tasks, informative/uninformative central/peripheral cues preceded the stimulus by 100 to $1000 \mathrm{~ms}$. The results confirm effects of cues on the speed of stimulus processing, while effects on response selection and spatial coding were rare. This bears consequences for attentional accounts of the Simon effect.

\section{(389)}

Processing of Global and Local Information After Practice. CYNTHIA L. DULANEY \& WILLIAM MARKS, Memphis State University-The present research tested Navon's (1991) stationary advantage hypothesis of global precedence by examining the processing of globa and local information after extensive practice identifying local elements of stimuli $(10,080$ trials). Our results indicate that with extensive practice in naming local elements, local information can be processed as rapidly as global information. However, the processing of global information is unaffected by local practice. This research supports the hypothesis that global processing is stationary.

\section{(390)}

Memory Activation and Selective Attention. CATHERINE HANSON, Temple University - The effect of priming (i.e., the activation of target related knowledge) on visual selective attention was examined by manipulating both memory activation and the relation between targets and activated knowledge structures. Subjects were asked to detect exemplars from either one or three categories and presented targets were either subordinate or superordinate level category members. Performance reflected a tradeoff between the type of target presented and the number of primed target categories.

\section{(391)}

Learning and Transfer of Novel Verbal Information in Amnesia. SUPARNA RAJARAM, SUNY at Stony Brook, \& H. BRANCH COSLETT, Temple University-Acquisition of new information was tested in two amnesics with focal brain pathology (bilateral hippocampus and basal forebrain). Using the priming paradigm, the production of the deleted or fragmented last words of 3-word sentences was assessed. Transfer of newly acquired information was tested by substituting the last words with related or unrelated words. Striking differences in learning and transfer were obtained as a function of both the retrieval conditions and the underlying brain pathology.

\section{(392)}

Bypassing the Single-Channel Bottleneck in Dual-Task Performance. JAMES C. JOHNSTON, NASA-Ames Research Center, \& DANIEL F. DELGADO, Sterling Software-Virtually any two tasks produce strong interference in the refractory-period paradigm, even when stimulus and response modalities differ. New experiments found almost no interference when the second task was zero-order step tracking (matching joystick position to stimulus position). When the second task required only a binary left-right choice response, much more interference was obtained. Zero-order tracking appears to bypass the single-channel bottleneck hypothesized to explain dual-task interference.

(393)

Gender Differences in EEG During a Vigilance Task Requiring Phonetic Discrimination. SHERRI GOLD, JAMES ARRUDA, LAURA COSTA, \& DOMINIC VALENTINO, University of Rhode Island (presented by Dominic Valentino)-In 2 experiments $(\mathrm{n}=72,30)$ we studied EEG of right-handed men and women while they performed a phonetic continuous-performance test. They responded to CPT targets with either left or right hand. Differences occurred in fast-frequency EEG (beta 2) at temporal regions. Males showed greater cerebral asymmetry, especially during left-hand responding. Females showed greater power, especially in the right hemisphere. Conclusions regard the relationship between beta, cognitive processing, and the cerebral organization of language.

\section{(394)}

Pigeons' Use of Landmarks in Digitized Images of an Outdoor Scene. MARCIA L. SPETCH, University of Alberta, \& DONALD M. WILKIE, University of British Columbia-Pigeons received food for pecking a hidden target location in digitized images of an outdoor scene, presented on a monitor/touchscreen system. Three landmarks (tree, flowers, log) were located near the target on a field of grass. After training, the landmarks were removed or shifted by imaging software. Landmark control was selective, and appeared to depend on proximity to the target. This research demonstrates the usefulness of video-image technology for studies of animal cognition.

(395)

Scalar Expectancy Theory Models Timing Data From Single Trials. KEN CHENG \& PAUL MICELI, University of Toronto-Various models based on Scalar Expectancy Theory simulated well quantitatively four data sets based on single trials from the peak procedure. Models simulated means and SDs across trials of the start, end, middle, and duration of the run (phase of high rate of responding), and the correlations between these statistics. Each model sampled from a Gaussian distribution of expected reward times and one or two Gaussian distributions of thresholds for starting and ending the run.

(396)

Characteristics of Chunking Nonadjacent Items in Rat SerialPattern Learning. DON M. BENSON, STEPHEN B. FOUNTAIN, \& JAMES D. ROWAN, Kent State University (presented by Stephen B. Fountain)-Rats were required to learn two interleaved serial patterns that were structured or unstructured. Rats acquired the interleaved patterns at different rates. Acquisition rate was dependent on pattern complexity, the nature of rules required to describe the interleaved patterns, and the nature of departures from perfect organization. The results support the idea that rats are sensitive to the organization of nonadjacent pattern elements and that they detect and sort structural relationships in patterns presented concurrently.

Vocal Color Naming in Budgerigars. KAZUCHIKA MANABE \& JOHN E. R. STADDON, Duke University (sponsored by John E. R. Staddon)-Three budgerigars were trained with food reinforcement to make calls of different peak frequencies in response to different visual stimuli. High calls were reinforced in the presence of Red (or Green), low calls in the presence of Green (or Red). All three birds performed at better than $90 \%$ correct by the end of training. This study is the first to show color naming in this intelligent avian species.

(398)

Directing the Pigeons' Spatial Attention Across Contours. MARK D. WARNER \& MARK E. RILLING, Michigan State University (pre- 
sented by Mark E. Rilling)-Pigeons were trained in a successive discrimination procedure to discriminate simple line drawings differing by a single feature added to $S+$. Probes were contour deleted versions of $\mathrm{S}+$. The results suggest that pigeons attend to contour other than the differentiating feature and they attend most strongly to the differentiating feature. Subsequent experiments demonstrate that by varying the location of the differentiating feature the pigeons' spatial attention can be directed to specific contours.

\section{(399)}

Reference Memory for Feeding Sites in Pigeons. JEROME FRIEMAN \& DAWN R. REMMERS-ROEBER, Kansas State University-Spatial memory was examined in an open-field setting by training pigeons to eat from 3 of 12 feeding sites. Subjects found food at a given site for five trials before being trained elsewhere. When tested 15 days and 41 days after the last training session, all subjects visited the two sites trained last. After 15 days only half the subjects visited the first site. After 41 days most subjects no longer visited the first site.

(400)

Directed Forgetting in Pigeons: A Substitution Procedure Which Precludes Response-Pattern Incompatibility Effects. DOUGLAS S. GRANT \& ALEX SOLDAT, University of Alberta-Choice between two stimuli was required on remember-cued $(R)$ and forget-cued $(F)$ training trials. Positive and negative stimuli depended on the sample on $\mathrm{R}$ trials (conditional matching), but was independent of the sample on $\mathrm{F}$ trials (simple discrimination). During subsequent testing, presentation of an F cue reduced matching accuracy. These results (a) cannot be explained in terms of response pattern incompatibility and (b) suggest that the $F$ cue reduced code maintenance.

(401)

A Two-Factor Theory for Spying. LeROY A. STONE, West Virginia University-Psychological research regarding national defense espionage and spying behavior is almost nonexistent in the psychological literature. The present project was initiated to explore whether a quantitatively-based theoretical model could be built on the limited research results just recently obtained and reported. Based upon canonical and multiple correlation, a two-factory theory for spying motivations was constructed and tested. Possible applied utilizations for predicted behaviors, based on the theory, were suggested.

(402)

Feature Positive and Negative Discriminations of Turning Response in Rats. JOSÉ LINO OLIVEIRA BUENO \& MARCIA CASERTA GON, Universidad de Sao Paulo (sponsored by José Aparecido da Silva)-Rats were water reinforced after turning right in a serial positive discrimination $(\mathrm{A} \rightarrow \mathrm{B}+; \mathrm{B}-)$ and after turning left in a serial feature negative discrimination $(C \rightarrow D-; D+)$ procedure. Transfer tests showed that rats did not transfer excitatory and inhibitory properties to a novel stimulus. Rats transferred excitatory but not inhibitory properties to a known stimulus, previously used in the training sessions (B and $\mathrm{D})$. The instrumental conditional discrimination is discussed in terms of an "occasion-setting" strategy involving a hierarchical relation among stimuli.

(403)

Session Duration and Context Extinction Effects in Conditioned Taste Aversion. TODD R. SCHACHTMAN, JEFFREY L. CALTON, \& JULIE A. HART, University of Missouri-Rats were given aversion conditioning to flavors in distinctive contexts. Conditioned aversions were strong when session duration was brief (e.g., $5 \mathrm{~min}$ ) compared to long session durations (e.g., $60 \mathrm{~min}$ ). Attenuation of the aversion to the flavor occurred when the context was extinguished, revealing that context-US associations supported the strong CR to the flavor with short session durations.

\section{(404)}

Different Rules Govern Patch Leaving in Progressively-Depleting and Suddenly-Depleting Patches. SUZANNE H. MITCHELL, University of Chicago, \& JASPER BRENER, SUNY at Stony Brook-Rats earned food by working on a "patch" beam and travelled to new patches by working on a "travel" beam. Unpredictably, reinforcers were with- held to simulate sudden patch depletion. Unlike performance in progressively-depleting patches, the work performed prior to patch leaving was directly related to the work costs of food in the patch but uninfluenced either by the work costs of traveling to a new patch or the food density in the environment.

\section{(405)}

Generality of Retention Interval Differences: Evidence From Rotationally-Induced Aversions. W. ROBERT BATSELL, JR. \& MICHAEL R. BEST, Southern Methodist University-In taste-aversion learning, retention interval differences occur when aversions are weaker 1 day after conditioning than at later tests. One interpretation of the increased drinking at the 1-day interval is based on physiological aftereffects of the drug US. To test this hypothesis, retention interval experiments were conducted using rotational stimulation as the US. Taste aversions were weaker 1 day following conditioning with rotational stimulation, showing that the increased drinking at the 1-day interval is not due to drug aftereffects.

\section{(406)}

Local Enhancement in Pigeons: Social and Reinforcement Influences. DAVID E. HOGAN, LYNN A. BERBERICH, \& CAROL MOKAS, Northern Kentucky University-When follower pigeons were nondifferentially reinforced for pecking a key that was either adjacent or nonadjacent to a key pecked by a leader bird, the followers exhibited a marked preference for the adjacent key (a local enhancement effect). The plasticity of this local preference was examined when the delay of reinforcement for adjacent choices was either 4,8 , or 16 times longer than the delay for nonadjacent choices $(.75 \mathrm{sec}$.).

(407)

Separation of Primary and Conditioned Reinforcement Effects on Choice. ROGER DUNN, San Diego State University, BERTRAM O. PLOOG, Hunter College, CUNY, \& RAY A. PRESTON, University of Rochester Medical Center-Delay reduction theory provides a successful model for the combined effects of rate of primary reinforcement and strength of conditioned reinforcement in concurrent chains. The effect of conditioned reinforcement rate has not been established. Conditioned and primary reinforcement rate effects were assessed independently by holding one constant while the other was varied across conditions. Choice was less sensitive to either rate than to both rates varied together. Several versions of the model will be compared.

\section{(408)}

Reward Signals Improve Discrimination Learning. ROGER M. TARPY, BRIAN M. CUSATO, JAMES C. DENNISTON, Bucknell University, \& JEAN E. ROBERTS, Penn College of Technology (presented by Jean E. Roberts)-Rats were reinforced for choosing right or left (or 1 vs. 2 lights) in a Y-maze. For some subjects, reward was accompanied by a tone. Although speed of response was generally not affected, accuracy of discrimination was improved by the reward signal. These results fail to support Reed's marking hypothesis of the signaled reward effect but are consistent with Tarpy's efficiency theory.

\section{(409)}

Defeat Inhibits Sexual Behavior in Male Rats Tested With Colony Odors. JON L. WILLIAMS \& KATHERINE SAPADIN, Kenyon College-Male rats were either defeated by an aggressive (alpha) colony resident or given no defeat experience. Four hours later, they were tested for sexual behavior with hormone-treated ovariectomized females in a tub, which either contained the bedding of alpha rats or clean bedding. Only the defeated rats, tested in the alpha-odor environment, showed significant decrements in sexual responses. These data are discussed in terms of the author's stress-coping-fear-defense (SCFD) theory.

(410)

Taste Reactivity in Rats Selectively Bred for High Versus Low Saccharin Consumption. STEPHEN W. KIEFER, NANCY E. BADIA-ELDER, STEPHANIE L. ROCK, RICHARD L. ELDER, DAWN R. REMMERS-ROEBER, Kansas State University, \& NANCY K. DESS, Occidental College-Rats bred for high vs. low saccharin consumption ingested different amounts of $0.1 \%$ saccharin but did not 
differ in saccharin taste reactivity before, during, or after consumption tests. Lines also did not differ in reactivity to $0.01 \%-0.3 \%$ saccharin, nor in reactivity to or intake of saccharin after pairing with $\mathrm{LiCl}$ illness. The line difference in saccharin intake apparently does not derive from brainstem-mediated hedonic evaluation of saccharin but rather from forebrain-mediated processes.

(411)

Perception of Altered Songs by Zebra Finches. AMY NESPOR \& ROBERT DOOLING, University of Maryland (presented by Robert Dooling)-Zebra finches (Poephila guttata) produce complex, learned, stereotyped songs. We trained finches to discriminate among natural songs and altered songs. Altered songs consisted of syllable deletions, reversals, and transpositions. Discrimination thresholds for changes in syllable level and inter-syllable interval were also determined. For comparison, budgerigars were tested on these same stimuli. Finches easily discriminate among most such changes in full length song. Results reveal the relative salience of different features of song.

(412)

The McCollough Effect in Pigeons. ANGELO SANTI, Wilfrid Laurier University, LORRAINE G. ALLAN, \& SHEPARD SIEGEL, McMaster University-Recent research concerning the orientationcontingent color aftereffect (the McCollough effect) has used a variant of the method of constant stimuli to evaluate the aftereffect in humans. We report the results of experiments that have applied this procedure to evaluating the McCollough effect in pigeons.

(413)

Fimbria/Fornix Lesions Affect Relational But Not Response Learning in the Rat. PHILLIP J. BEST \& DOUGLAS B. MATTHEWS, Miami University-Male rates with fimbria-fornix or sham lesions were trained in a Morris water maze to swim to a platform from four different start locations (N,E,S,W) under two conditions; either the escape platform was located in a position fixed relative to the room (place condition), or fixed relative to the animal's start location (response condition). The lesions produced a deficit in the place condition but not in the response condition.

Distinct Periaqueductal Gray Regions Control Different Stages of Defensive Behavior. JOSEPH P. DECOLA, BEATRICE M. DE OCA, \& MICHAEL S. FANSELOW, UCLA-Rats show the conditional defensive response of freezing when returned to a chamber previously paired with shock. Two procedures attenuate this conditioning. Massed shocks condition less fear than distributed shocks and a single shock delivered immediately upon placement into the chamber does not condition. Dorsolateral periaqueductal gray lesions enhance conditioning with these two procedures. Ventral PAG lesions reduce conditioning with optimal procedures. These regions support different aspects of defense and activity in the dorsolateral PAG inhibits fear conditioning. (415)

Lack of Tolerance to Anti-Contrast Actions of Chlordiazepoxide. CHARLES F. FLAHERTY, SEAN CLARKE, \& CYNTHIA COPPOTELLI, Rutgers University-Negative contrast occurred through repeated downshifts of sucrose (three days of $32 \%$ sucrose and two days of $4 \%$ sucrose for eight cycles). Chlordiazepoxide $(8 \mathrm{mg} / \mathrm{kg}$ administered on the second postshift day of each cycle) reduced contrast in each cycle-showing lack of tolerance to the contrast-reducing properties of the drug. However, tolerance did develop to sedative effects of the drug-indicating that contrast-reducing and sedative effects of chlordiazepoxide are dissociable. 


\section{HUMAN MEMORY IV \\ Palladian Room, Saturday Afternoon, 1:30-2:50}

Chaired by Stephanie M. Doane, University of Illinois

1:30-1:45 (416)

Witness Interrogation as a Cause of Forgetting. JOHN S. SHAW, ROBERT A. BJORK, \& ALISON HANDAL, UCLA (read by Robert A. Bjork)-In two experiments, subjects were shown slides depicting a theft or theft scene. During a subsequent interrogation phase they were questioned repeatedly about certain aspects of what they had witnessed. On a final criterion test, recall of those details was enhanced, but recall of other details in the same category as the practiced details was impaired. Repeated interrogation can apparently modify a witness's memory, even when no misinformation is contained or implied in the questioning. 1:50-2:05 (417)

The Laboratory Creation of False Memories: How Generalizable? DANIEL REISBERG, WYNONA KARBO, \& JASON SCULLY, Reed College-A number of psychologists have questioned the reliability of eyewitness testimony, particularly testimony about long-past events. Clearly relevant here are laboratory studies of memory errors, including studies which "plant" false memories. But how generalizable are these laboratory procedures? We report two studies-one using Jacoby's false-fame procedure to plant false autobiographical memories (bogus high-school classmates), and one unsuccessful attempt, using Loftus's misinformation paradigm, to change how actions within an event are remembered.

$$
\text { 2:10-2:25 (418) }
$$

The Effects of Divided Attention at Encoding and Retrieval. FERGUS I. M. CRAIK, RICHARD GOVONI, \& MOSHE NAVEHBENJAMIN, University of Toronto-Division of attention during encoding is associated with a marked reduction in later memory performance. Surprisingly, divided attention during retrieval has a much smaller effect. The present experiments replicated this asymmetry, and explored its causes. First, a complementary asymmetry was found in the divided attention task. Second, it appears that processing resources can be allocated in a graded fashion at encoding, whereas successful retrieval demands substantial resources, with a concomitant decrease in secondary task performance.

$$
\text { 2:30-2:45 (419) }
$$

Explaining the Influence of Extrinsic Variables on Memory Performance. DOUGLAS HERRMANN, National Center for Health Statistics, PAUL MULLIN, Bureau of Labor Statistics, \& ALAN SEARLEMAN, St. Lawrence University-Many variables that are often considered extrinsic to the memory have been demonstrated to influence memory performance. However, few theoretical explanations have been advanced to account for these effects. This paper will consider some of the constructs that might account for such effects and suggest research needed to investigate these constructs.

\section{SYMPOSIUM II: VISUAL OBJECT CONCEPTUALIZATION} Diplomat Room, Saturday Afternoon, 1:30-4:00

Chaired by Irving Biederman, University of Southern California, and Edward A. Wasserman, University of Iowa

\section{1:30-1:35 (420)}

Introductory Remarks. IRVING BIEDERMAN, University of Southern California.

$$
\text { 1:35-2:00 (421) }
$$

Visual Concepts in Pigeons. EDWARD A. WASSERMAN, University of lowa-Pigeons in operant conditioning situations readily categorize lifelike visual stimuli-such as photographs of automobiles, cats, chairs, and flowers-whether they are required to do so by the prevailing contingencies of reinforcement or not. Empirical evidence that supports this conclusion will be presented as will early results from research conducted in collaboration with Biederman which encourages us that both people and pigeons may respond to complex visual stimuli in accord with a piecemeal recognition process.

$$
\text { 2:05-2:30 (422) }
$$

Object Shape and Object Name in Children. BARBARA LANDAU, University of California, Irvine-Recent studies have shown that object shape is a privileged property in children's generalization of object names. Several possible causes of this shape bias are explored, with special attention to the use of shape in object naming when information about object function is explicitly provided. The robust reliance on shape even when function is understood suggests a (possibly modular) primacy for object shape that emerges independently of action-based or general knowledge about particular objects.

\section{2:35-3:00 (423)}

Neuropsychological Studies of Object Recognition. MARTHA J. FARAH, University of Pennsylvania-Is face recognition "special"'? How does it differ from nonface object recognition, in terms of the underlying representations and processes? I will review a number of studies with brain-damaged and normal subjects, aimed at answering these questions.

$$
\text { 3:05-3:30 (424) }
$$

Intermediate Representations and Visual Shape Recognition. IRVING BIEDERMAN, JOZSEF FISER, ERIC E. COOPER, \& PETER C. GERHARDSTEIN, University of Southern California-Some recent models of object recognition posit only two layers, an input filtering layer and a single subsequent stage by which those filter values are mapped directly onto a layer representing objects. Other models posit additional layers between the input and object layers, in which intermediate representations, such as a geon structural description, are activated to allow viewpoint invariance. Although the two-stage models may be adequate for face recognition, object recognition may require the activation of intermediate representations.

$$
\text { 3:35-3:55 (425) }
$$

Discussion. LAWRENCE W. BARSALOU, University of Chicago.

LANGUAGE/DISCOURSE PROCESSING II Hampton Room, Saturday Afternoon, 1:30-3:00

Chaired by Randall Engle, University of South Carolina

$$
\text { 1:30-1:45 (426) }
$$

Why Is the President Less Accessible than Hillary? DEBORAH M. SHAIBE \& JANET L. McDONALD, Louisiana State University (read by Janet L. McDonald)-Previous research has demonstrated that participants mentioned first in a sentence are most accessible to the comprehender. Additionally, it has been shown that proper names are better controllers of discourse focus than are common nouns. The current study tests the relative strength of these two factors by crossing participant type (Proper Name vs. Common Noun) with position. Results indicate that Focus interacts with Order of Mention, suggesting an extension of the Structure Building Hypothesis (Gernsbacher, 1990).

\section{1:50-2:00 (427)}

Allocation of Working Memory While Reading Expository Text. DESIREE BUDD \& PAUL WHITNEY, Washington State University (read by Paul Whitney)-Two experiments were conducted to examine how working memory span (WMS) affects the processing of expository text. In Experiment 1, the distance between thematic or detail information and the presentation of a related question was varied. In Experiment 2, presence or absence of topic sentences was manipulated. Question answering accuracy and sentence reading times indicated that all subjects performed macroprocessing, but low WMS subjects performed macroprocessing at the expense of microprocessing.

$$
\text { 2:05-2:15 (428) }
$$

Modeling the Time Course of Sentence Verification Processes. FRANZ SCHMALHOFER, University of Kaiserslautern, WILLIAM B. BAGGETT, MARK C. LANGSTON, \& ARTHUR C. GRAESSER, Memphis State University-When subjects have to verify test sentences pertaining to a previously studied text or some demonstration exam- 
ples, they use different types of memory traces such as verbatim, propositional, and situational representations. These representations become activated at various points in time. A model of the time course of such verification processes is presented which describes sentence verification as a construction-integration process.

$$
\text { 2:20-2:35 (429) }
$$

Probabilistic Constraints and Working Memory Capacity in Syntactic Ambiguity Resolution. MARYELLEN C. MACDONALD, University of Southern California, \& NEAL J. PEARLMUTTER, University of Illinois-MacDonald, Just, and Carpenter (1992) argued that working memory capacity limited the maintenance of alternative interpretations of syntactic ambiguities. We replicate their central finding, that high, but not low capacity subjects read temporarily ambiguous sentences more slowly than unambiguous controls. We investigate both subject groups' sensitivity to probabilistic constraints that have been shown to guide ambiguity resolution. Only highs, not lows, were sensitive to these constraints, which appears to account for the reading time differences.

\section{2:40-2:55 (430)}

Comprehension Skill and Flexible Suppression. MORTON ANN GERNSBACHER, University of Wisconsin-Madison-We have found that more-skilled comprehenders are more facile at quickly suppressing irrelevant information (e.g., a meaning of an ambiguous word not implied by a sentence context). On a task that required suppressing a meaning of an ambiguous word that was implied by the sentence context, more-skilled comprehenders were again more facile at suppression, although, as we have found before, on a task that did not require suppression, more- and less-skilled comprehenders performed equally well.

\section{INDIVIDUAL DIFFERENCES}

Blue Room, Saturday Afternoon, 1:30-3:40

\section{Chaired by Lawrence M. Ward, University of British Columbia}

\section{1:30-1:50 (431)}

Averaging Across Subjects Alters Psychological Structures in Similarity and Identification Data. F. GREGORY ASHBY, University of California, Santa Barbara, W. TODD MADDOX, Arizona State University, \& W. WILLIAM LEE, University of California, Santa Barbara-Averaging across subjects increases symmetry in similarity and identification data and thereby alters the underlying psychological structure. Multidimensional scaling models of similarity and the similaritychoice model of identification assume high degrees of symmetry and, therefore, they usually fit averaged data well, even if they fail on each individual subject. Thus, a good fit of either model to averaged data is not evidence that the model describes the psychological structure of any single subject.

\section{1:55-2:10 (432)}

Resistance to Extinction or Persistence in Failure: Capaldi's Model or Achievement Motivation? VIRGINIA BLANKENSHIP, Northern Arizona University-Capaldi's sequential model of learning relates resistance to extinction to number of nonreinforced trials followed by a reinforced trial ( $\mathrm{N}$-lengths) and to number of $\mathrm{NR}$ transitions. In achievement motivation research, persistence in the face of failure is related to individual differences in need for achievement. In a study with 150 human subjects, amount of time persisting at a failed task is related to $\mathrm{N}$-lengths, NR transitions, and individual differences in achievement motivation.

$$
\text { 2:15-2:30 (433) }
$$

The Source of Individual Differences in Learning. JAMES W. HALL \& DAVID VINSON, Northwestern University-We examined the proposal that individual differences in learning arise from differences among subjects as strategists; fast learners are especially skillful in applying appropriate elaborative strategies. That notion implies little or no relationship between individual differences in such intentional learning and differences when learning occurs without conscious elaboration. However, we observed similar individual and item differences for strategic and nonstrategic learning. Apparently the same factor(s) are critical whether or not conscious elaboration is involved.

$$
\text { 2:35-2:50 (434) }
$$

Age Differences in Explicit and Implicit Memory: Comparing the Magnitude. IVAN J. TORRES \& NAFTALI RAZ, Memphis State University (read by Naftali Raz)-Young and elderly adults ( $\leq 25$ vs. $\geq 65$ ) were administered data-driven and conceptually driven implicit memory tests. Cued and free recall were assessed as well. Age differences measured by the effect size $(d)$ expressed in standard deviation units were greater on explicit than implicit tests. The median $d s$ were: .54 for free recall, .45 cued recall, .27 data-driven implicit memory, and .22 conceptually driven implicit memory. Considerable variability across tasks, groups, and test forms was observed.

$$
\text { 2:55-3:10 (435) }
$$

Color, Smell, Taste, and Dance: The Role of Linguistic Codability. RUTH S. DAY, ROBERT C. HUBAL, JENNIFER ZERVAKIS, \& AYANA N. KEE, Duke University-To what extent do people translate their perceptual experiences into linguistic codes, then use these codes to support memory? Previous research using colors as stimuli yielded mixed results-linguistic codability did not always affect memory. Our subjects described stimuli in several domains including color, smell, taste, and dance. Obtained measures of linguistic codability (e.g., response speed and agreement across subjects), memory experiments, and individual differences help clarify the role of linguistic codability in cognition.

$$
\text { 3:15-3:35 (436) }
$$

Thinking Styles. ROBERT J. STERNBERG, Yale University-Thinking styles are a bridge between cognition and personality. They are neither abilities nor personality attributes, but rather personal preferences for the use of abilities. This talk with present a theory of such styles, the theory of mental self-government. Four empirical tests of the theory will be described, showing the theory's (a) construct validity, (b) usefulness as a psychological account, and (c) educational relevance for teaching and learning. Measures will also be described.

\section{JUDGMENT/DECISION MAKING I}

Empire Room, Saturday Afternoon, 1:30-3:25

\section{Chaired by Kathleen M. Galotti, Carleton College}

\section{1:30-1:45 (437)}

Loss Aversion and Endowment Effects for Undesirable Items. DENISE BEIKE \& STEVEN J. SHERMAN, Indiana University (read by Steven J. Sherman)-Two explanations for status quo biases for undesirable items were empirically tested: a) the endowment effect (ownership adds value), and b) loss aversion (losses outweigh equal gains). A study using a buying/selling/choosing paradigm demonstrated status quo, and only loss aversion was supported as a mechanism. Another study using a trading paradigm again demonstrated status quo biases; and, as no boost in value occurred due to mere ownership, endowment effect again failed to receive support.

1:50-2:10 (438)

Asymmetrical Evaluations of Future Gains and Losses: Temporal Discounting Model. MARY KAY STEVENSON, Purdue University-These studies were designed to estimate discounting functions for gains and losses using a rating task and a preference task. The results indicate that the magnitude of outcomes has a different impact on the evaluations depending on the time of the outcome, the judgment task and whether it is a gain or loss. These patterns have occurred with time and probabilities. A general model of temporal discounting is proposed to account for these results.

$$
\text { 2:15-2:35 (439) }
$$

Evaluation of Uncertainty in Intertemporal Choice. GIDEON KEREN \& PETER ROELEFSMA, Free University of AmsterdamUncertainty is an intrinsic component of intertemporal choices. Studies on intertemporal choice often formulate their choice problems in a manner which implicitly assumes that future outcomes are certain. We present three studies showing that uncertainty is an essential dimension in any 
intertemporal choice that dominates other possible effects. Problems associated with separating the uncertainty component in intertemporal choice will be briefly discussed.

\section{2:40-3:00 (440)}

Effects of Different Types of Decoys on Choice. DOUGLAS H. WEDELL, University of South Carolina-Decoys are alternatives added to a choice set in order to alter relative choice proportions among the other alternatives in the set. The present experiments used a withinsubjects design to study four different types of decoys: asymmetrically dominated, inferior, compromise, and substitution decoys. The pattern of results replicated those from between-subjects designs. Process tracing measures were used to distinguish between different accounts of decoy effects on choice.

\section{3:05-3:20 (441)}

Judgmental Versus Statistical Prediction: Information Asymmetry and Combination Rules. ILAN YANIV \& ROBIN M. HOGARTH, University of Chicago-The relative predictive accuracy of human and statistical models has long been the subject of controversy even though models have demonstrated superior performance in many studies. We propose that relative performance depends on the amount of contextual information available and whether it is distributed symmetrically to humans and models. Given their different strengths, human and statistical predictions can be profitably combined to improve prediction.

ANIMAL LEARNING/CONDITIONING III Ambassador Room, Saturday Afternoon, 1:30-3:05

Chaired by Donald F. Kendrick, Middle Tennessee State University

$$
\text { 1:30-1:45 (442) }
$$

Altering the Sexual Preferences of Female Zebra Finches. R. WEISMAN, S. SHACKLETON, L. RATCLIFFE, P. BOAG, \& D. WEARY, Queen's University-We examined acquired sexual preferences in female zebra finches by changing their parent's beak colors. We painted one parent's beak red and the other's orange (counterbalancing sex and beak color between rearing groups). At maturity, females preferred males marked with their father's beak color, whether orange or red. In various control rearing conditions, females had no preference between red and orange beaked males. The results suggest a role for differential associations in sexual imprinting.

$$
\text { 1:50-2:00 (443) }
$$

Classical Conditioning Mediates the Establishment of a Dominance Hierarchy in Softshell Turtles (Trionyx spiniferus). ROGER L. MELLGREN, VICKI K. KRUMKE, \& MARK E. BUSHONG, University of Texas at Arlington-The daily meal (US) was presented following a 10-min change in brightness (CS) to a group of young captive softshell turtles. As they learned to anticipate the food, the large turtles became active and aggressive during the CS and the smaller turtles remained buried in the sand, avoiding aggressive attacks. The larger, dominant turtles obtained food first and the smaller, submissive turtles learned to delay feeding until the dominant subjects were finished.

$$
\text { 2:05-2:20 (444) }
$$

Compounding Excitors With Excitors or Inhibitors From the Same and Opposite Incentive Class. STANLEY J. WEISS, American University, DAVID A. THOMAS, National Institutes of Health, \& RICHARD D. WEISSMAN, American University-Appetitive or aversive inhibitors were instrumentally conditioned in rats with the $\mathrm{A}+, \mathrm{AB}-$ discrimination procedure. An inhibitor most effectively suppressed barpressing when compounded with a discriminative stimulus $(\mathbf{S}+)$ from the same incentive class. In a second test, bar pressing was enhanced only when appetitive $S+s$ or aversive $S+s$ were compounded. These results support appetitive-aversive interaction theory. Generally, an excitor of one incentive class had properties in common with an inhibitor of the other.

$$
\text { 2:25-2:40 (445) }
$$

Food Deprivation States as Conditioned Modulatory Stimuli. T. L. DAVIDSON \& STEPHEN C. BENOIT, Purdue University-Rats solved a Pavlovian discrimination problem based on stimuli arising from 0 and 24-hr food deprivation. Transfer tests assessed what the rats learned during this training. Discriminative control by deprivation stimuli transferred strongly to a test context that had been reinforced only when food deprivation cues were presented to be absent, but did not transfer to a novel, nonreinforced, context. This outcome suggests that food deprivation signals came to modulate the response-evoking capacity of contextual cues.

\section{2:45-3:00 (446)}

Configurational Discrimination in Pigeons. M. E. BITTERMAN \& P. A. COUVILLON, University of Hawaii-Pigeons were trained with colored stimuli, first in an ambiguous-cue problem $(A+B-$, $\mathrm{B}+\mathrm{C}-)$, then in a three-component "loop" problem $(\mathrm{A}+\mathrm{B}-, \mathrm{B}+\mathrm{C}-$, $\mathrm{C}+\mathrm{A}-)$, and finally in a four-component loop problem $(\mathrm{A}+\mathrm{B}-$, $\mathrm{B}+\mathrm{C}-, \mathrm{C}+\mathrm{D}-, \mathrm{D}+\mathrm{A}-)$. Control of performance by components soon gave way to control by configurational (pair-unique) properties.

\section{IMPLICIT MEMORY II}

Palladian Room, Saturday Afternoon, 3:00-5:00

Chaired by Barbara H. Basden, California State University, Fresno

\section{3:00-3:20 (447)}

On the Persistence of Priming. J. W. WHITLOW, JR., Rutgers University, \& PAMELA H. DALTON, New York University-This paper critically examines the claim that priming is a relatively persistent form of memory. Two experiments are reported that compare the persistence of priming in perceptual identification and in word stem completion to the retention of recognition accuracy over a 1 -week interval. We show that data from these experiments conform to published data on the persistence of priming yet exhibit the same decay function as seen in recognition memory.

$$
\text { 3:25-3:45 (448) }
$$

Encoding Strategy Effects on Retrieval Tested by Implicit and Explicit Measures. SHLOMO BENTIN, Hebrew University, \& MORRIS MOSCOVITCH, University of Toronto-Words were studied either performing lexical decisions or color discriminations. Explicit and implicit memory was assessed immediately and after 24 hours. Mixing decisiontypes at study and repeating LDs caused similar repetition priming for all study conditions and testing times. The $\mathrm{d}^{\prime}$ was twice as big following "deep" than "shallow" study, and reduced at delayed testing. Blocking decisions at study reduced priming and the $d$ ' for "shallower" and enhanced priming for "deeper" studied words. Repeating shallow decisions caused no repetition effect.

\section{3:50-4:10 (449)}

Awareness and Novelty in the Implicit and Explicit. DON E. DULANY, EVAN PRITCHARD, NEVIN GREENBERG, \& KATHARINE GREENBERG, University of Illinois-Subjects classified grammatical and nongrammatical strings with feedback, evocatively in one second or deliberatively in two seconds. At test in either of those conditions, they classified old and novel strings, on later trials reporting a classification rule. Explicit and implicit tests revealed both explicit and implicit learning of old strings. Only when both learning and remembering were explicit did learning transfer to novel strings. In all conditions, rules in awareness predicted classification without significant residual.

\section{4:15-4:35 (450)}

Bias in Implicit Memory Tasks. ROGER RATCLIFF \& GAIL McKOON, Northwestern University-Data are presented to support a bias explanation of priming in Schacter and Cooper's object decision task. Standard results show priming from earlier study of possible figures, but no priming for impossible figures. Using response deadlines, memory load, or manipulation of similarity between studied and tested figures, we show equivalent effects for possible and impossible figures. We also show bias effects in stem completion, picture naming, and perceptual identification.

\section{4:40-4:55 (451)}

Attention in Explicit and Implicit Memory Tasks With Short- and Long-Term Probes. RONALD T. KELLOGG, CHRISTOPHER NEWCOMBE, DARREN KAMMER, \& KATHERINE SCHMITT, University of Missouri-Rolla-We examined attention in light of the functional 
independence criterion of multiple memory systems. Attention at encoding strongly affected explicit recognition, though not the magnitude of decline in hit rates between short- and long-term probes and not the time required for correct recognition. Implicit memory as indexed by priming in lexical decision times neither declined over time nor varied with attention at study. We discuss the implications of these findings for multiple memory systems.

\section{PERCEPTION II}

Diplomat Room, Saturday Afternoon, 4:10-5:05

\section{Chaired by Stephen W. Link, McMaster University}

\section{4:10-4:25 (452)}

The Detection of a Tone Masked by Another Tone. VIRGINIA M. RICHARDS, University of Pennsylvania-Several experiments were completed in order to estimate the critical cue for the detection of a tonal signal masked by a tone of different frequency. Changes in the overall level, the pitch, and envelope pattern appeared to contribute little to the detection of the added tone. Overall, we failed to disrupt the detection of a tone masked by another tone, suggesting the changes in the pattern of activity across frequencies is critical for detection. (Supported by the National Institutes of Health.)

$$
\text { 4:30-4:45 (453) }
$$

When Does Skill Improve Sensitivity to Timing? WILLIAM YEE, SUSAN HOLLERAN, \& MARI RIESS JONES, Ohio State University (read by Mari Riess Jones)-Effects of musical skill (High, Low) on time discrimination in auditory sequences is studied using a 2AFC procedure. In Experiment 1, sequence structure (Metrical, Nonmetrical) was a between-subjects variable. Skilled listeners were significantly superior to unskilled listeners only in Metrical conditions. In Experiment 2 , sequence structure was within-subjects variable, and here no significant skill differences were found. In both studies performance with nonmetrical sequences was poorer than with metrical sequences. 4:50-5:00 (454)

Interactions Between the Mueller-Lyer and Horizontal-Vertical Illusions. CLARE PORAC \& HELENA KADLEC, University of Victoria-Variants of the wings-in and wings-out components of the MuellerLyer illusion were presented in horizontal and vertical orientations to explore additivity of the Mueller-Lyer and Horizontal-Vertical figures. The data supported additivity; however, decomposition of the illusion magnitudes revealed by the measurements of the joint HV-ML forms into $\mathrm{HV}$ and $\mathrm{ML}$ portions indicated that the two illusions combine in different ways for individual variants of the combined illusion forms.

\section{SEMANTIC PRIMING}

Hampton Room, Saturday Afternoon, 3:10-5:00

Chaired by Keith Rayner, University of Massachusetts

\section{3:10-3:25 (455)}

Prime Task Effects on Naming RTs. FRANCES J. FRIEDRICH, University of Utah-Several studies were conducted using a semantic priming paradigm in which naming RTs were measured for target words. Either a lexical decision or a letter search task was performed on the prime word. The nature of the prime task influenced whether priming occurred, a result consistent with previous studies using lexical decision as the target task. However, some evidence did emerge showing priming at short SOAs, regardless of the prime task.

$$
\text { 3:30-3:45 (456) }
$$

Repetition Priming: Effects of Prime-Target Reversal in Lexical Decision. DAVID S. GORFEIN, Adelphi University, \& ANDREA BUBKA, St. Peter's College-In a lexical decision task both related (CIRCUS-RINGMASTER) and unrelated (SICK-CEMENT) pairs were presented. On a second occurrence some of the pairs were reversed so that the prime became a target and target prime (RINGMASTERCIRCUS, CEMENT-SICK). In contrast to an identical repetition, the repetition effect in reversed pairs was tiny. Results are discussed in relation to a theory of list wide episodic priming.

$$
\text { 3:50-4:10 (457) }
$$

On the Blocking of Semantic Activation. MARILYN C. SMITH, University of Toronto, \& DEREK BESNER, University of WaterlooSemantic priming is freqently considered to occur automatically. Arguing against such automaticity is the finding that the way in which the prime is processed can influence priming. Here we present further evidence against the automatic spread of semantic activation by demonstrating that mode of target processing can also influence semantic priming. When subjects are required to perform a letter search on the target, priming does not occur. We propose that output from the semantic system can be blocked.

$$
\text { 4:15-4:35 (458) }
$$

On Obtaining Additive Effects of Priming and Target Degradation. JENNIFER A. STOLZ \& JAMES H. NEELY, SUNY at Albany (read by James $\mathrm{H}$. Neely) -We find additive semantic priming and target degradation effects for lexical decisions when the proportion of related priming trials (RP) is low and the typical enhanced priming for degraded targets with a higher RP. This was so at both short and long prime-target SOAs, even though priming increased with increasing RP only at the long SOA. These results undermine expectancy-based accounts of the Priming $\times$ Target Degradation interaction.

$$
\text { 4:40-4:55 (459) }
$$

Summation of Semantic Priming Across Weak Associates: The Whole is Greater Than the Parts. WILLIAM MILBERG, MIEKE VERFAELLIE, \& ELISA BOLTON, Boston University School of Medicine-In a series of priming experiments subjects made lexical decisions to a target preceded by two serially presented word primes. Individually these primes were weakly associated with both the target and each other, but in combination, were likely to specify target identity (e.g., BUILDING-KING-CASTLE). Priming effects for these "conceptual" pairs greatly exceeded the combined effects of each prime in isolation, raising the possibility of nonlinear summation of activation in semantic memory.

\section{REPETITION/PRIMING EFFECTS II \\ Blue Room, Saturday Afternoon, 3:50-5:05}

\section{Chaired by Kenneth I. Forster, University of Arizona}

\section{3:50-4:00 (460)}

The Role of Semantic Context on Repetition Priming Effects. AYDIN Y. DURGUNOGLU, University of Minnesota, Duluth-The effects of semantic context on the size of the repetition priming was examined with a lexical decision task. The repetition effects were similar if the semantic context accompanying each of the two presentations primed the same sense (dog/howl) or the different senses (dog/tree) of a homograph (BARK). Repetition effects increased only when the prime was identical in both presentations $(\mathrm{dog} / \mathrm{dog})$. The implications for semantic versus perceptual bases of repetition priming is discussed. 4:05-4:15 (461)

Affective-Priming. LARRY HOCHHAUS, Oklahoma State University-Do reaction times to positively and negatively toned words in a lexical decision task depend on phasic interactions between the words themselves? Participants were shown pairs of letter strings and responded "yes" if both were words. "Yes" times were significantly faster when both words carried the same emotional tone. The affective priming of one word by another is a factor that may mask more global mood congruity effects in other lexical decision research.

\section{4:20-4:40 (462)}

Building New Associations in Semantic Memory. CHRIS SCHRIJNEMAKERS, University of Nijmegen, \& JEROEN G. W. RAAUMAKERS, University of Amsterdam (read by Jeroen G. W. Raaijmakers)-Prime target pairs were repeated nine times in a lexical decision task. The word primes were either related, unrelated, or neutral (the word BLANK). After the initial nine study trials, a final test was given in which subjects 
were given both a primed lexical decision task and a primed perceptual identification task. The results gave evidence for automatic episodic priming as well as for storage of new information in semantic theory.

4:45-5:00 (463)

Repetition Priming of Nonwords in Young and Older Adults. LEAH L. LIGHT, Pitzer College, \& DONNA La VOIE, Claremont Graduate School-Older adults show as much benefit from a prior experience as young adults when tested in item repetition priming tasks. On associative priming tasks age differences are often reported. We describe three experiments comparing young and older adults on a nonword naming task. These experiments show that older adults do not differ from younger adults in number of acquisition trials needed before demonstrating associative priming or in persistence of new representations of novel nonwords.

\section{JUDGMENT/DECISION MAKING II \\ Empire Room, Saturday Afternoon, 3:35-4:50}

\section{Chaired by Shawn P. Curley, University of Minnesota}

\section{3:35-3:50 (464)}

The Computer as Expert Opponent in Experimental Games. A. W. MACRAE, University of Birmingham, U.K.-Much experimental work on human strategy in games has the defect that confederate opponents adopt a Minimax strategy, unresponsive to the strategy followed by the subject, who consequently has nothing to gain or lose by any choice of strategy. A computer program incorporating an active prediction of the player's next move makes it possible to study the extent to which players can randomize and can optimize their strategy under different payoff structures.

\section{3:55-4:10 (465)}

On the Existence of Benevolent Dictators. RAMI ZWICK, University of Pittsburgh, \& EYTHAN WEG, Purdue University-Since Kahneman, Knetsch, and Thaler (1986) reported on the benevolent dictators, thus creating the groundwork for a revision of the fundamental assumptions of economics science, there appeared a substantial number of replications, some refuting and some supporting their conclusions. We argue that the use of dictator games is an appropriate paradigm for the intended demonstrations, and produce an alternative, where dictators face a non-degenerate, but nonetheless dummy opponent. Experimental evidence is reported.

\section{4:15-4:30 (466)}

Preference Reversals and Self Control in Humans. LEONARD GREEN, NATHANAEL FRISTOE, \& JOEL MYERSON, Washington University - In the present study, smaller, more immediate rewards were preferred to larger, more delayed rewards, but adding a constant delay caused preference to reverse. For three pairs of hypothetical monetary rewards, the function $D_{\mathrm{L}}=a D_{\mathrm{s}}{ }^{b}+c$ accurately described the relation between the delays to the larger and smaller rewards at preference reversal $\left(r^{2} s>.99\right)$. Such results are inconsistent with simple exponential and hyperbolic models of delay discounting in self control. 4:35-4:45 (467)

The "Spendability" of Unanticipated Money. HAL R. ARKES, $\mathrm{Na}$ tional Science Foundation, CYNTHIA A. JOYNER, FTI CorporationJury Analysts Group, MARK V. PEZZO, Ohio University, JANE GRADWOHL NASH, Stonehill College, KAREN SIEGEL-JACOBS, University of Colorado, \& ERIC STONE, University of MichiganTraditional theories of choice accept the principle of fungibility-the proposition that the source of money should not influence its consumption. Contrary to this principle, we hypothesized that unanticipated funds would be spent more readily than anticipated funds. One group of males did and another group did not anticipate $\$ 5$ given to them before a basket- ball game. The unanticipated-money group spent almost three times as much as the anticipated-money group at the game.

ANIMAL LEARNING/CONDITIONING IV
Ambassador Room, Saturday Afternoon, 3:15-5:00

Chaired by George A. Cicala, University of Delaware

$$
\text { 3:15-3:30 (468) }
$$

Do "Central" Variables Contribute to Within-Session Changes in Responding? FRANCES K. MCSWEENEY, JEFFREY N. WEATHERLY, \& KELLY S. JOHNSON, Washington State University-Responding may increase to a peak and then decrease within experimental sessions. This systematic change is sometimes dismissed as "warmup" followed by "satiation." However, variables generated by responding, reinforcement, the passage of time, interfering responses and central factors may all contribute to the within-session changes in responding. The evidence that central factors (e.g., a focusing followed by a waning of attention) play a role will be evaluated.

$$
\text { 3:35-3:50 (469) }
$$

Relevant and Irrelevant Variation Among Stimuli During Visual Discrimination. JOHN M. HINSON, CARI B. CANNON, Washington State University, \& LINDA R. TENNISON, Longwood CollegeIn various conditions, pigeons were trained to discriminate twodimensional visual stimuli. The criterion for correct responding was based on values of only one dimension. Stimulus range was varied by extending stimuli along dimensions either relevant or irrelevant to the discrimination criterion. Extensions of stimulus range reduced discrimination performance even when the dimension of variation was irrelevant to the discrimination criterion. Thus, pigeons attended to some information that should have been ignored.

\section{3:55-4:15 (470)}

Latent Inhibition: A Neural Network Approach. NESTOR A. SCHMAJUK, Northwestern University, \& JEFFREY A. GRAY, Institute of Psychiatry -A real-time network assumes that animals build an internal model of the world to generate predictions of environmental events. Whenever predicted and observed events differ, orienting responses are emitted, ongoing behaviors are inhibited, and attention to stimuli is increased, in proportion to the total novelty (Gray, 1971; Sokolov, 1960). Computer simulations show that the neural network correctly describes many features that characterize latent inhibition.

\section{4:20-4:35 (471)}

Quantitative Two-Process Analysis of Avoidance Conditioning in Goldfish. P. A. COUVILLON \& M. E. BITTERMAN, University of Hawaii-Classical and avoidance conditioning were studied in a variety of shuttlebox experiments with goldfish. All of the data could be simulated quantitatively with a version of Mowrer's early theory expressed in three simple equations-two learning equations (one classical, the other instrumental) and a performance equation. The good fit suggests that the theory is worth trying to develop further with new experiments designed to challenge it.

\section{4:40-4:55 (472)}

Response and Shock Factors in Negative Reinforcement by Timeout From Avoidance. JEFFREY MIKORSKI \& MICHAEL PERONE, West Virginia University (read by Michael Perone)-By pressing a lever, rats avoided shocks on a schedule in which a warning signal before each shock was varied from $4 \mathrm{sec}$ to $19.5 \mathrm{sec}$. Pressing a concurrently available lever occasionally produced a 60 -sec timeout during which the avoidance schedule was suspended. Overall responding on both levers increased with signal duration. Timeout rates were correlated with avoidance rates, but not with shock rates. Timeout responding may be maintained by escape from the effort associated with avoidance. 
POSTER SESSION III

Regency Ballroom, Saturday Evening, 5:35-7:05

\section{(473)}

The Effects of Aging on Automatic Lexical Access. MARC E PRATARELLI, ANN M. GALLOWAY, Fort Hays State University, \& STEVEN LINNVILLE, Naval Health Research Center-Studies of cognitive-slowing in aging have paid less attention to automatic processing than controlled information processing. A masked priming technique was used with an LDT to assess the integrity of automatic lexical access in 55-85 year-old adults. Comparison with results obtained from college students showed no effects of cognitive slowing in the priming effect. This evidence suggests fast automatic processes may be more resilient to the effects of aging than slower conscious controlled processes.

Age Differences in Word Encoding. PHILIP A. ALLEN \& LISA BETTS, Cleveland State University-We conducted two naming/lexical decision experiments that compared the performances of younger and older adults when words and pronounceable nonwords were presented in consistent lowercase ("hello"), mixed case by syllable ("HELlo"), and mixed case by letters ("hElLo"). There were no age differences in word frequency effects. However, older adults did show age deficits in processing the mixed case by letters condition. These results indicate that there are age differences in word encoding.

(475)

Looking and Talking: How Children Explain Two Cognitive Domains. ANN REPP \& RICHARD P. MEIER, University of Texas at Austin (presented by Richard P. Meier)-This study probed children's explicit knowledge of two complex cognitive domains-language and vision. Subjects responded to two types of tasks: interviews (e.g., "Why do people need to be able to talk/see?"') and drawing completion tasks. Analyses indicate (1) a restructuring of conceptual relations in both domains between 6 and 10 years of age, and (2) a more elaborate knowledge of vision than language. Results are discussed in terms of behaviorally-based and functionally-based explanations.

\section{(476)}

Spatial Cues and the Elimination of Age-Related Distraction in Reading. LYNN HASHER, MICHELLE CARLSON, S. LISA CONNELLY, Duke University, \& ROSE T. ZACKS, Michigan State University-Connelly, Hasher, and Zacks, 1991 found that older adults were more slowed than younger adults in reading target text when that text was interspersed with distracting text that occurred in unpredictable locations. Two new studies show that this age-related distractor effect can be eliminated when the distractor occupies fixed spatial locations. Reduced susceptibility to distraction is consistent with other findings (e.g., Connelly \& Hasher, 1993) showing that older adults are as able as younger adults to utilize spatial cues.

\section{(477)}

Age-Related Differences in Search Strategies. D. KRISTEN GILBERT \& WENDY A. ROGERS, Memphis State University (presented by Wendy A. Rogers)-The digit symbol substitution subscale (DSS) of the WAIS (Wechsler, 1972) consistently reveals differences in performance between young and old adults. The current research assessed the performance of young and old adults on a noun-pair lookup task (which is similar to the DSS), to determine the search strategy used by each subject. Results indicated that search strategies differ according to age group and type of task (i.e., consistent or varied noun-pair combinations). (478)

Age-Related Differences in Working Memory: Differential Fan Effects. WENDY A. ROGERS, Memphis State University, JUDY CANTOR, AT\&T Bell Laboratories, \& JENNIFER E. NESTOR, Memphis State University (presented by Judy Cantor)-Age-related differences in working memory have been well-documented. The purpose of the present study was to use the fan manipulation test for young and old adults to assess the relationship between long-term memory activation and working memory. Older adults showed a larger increase in recognition time as fan increased; in addition, they had more intrusion errors during the acquisition phase. Results are discussed in terms of activation and inhibition theories.
(479)

Orthographic Representations in Developmental Dysgraphia. JAMES M. HODGSON \& GRETCHEN JOHNSON, Massachusetts General Hospital-Developmental dysgraphia is characterized by numerous phonologically plausible spelling errors. This may indicate (1) a general impairment in development of orthographic representations, (2) a specific impairment in developing an output orthographic lexicon, (3) impaired access to existing orthographic representations for spelling. These alternatives are assessed in a battery of visual word recognition measures administered to college educated adult dysgraphics. Results suggest that (1) is incorrect. Data bearing on decisions among variants of (2) and (3) are considered.

$$
\text { (480) }
$$

Early Differentiation of Natural Kind Categories. KEN SPRINGER \& THUY NGUYEN, Southern Methodist University-Three experiments examined the organization of children's natural kind concepts as reflected in distinctions between biological versus nonbiological natural kinds (apple versus gold). Preschoolers in Experiment 1 predicted changes such as aging would make biological natural kinds noxious, but not affect nonbiological ones or artifacts. Experiment 2 replicated this with unfamiliar objects, indicating category-based responses. Experiment 3 explored beliefs about mechanisms underlying noxiousness. Overall, the results implicate early, principled distinctions among natural kind categories.

(481)

Forecasting Chaotic Processes: Lyapunov Exponents Are Related to Error Magnitudes. MARY ANN METZGER \& MICHAEL F. THEISZ, University of Maryland, Baltimore County-Forty-eight college students were asked individually to make forecasts for successive values of a chaotic process, presented as 600 points on an evolving graph on a video screen. Separate groups pointed to the next expected point on the evolving graph for: Henon or Logistic systems, Lyapunov exponents (measured in bits/iteration) selected for three levels of predictability of the graph, and missing information. The primary finding was that Lyapunov exponents influenced strategies and errors.

(482)

Two Processes in Order Information Processing. JERWEN JOU, XIEZHANG LI, \& IFRAJ T. QUIYIM, Georgia Southern University-Symbolic distance effect refers to faster response in deciding the relative magnitude of two items when the difference in the magnitude between the two items is large than when it is small. This effect was found to arise from a quick parallel-like comparison process. When the comparison required finer or serial-like discrimination, the distance between items either had no effect or a reverse-distance effect-the larger the distance, the slower the response.

Interactive Parallel Processing of Multiple Word Memory Probes. DAVID BURROWS, Skidmore College-Subjects viewed 16-item memory lists and then made yes/no recognition judgments. On some test trials a single word was presented. On others, two words were presented simultaneously and separate responses to each word were required. Aggregate response times to the two-word tests were less than predicted by a serial processing model. The pattern of response times suggests an interactive parallel process.

(484)

Mislocations and Intrusions With Unfamiliar, Familiar, and Labeled Letter-Like Forms. GARVIN CHASTAIN, CRAIG KING, KRISTEN LUSCHER, MICHELE ROEDER, \& ROBIN THURBER, Boise State University-Mislocation errors outnumber intrusion errors when several letters are presented with one cued for report, whereas this is not the case with symbols or letter-like forms. Relative to no initial experience, in initial familiarization with forms and learning labels for them yielded similar mislocation to intrusion frequencies that more closely resemble those with letters. Labels therefore provide no advantage over familiarization in reducing intrusion relative to mislocation errors as typically observed with letter stimuli.

\section{(485)}

The Time Course of Automatic and Non-Automatic Information Processing. GREGORY B. MALLEY \& DAVID L. STRAYER, University of Utah (presented by David L. Strayer)-We used the speed- 
accuracy decomposition procedure (Meyer, Irwin, Osman, \& Kounios, 1988 ) and the random walk modeling procedure (Ratcliff, 1978) to investigate the accumulation of evidence as a function of expertise. Subjects received over 60,000 trials of practice in consistently mapped and variably mapped variants of a memory search task. The modeling procedures provided converging evidence that the development of automaticity is associated with an enhanced accumulation of evidence. Moreover, subjects adopted differential response criteria to capitalize on the differences in the rate of evidence accumulation.

(486)

Divided Attention to Visual and Auditory Stimuli: Detection and Identification. ANNE-MARIE BONNEL \& ERVIN HAFTER, University of California, Berkeley (sponsored by Ervin Hafter)-Studies of simultaneous attention to one auditory and one visual stimulus show that detection of a change is governed by "automatic" processing while identification of the direction of the change is "highly controlled." The generality of this result was tested here by introducing a delay between the background and the change to be detected or identified. The data show that removing transient information produces drastic effects on detection.

Color Versus Word and Nonword Judgments in the Stroop Task. CHRISTOPHER J. KOCH, George Fox College, \& JAMES M. BROWN, University of Georgia-The relative-speed-of-processing account of the Stroop effect assumes that words are read faster than colors are named thereby producing interference with color naming. This assumption was examined. Words and nonwords were presented in four different colors for varying durations. In Experiment 1, Ss responded to the color print. The Stroop effect was found for color words. In Experiment 2, Ss responded either word or nonword. Word/nonword judgments were faster for color words than noncolor words.

(488)

Negative Priming in Auditory Shadowing. WILLIAM P. BANKS \& DAVID ROBERTS, Pomona College-Three experiments studied the negative priming effect in shadowing one of a pair of words presented dichotically. Inhibition of $100 \mathrm{msec}$ was found on trial $n+1$ when the word had been rejected on trial $n$. The effect was the same for both ears, but turned to facilitation for trials $n+3$ and $n+5$. It made no difference whether the rejected and shadowed presentation of a word were on the same or different ear.

\section{(489)}

Attention and Covariation Learning in the Erikson Flanker Task. MICHAEL A. STADLER, University of Missouri-Columbia, \& ROBERT W. PROCTOR, Purdue University-Miller (1987) showed that subjects learn covariations between purportedly attended and unattended stimuli, which suggests that covariation learning does not require attention. Experiment 1 examined learning as a function of covariation strength. In Experiment 2, the relation between covariation strength and learning did not hold when attended and unattended stimuli were separately grouped by the Gestalt principle of similarity. This finding suggests that at least some minimal amount of attention is necessary for learning.

(490)

Decay of Distractor Inhibition in a Local-Global Letter Matching Task. EWALD NEUMANN, National Institute of Mental Health, \& KRISTIN HOOD, Middlebury College-The duration of distractor inhibition was investigated in a letter-matching procedure using localglobal letters. Response-stimulus intervals (RSIs) between a prime and a probe stimulus varied between $250 \mathrm{~ms}$ and $2500 \mathrm{~ms}$. Negative priming was obtained in the $250 \mathrm{~ms}$ RSI condition while no negative priming was found in the $2500 \mathrm{~ms}$ RSI condition. This was taken as evidence for a complete decay of distractor inhibition within about two and a half seconds.

(491)

Influences of Attention on the Identification of Disoriented $\mathrm{Ob}$ jects. JANICE E. MURRAY, University of Otago-Subjects either named a disoriented object and ignored a changing letter display centered in the object, or ignored the object and counted red Ts. Following 5 blocks of trials, all subjects named the disoriented drawings. Subjects in the Object-Ignore group showed a robust orientation effect for naming, in contrast with the reduced orientation effect found for ObjectAttend subjects. The extraction and use of orientation-invariant attributes to identify objects appears to require attention.

(492)

Age and Target-Distractor Similarity in Visual Search. A. HEATHER DOHN, WILLIAM J. HOYER, LISA KOTARY, Syracuse University, \& CHANDAN J. VAIDYA, Stanford University (presented by William J. Hoyer)-Effects of display size and target-distractor similarity on adult age differences in visual search were investigated in four experiments. Compared with younger adults, older adults exhibited steeper slopes when targets and distractors were relatively similar, especially in negative probe conditions. Furthermore, there were age differences in the cost of adding a highly confusable non-target item to the display. Results were interpreted as supporting the Duncan and Humphreys (1989) model of stimulus similarity.

(493)

Dimensional Constraints on Response Selection: Evidence From Correlational Cues. ASHER COHEN, Hebrew University, \& RACHEL SHOUP, Indiana University-Stimuli that are correlated with a particular response can cause a response competition with targets requiring a different response (Miller, 1987). Several experiments show that this phenomenon does not occur when the cues are correlated to a response on the basis of one perceptual dimension (e.g., color) and the target's response is defined on the basis of another dimension (e.g., orientation). These studies suggest that perceptual dimensions constrain response selection.

(494)

The Simon Effect: Location Coding With Respect to a Referent? ROBERT W. PROCTOR \& CHEN-HUI LU, Purdue University-The Simon effect has been attributed to location coding with respect to a referent. Contrary to that account, the Simon effect was shown to be larger without a fixation point than with one. Moreover, a referent stimulus did not increase the magnitude of the Simon effect when presented in the absence of a fixation point, and the Simon effect was eliminated when the referent and target were in different colors.

(495)

Mechanisms of Spatial Attention: Altitudinal "Neglect" in the Normal Brain. MAXWELL DRAIN \& PATRICIA A. REUTERLORENZ, University of Michigan (presented by Patricia A. ReuterLorenz)-The existence of an upward attentional bias in normal subjects is established and related to the occurrence of altitudinal neglect in brain-damaged patients. A hemispheric component of vertical orienting is indicated by evidence for a strong upward bias in the RVF and an absence of bias in the LVF. Possible constrains imposed by perceptual and representational factors are also examined. These findings are considered in terms of the hemispheric control of visual-spatial attention. (496)

Subjective Randomness Effects in a Visual Task. KENNETH M. STEELE \& SHAY R. BOYD, Appalachian State University-People have difficulty generating random sequences of numbers. Mathematicallyappropriate repetitive runs are generated too infrequently. This finding may reflect difficulties with the task or accurately indicate that subjective randomness is a centered or balanced blend of alternatives. We examined whether this balanced blend effect would occur in a simple visual task. Subjects were given paper circles and asked to place marks following different types of instructions. The results supported the balanced blend hypothesis.

\section{(497)}

Assessing Diagnosticity: Implications for Judgments Involving Base Rates. SANDRA L. SCHNEIDER \& CAROL L. FISHBACK, University of South Florida-This study examines the contribution of base rate and diagnostic information to familiar predictive judgments. Subjects $(n=100)$ estimated the probability that handwriting samples, independently classified by diagnosticity, were written by females or males. Results revealed minimal use of base rates, but strong reliance on diagnosticity. Nevertheless, estimates of diagnosticity were generally conservative, especially with highly diagnostic samples. Subjects' ability to make accurate judgments depends on how well they assess diagnosticity-an ability too often ignored. 
(498)

Inattention to Data Relevant to Alternative Hypotheses. RANDALL S. CHADWICK \& MICHAEL E. DOHERTY, Bowling Green State University (presented by Michael E. Doherty)-We gave subjects three Bayesian information selection tasks in a Latin Square design (1) a 'pseudodiagnosticity' task, (2) one patterned after Skov and Sherman (1986), and (3) a mixed task for which half the $P(D \mid H)-P(D \mid \sim H)$ pairs were non-diagnostic. Most subjects failed to select $P(D \mid \sim H)$ values in both the pseudodiagnosticity and mixed tasks, while selecting normatively in the Skov \& Sherman task. Subjects' strategies persisted for all tasks. This shows that subjects' understanding of diagnosticity is, at best, superficial.

\section{(499)}

Dynamic Choice Behavior: Measurement-Free Tests of Luce's Choice Model. IN JAE MYUNG \& PAMELA TAYLOR, Ohio State University-Subjects were asked to make a choice among a set of alternatives repeatedly over a series of learning trials with probabilistic feedback. A factorial manipulation of the number of alternatives and outcome probabilities enabled to test the Luce's choice rule (1963) and simple scalability without having to measure utilities of alternatives. The results showed that simple scalability held reasonably well but the choice rule was clearly violated.

Decision Processes of Physicians' Reporting Cause of Death. DAVID J. MINGAY, University of Chicago, ALBERT F. SMITH, SUNY at Binghamton, JAMES A. WEED, \& JARED B. JOBE, $\mathrm{Na}$ tional Center for Health Statistics-Physicians completed a death certificate based on a case vignette with a cause-of-death section formatted in one of three ways. The underlying cause-of-death was reported equally well on a certificate with the standard causal sequence and one with the causal sequence reversed, and significantly less well on an "underlying cause only" certificate. Results will be discussed in terms of physicians' decisional processes and implications for redesigning the death certificate.

\section{(501)}

Decision Field Theory of Decision Trees. JEROME BUSEMEYER \& BO JIANG, Purdue University-Literature on dynamic decision theory is mostly limited to prescriptive theories (dynamic programming, optimal control). Little is known about how individuals make decisions involving multiple action-event sequences. The purpose of this paper is to present a cognitive theory of decision making for decision trees. Experimental evidence for violations of dynamic programming assumptions (dynamic consistency, principle of optimality) will be presented.

(502)

Poor Statistical Reasoning: Do Forecasts Simulate Noise as Well as Patterns in Data? NIGEL HARVEY, University College, LondonPeople saw 58-point time-series formed by adding noise to sine waves. For each series, they had to forecast the next six points and then draw a best-fitting line through all 64 points. Only four out of twenty subjects thought that their forecasts should be closer than the original data to this line. We also compared differences between responses and optimal forecasts with those obtained when series had to be simulated rather than forecast.

Transfer of Inhibition in Human Contingency Learning. DOUGLAS A. WILLIAMS, University of Winnipeg-Conditions that embue predictive cues with generic inhibitory properties were explored in human contingency learning. An inhibitor trained to suppress responding to a single excitor did not have the generalized ability to suppress other separately established excitors. Successful transfer of inhibition required multiple exemplars of the inhibitory properties of the cue in two different excitatory contexts. Results implicate two forms of inhibition, compound-specific and general, which are analogous to those seen in animal learning.

\section{(504)}

Memory and Decisions: Explanations or Availability? MICHAEL B. WOLFE \& NANCY PENNINGTON, University of Colorado (presented by Nancy Pennington)-Two experiments examine the relationship between memory and decisions, comparing explanation-based and availability accounts. In Experiment 1, when an explanation of events was easy to construct, decisions moved in the predicted direction, but availability of evidence was also increased. In Experiment 2, decision effects were still obtained in the direction of the easy-to-construct explanation, even when availability of evidence was controlled. Thus availability is ruled out as an account for decision effects in these experiments. (505)

Connectionist Modeling of Learning in a Probabilistic (Decision Making) Environment. STEPHEN E. EDGELL, ROBERT M. ROE, \& JACEK M. ZURADA, University of Louisville-The connectionist models of Gluck and Bower were tested against several results from nonmetric multiple-cue probability learning studies (e.g., the effect of irrelevant information, relevant configural information, etc.). Both the additive and configural-cue models were tested. Similar models using the delta learning rule (rather than the LMS rule) and the new lambda learning rule were also tested as were back-propagation models. The results were mixed, with several shortcomings with models of this class found.

\section{(506)}

Process Dissociation of Conformity: Separating Perceptual From Social Influence. HUNTER G. HOFFMAN, LARRY L. JACOBY, \& DAN J. BOSNYAK, McMaster University-We conceptualized conformity as a Stroop-like conflict. Jacoby's (1991) "process dissociation" procedure was used to separate the two competing sources of influence on an Asch-type conformity task: reliance on the stimulus (discriminating loudness) and social influence. We found (1) Instructions to "ignore the confederate" reduced conformity, leaving subjects' reliance on loudness invariant. (2) Increasing stimulus ambiguity decreased reliance on loudness, leaving conformity invariant. (3) The latter manipulation also produced a dissociation on an auditory Stroop task.

(507)

Further Evidence for Sublexical Components in Implicit Memory for Novel Words. JENNIFER DORFMAN, University of Arizona-In a previous study, I showed that priming in a word-judgment task occurs for nonwords formed out of morphemic and syllabic components but not unfamiliar "pseudosyllabic" components. The present study replicates this general effect using a perceptual identification paradigm. The results are interpreted in terms of the activation and integration of prior linguistic knowledge and as evidence against the role of new (e.g., perceptual) representations in implicit memory for novel information.

(508)

Implicit and Explicit Memory for Compound Words. MARK TIPPENS REINITZ \& JONATHAN B. DEMB, Boston University-Subjects studied visually-presented compound words (e.g., "TOOTHPASTE," 'HEARTACHE') and then received perceptual identification and recognition tests that contained old, recombined (e.g., "TOOTHACHE"), and partially and completely new words. False recognitions increased with increasing number of previously studied components; however, priming in perceptual identification occurred only for old words. Explicit, but not implicit, memories for compound words are composed of parts that roughly correspond to single component words.

\section{(509)}

The Need to Discriminate Between Traces Causes Interference in Recognixing Pictures. C. C. CHANDLER, Washington State University-Memory for target pictures (e.g., Fern A) was tested using a forcedchoice recognition test (Fern A vs. Fern C). Studying a related picture (Fern B) reduced accuracy. However, the related picture did not interfere when it was shown during the test. These results suggest that Fern B did not interfere by blocking access to the target (Fern A). Instead, interference occurred when the subject had to discriminate between two long-term memory traces.

\section{(510)}

Visual Retrieval Cues Can Cause Release From Verbal Overshadowing. MARIA A. BRANDIMONTE, University of Trieste, JONATHAN W. SCHOOLER, University of Pittsburgh, \& PATRIZIA GABBINO, University of Trieste (sponsored by Jonathan W. Schooler)Two experiments showed that spontaneous and/or induced verbal over- 
shadowing of visual memories can be eliminated by using a visual retrieval cue (color) which was encoded at the time of initial learning. This effect, which we termed "release from verbal overshadowing," demonstrates that visual information which has undergone verbal recoding at the time of input is simply "inaccessible," not definitively "lost." (511)

Selective Interference With Short-Term Memory for Digits and Spatial Locations. JOEL MYERSON, SOO HYUN RHEE, SANDRA HALE, \& RICHARD A. ABRAMS, Washington University-Subjects performed several working memory tasks including interference conditions that avoided the confounds of dual-task paradigms. Results supported the existence of separate slave systems in working memory. Digit span was impaired when subjects named each digit's color aloud, but was unaffected when subjects indicated color by pointing. The reverse pattern was obtained for spatial span. The nature of the spatial refresh process was examined, and results failed to support a role for image generation.

Implicating Arousal in Memory for Humorous Material. STEPHEN R. SCHMIDT \& ALAN R. WILLIAMS, Middle Tennessee State University-Heart rate was monitored while subjects viewed three versions of Far Side cartoons: original humorous, bizarre nonhumorous, and literal non-humorous. Relative to literal cartoons, both the bizarre and humorous cartoons elicited heart rate deceleration indicative of increased attention. However, after 15-20 sec, the humorous cartoons produced heart rate acceleration, indicative of autonomic arousal. The humorous versions were remembered better than the bizarre and literal versions, linking heart rate acceleration to enhanced memory.

The Concurrent Encoding of Object-Based and View-Based Object Representations. MICHAEL J. TARR \& MAREK C. CHAWARSKI, Yale University-What kinds of information do perceivers learn about unfamiliar objects during recognition? We have investigated the possibility that objects are routinely encoded in two distinct formats: one object-based (e.g., an orientation-independent structural description); and, one view-based (e.g., a viewpoint-dependent image-like representation). Our results indicate that perceivers concurrently encode both types of object representations and then use each according to task demands. Such findings suggest that there is no single "default" recognition mechanism.

\section{(514)}

Effects of Familiarity on Young and Old Working Memory Span. MARILYN L. TURNER \& JULIE K. GILPIN, Wichita State University-We propose working memory (WM) and short term memory (STM) spans predict verbal and spatial ability in the elderly whether items are familiar or unfamiliar. Further, familiarity affects age-related differences in spatial but not verbal spans. We review results of an experiment in which elderly span scores were related to reading comprehension and spatial orientation scores regardless of familiarity. Conversely, familiarity affected the relationship between STM (but not WM) young span and ability scores.

Autobiographical Memory and Aging: Effectiveness of Year- and Event-Based Retrieval. LESLIE J. CAPLAN, PAULA DARBY LIPMAN, \& CARMI SCHOOLER, National Institute of Mental HealthOlder (mean age $=71.7$ years) and middle-aged (mean age $=55.8$ years) adults recalled and dated autobiographical events. Two types of retrieval cues were used: year and type of event (e.g., births, illnesses). Older adults' recall was more accurate when retrieval was based on event type. Middle-aged adults' recall accuracy did not depend on retrieval condition.

\section{(516)}

Memories and False Memories of Childhood Experiences. IRA E. HYMAN, JR., F. JAMES BILLINGS, SUSAN G. HUSBAND, TROY H. HUSBAND, \& DONALD B. SMITH, Western Washington University - We investigated if individuals will create memories in response to interview demands. Parents of college students were surveyed regarding events that happened when the students were children. The students were questioned about these events and one false event. In study one, students were interviewed once and in study two, twice. Some students created memories when given false event cues. Study two indicated that actual and created memories may become more detailed with repeated interviews.

Impaired Implicit Sequence Learning With an Incompatible Stimulus-Response Mapping. DANIEL B. WILLINGHAM, University of Virginia-Huntington's patients show impaired implicit sequence learning, which has been interpreted as evidence for a striatal role in such learning. But attentional distraction impairs implicit sequence learning in controls, and simply producing a response may be very attentiondemanding for Huntington's patients. Here, we made it attentiondemanding for controls to produce a response by making the stimulusresponse mapping incompatible. Subjects showed no implicit sequence learning, leaving open an attentional account for Huntington's patients learning deficit.

Remembering and Knowing in Amnesia. BARBARA J. KNOWLTON \& LARRY R. SQUIRE, VAMC and University of California, San Diego-Amnesic patients and control subjects took a recognition test $\mathbf{1 0}$ min after learning and indicated for each recognized word whether they specifically "remembered" it, or whether they "knew" the word was presented but did not recollect anything specific about it. Amnesic patients were significantly impaired on both types of judgment, and their performance resembled that of control subjects tested after a 1-wk delay. Both "Know" and "Remember" responses depend on brain structures damaged in amnesia.

(519)

Effects of Information Format on Learning and Reporting Navigational Routes. CAROLYN BACKER CAVE, Vanderbilt University-Four experiments explored how subjects learn and report navigational routes. First, learning from maps was more accurate than from a written description or a series of slides. Second, pictorial (analog) presentation of landmarks produced faster learning than verbal (symbolic) presentation, while presentation format made little difference in how quickly turns were learned. Third, subjects' reports that included maps were slightly more accurate.

Conscious Recollection During Implicit Memory Testing, and Concomitant Brain Electrical Activity. KEN A. PALLER, Lawrence Berkeley Laboratory, MARTA KUTAS, \& HEATHER McISAAC, University of California, San Diego-In a series of experiments, implicit memory tests were given while event-related brain potentials were recorded from the scalp. Potentials differed reliably as a function of prior study conditions designed to influence recollection and priming differentially. These results suggest that: (a) subjects engaged in recollection during the implicit memory tests, even though not instructed to do so, and (b) the electrophysiological differences reflect processes underlying the two different types of memory phenomena.

(521)

Cue Construction and Speed-Accuracy Tradeoffs in Recognition Memory. NEIL MULLIGAN \& ELLIOT HIRSHMAN, University of North Carolina at Chapel Hill (presented by Elliot Hirshman)-We examine the effects of Modality-match and Levels-of-processing (LOP) using the response signal paradigm. The results demonstrated that Modality-match affected the point at which performance first rose above chance (the intercept), but not the asymptotic level of performance. The LOP variable affected both intercept and asymptote. The dual-process model of recognition memory cannot account for these results. An alternative explanation, emphasizing the role of cue construction processes in global matching models, is proposed.

(522)

Depressive Deficits in Recollective Components of Recognition. PAULA T. HERTEL, STEPHANIE MILAN, BRIAN J. LYMAN, Trinity University, \& CLARK D. TERRELL, University of Texas Health Science Center at San Antonio-Depressed and nondepressed subjects participated in an experiment designed to separate automatic and controlled components of recognition (Jacoby, 1991). First, they judged 
the relation of target words to paired words. Later, targets were either presented alone at test or with the paired word. In the absence of differences in hits and false alarms, the process-dissociation procedure revealed a depressive deficit in recollection, but not familiarity. Independently, the paired test improved recollection without increasing familiarity.

(523)

Immediate Serial Recall of Static Facial Emotional Expressions. MARIE POIRIER, ERIC GIRARD, ARVID KAPPAS, \& GILLES KIROUAC, Laval University-Two experiments studied the immediate serial recall of 6 static emotional facial expressions, subjects responding with cards reproducing presented expressions. Presentation and recall either involved the same person or they did not. The effect or articulatory suppression is examined. Results show serial position curves and performance levels close to those observed with verbal material. Confusion errors were higher for fear-surprise and disgust-anger pairs. The role of working memory in processing facial configurations is discussed.

(524)

Retrieval Time of Memory for Spatial Location. CHRISTOPHER CARSWELL \& JODIE M. PLUMERT, University of Iowa (presented by Jodie M. Plumert)-Two experiments further examined the processes underlying comprehension of spatial descriptions. Subjects learned object locations and then performed a sentence verification task. Experiment 1 showed that locations were verified faster when described using lower (e.g., "the book is in the bag") than higher levels (e.g., "the book is on the second floor") of the spatial hierarchy. Experiment 2 showed that this advantage was unrelated to possible problems with encoding higher levels of spatial hierarchies.

(525)

Individual Difference in Working Memory Capecity and Retrieval. RANDALL ENGLE \& ANDREW CONWAY, University of South Carolina-Retrieval of a fact from long-term memory can be thought of as activation of the set containing the fact, followed by search of the active set. Four studies showed that: (1) time to activate the set is independent of its size, (2) working memory capacity has no effect on the retrieval time from LTM, (3) WM capacity does have an effect on the time to search the active set, but, (4) only under interference conditions. (526)

Evoked Potentials During Spatial and Object Recognition Memory. RICHARD M. VARDARIS \& ANNA A. IBATOULLINA, Kent State University-Subjects were asked to remember objects and their locations in a 4 by 4 spatial matrix. Evoked potential (EP) responses were recorded during four types of recognition memory trials: same object, same place; different object, same place; same object, different place; different object, different place. The scalp distribution of the EP data suggests that spatial and object memory may involve anatomically and functionally distinct neural systems. Implications of these findings for current theories of memory are considered.

\section{(527)}

The Representation of Rotated Objects in Memory. KAVITHA SRINIVAS, Boston College-The effect of rotating familiar and novel objects in depth was compared on priming, short-term, and long-term recognition. Short-term recognition appeared to be mediated by partbased viewpoint invariant descriptions of objects. However, the representations mediating priming and long-term recognition seemed more sensitive to viewpoint. These results suggest that multiple views of objects must be experienced in succession in order to establish viewpointinvariant structural descriptions.

Cross Format Priming: Transfer Appropriate Aging. LAURA STEEN-PATTERSON, Southern Methodist University, TODD C. JONES, Rice University, ALAN S. BROWN, \& DAVID B. MITCHELL, Southern Methodist University (presented by David B. Mitchell)Young and older adults (mean ages 19 and 74) named either words or pictures at study. At test, subjects named either pictures identical to studied pictures or pictures whose names matched the studied words. Replicating our earlier work, young subjects manifested equivalent priming from words and pictures. Older adults, however, revealed transfer appropriate processing: words produced less priming than pictures. There was an age difference in word-to-picture priming, but not in picture-topicture priming.

On Priming Flankers in a Lexical Decision Task. COLIN $M$. MACLEOD \& STUART C. GRANT, University of Toronto, Scarborough Campus-Three experiments investigated the effect of priming irrelevant flanker words on lexical decision to target words. Studied words, unstudied words, nonwords, and control strings (xxxxx) served as flankers. Compared with other types of flankers, words interfered with target processing more. Yet despite target word performance being facilitated by prior study, the studied/unstudied status of the flanker word did not affect target processing. Priming appears to have minimal impact when it applies to response-irrelevant information.

(530)

Priming for Words is Mediated by Abstract Visual Representations. JEFFREY S. BOWERS, Centre Hospitalier Cote-Des-NeigesRobust priming is reported between upper and lower case words that share few if any visual features in common, e.g., "GANG"/ "gang" (the letters " $G$ "/ /g," " A"/"a," "N"/" n" are dissimilar). However, priming for the same words is weak following a study/test modality shift. The combination of abstract and modality specific priming is problematic for a number of accounts of priming, and supports the view that priming reflects the modification of abstract orthographic representations.

(531)

The Influence of Multiple Primes: Three Experiments, Two Primes, One Outcome. DAVID A. BALOTA \& STEPHEN T. PAUL, Washington University-Three experiments are reported that address the combinatorial influence of two semantically/associatively related primes on target lexical decision and naming performance. In the doublerelated condition, both primes were related to the target but were unrelated to each other. Comparisons of priming effects for homographic targets (e.g., PIANO-HEART-ORGAN) and non-homographic targets (e.g., LION-STRIPES-TIGER) suggest that the combinatorial influence of multiple related primes was at the lexical level and not at the semantic level.

Repetition Blindness: The Role of Frequency, Task Information, Neighborhood Frequency, and Prime Duration. MANUEL PEREA \& SALVADOR ALGARABEL, University of Valencia (presented by Salvador Algarabel)-Three experiments on repetition blindness were performed using a prime-target-mask procedure (Hochhaus \& Marohn, 1991). In Experiment 1, we found stronger repetition blindness effects in high rather than in low-frequency words. In Experiment 2, when subjects were told that repeated pairs could appear, only high-frequency words showed repetition blindness effects. Moreover, unrelated primes inhibited target processing compared to neutral primes. In Experiment 3 , prime duration ( 250 or $500 \mathrm{~ms}$ ) did not affect the repetition blindness effect. Neighborhood frequency effects were also found.

(533)

Auditory Morphological Priming for English Derived Words. WILLIAM MARSLEN-WILSON \& XIAOLIN ZHOU, University of London (presented by Xiaolin Zhou; sponsored by William MarslenWilson)-In a set of auditory-auditory priming lexical decision experiments, we investigated the role of morphological structure in lexical representation and processing for English derived words. The data are discussed in terms of a model of lexical representation which includes abstractness of phonological representations and morphological structure (stem +affix) with competition between suffixes.

(534)

Semantic Blindness: Repeated Concepts are Difficult to Encode in Bilingual RSVP. DONALD G. MACKAY, MICHELLE D. MILLER, \& LISE ABRAMS, UCLA-This experiment demonstrates semantic blindness, an inhibitory effect of concept repetition predicted for recall of RSVP sentences. Proficient bilinguals read mixed, SpanishEnglish sentences containing target and pretarget words that were either identical (e.g., like-like), semantically identical across languages (e.g., gusta-like), or completely different (e.g., read-like). Inhibitory effects 
of repetition were equivalent in the identical and semantically identical conditions, i.e., repetition blindness occurred at purely semantic rather than orthographic or phonological levels.

Variations in Repetition Priming Effects With Language/Learning Disabled Children. JOSEPH F. BROWN \& THOMAS C. LORSBACH, University of Nebraska at Omaha (presented by Thomas C. Lorsbach)Two experiments examined the possibility that individual differences influence the extent to which changes in surface form affect repetition priming. Language/learning disabled (L/LD) and nonlearning disabled (NLD) children participated in two repetition priming experiments. For word targets, variation in surface form (upper vs. lower case) reduced repetition priming benefits more for $\mathrm{L} / \mathrm{LD}$ than NLD children. For picture targets, surface form (spoken vs. picture primes) had the same effect for both groups.

\section{(536)}

Event-Related Brain Potential Evidence for Message-Level Priming in Sentences. GARY E. RANEY, University of Massachusetts, \& IRA FISCHLER, University of Florida-The N400 component of the ERP was used to measure priming for the final word in sentences that ended with phrases such as " . . . the barber trimmed the moustache." Phrases were preceded by contexts that were consistent with (e.g., "The tailor talked while ...") or changed the meaning of the phrases (e.g., "The tailor who talked to ..."). Priming was largest when the meaning of the contexts and final phrases were consistent, suggesting that priming was determined by "message-level" comprehension.

Can Repetition Blindness (RB) Occur at a Conceptual Level? JEANETTE ALTARRIBA, WENDY J. FORSYTHE, \& EMILY G. SOLTANO, SUNY at Albany-RB is the inability to recall a repeated word in a rapid serial visual presentation. Researchers have concluded that RB is not occurring at a conceptual level, rather it occurs for any pairs with orthographic identity. Using a bilingual framework, we created the situation in which a repeated word was identical in meaning by using a word and its translation. Spanish-English bilinguals recalled sentences in which the language of the repeated word was switched. Results are discussed in terms of a type-token distinction (Kanwisher, 1987).

(538)

Making Normals Dyslexic: A Part-of-Speech Effect When Reading Briefly Presented Words. M. BEEMAN, Rush-PresbyterianSt. Luke's Medical Center, R. B. FRIEDMAN, J. GRAFMAN, \& B. KWABENAH, NINDS/National Institutes of Health-Following brain damage, some dyslexic patients have more difficulty reading functor words-articles, prepositions, pronouns, and connectives-than reading nouns. This part-of-speech (POS) effect is often thought to reflect selective damage to brain areas representing subparts of the mental lexicon. However, our normal subjects showed a strong POS effect when brief presentations limited them to $50 \%$ reading accuracy. This suggests that POS is confounded with other variables that modulate the intrinsic readability of words.

\section{(539)}

The Word-Superiority Effect in Acquired Dyslexia. NANCY HILDEBRANDT \& DAVID CAPLAN, Massachusetts General Hospital-If the word-superiority effect is word-specific (Hayman \& Jacoby 1989), then acquired dyslexic subjects should show normal effects on the Reicher-Wheeler task if they can access visual word form. However, $0 / 12$ dyslexic subjects showed normal Reicher-Wheeler effects. Correlations showed that an advantage emerged for words as exposure durations got shorter, as naming improved, and as accuracy increased in lexical decision. The results support the notion that the word-superiority effect is word-specific.

Impaired Oral Reading in Surface Dyslexia: Detailed Comparison of a Patient and a Connectionist Model. DAVID C. PLAUT, MARLENE BEHRMANN, Carnegie-Mellon University, KARALYN E. PATTERSON, MRC Applied Psychology Unit, \& JAMES L. MCCLELLAND, Carnegie-Mellon University-Mapping between orthography and phonology in the absence of semantics is investigated in a surface dyslexic patient, MP, and in a connectionist model. Both were tested on about 2500 monosyllabic words from the Seidenberg and McClelland corpus. We examined detailed effects of word frequency and spelling-sound consistency on naming accuracy and latency. We also performed an error analysis. While the general agreement in performance is encouraging, specific discrepancies suggest possible improvements of the model.

\section{(541)}

Nonword Pronunciation and Models of Visual Word Recognition. DAVID C. PLAUT, Carnegie-Mellon University, MARK S. SEIDENBERG, University of Southern California, JAMES L. McCLELLAND, Carnegie-Mellon University, \& KEN MCRAE, University of Western Ontario (presented by Mark S. Seidenberg)-Coltheart et al. (Psych. Rev., in press) argue that skilled nonword pronunciation requires the use of pronunciation rules and that connectionist models cannot perform as well as people because they do not incorporate such rules. We assess the performance of a connectionist model of pronunciation and Coltheart et al.'s model, using a corpus of pronunciations given by 24 subjects to nearly 600 nonwords. Both models generate plausible nonword pronunciations, but they differ in terms of specific predictions about performance.

The Effect of Hyphenation on Eye Fixation. RUDOLF GRONER, SALOME BURRI, University of Bern, \& PETER U. MÜLLER, University of Alberta-At the end of a line the last fixation tends to be shorter, while the first fixation on the following line becomes longer. Some experiments investigated the effect of end-of-line hyphenation. It was tested whether (1) disruption increases processing time at the end of the line and at the beginning of the next line, or (2) postponement of processing until the whole word is seen decreases the last fixation and increases the next fixation.

Representing Words in Connectionist Networks. DAPHNE BAVELIER, Salk Institute, \& MICHAEL I. JORDAN, MIT (presented by Michael I. Jordan)-We describe a new approach to the representation of written and spoken words in connectionist networks. This approach is based on dynamic time warping and multidimensional scaling, and allows words of different length to be represented by fixed-length vectors. We show that the representation naturally captures several factors that are known to be important in human judgments of inter-word similarity. We also argue that the approach avoids some of the ad-hoc nature of earlier connectionist word representations.

(544)

Timecourse of Lexicalization in Language Production. ROBERT R. PETERSON, MINSU SHIM, \& PAMELA SAVOY, Indiana University-Subjects named pictures that had two synonymous names (e.g., $\mathrm{COUCH} /$ SOFA). Occasionally, prior to a response, a target word was presented, which was phonologically related to one of the names (e.g., COUNT, SODA) or was unrelated. Subjects had to name the target. At short picture/target SOAs, priming occurred for both related targets. At longer SOAs, priming occurred only for the more common name. Thus, production involves early phonological activation of multiple lexical candidates

(545)

Parafoveal Effects on Syntactic Ambiguity Resolution: Evidence From Preposition Length. CURT BURGESS, University of California, Riverside, MIRIAM HOFFMAN, Stanford University, MICHAEL K. TANENHAUS, University of Rochester, \& KEVIN LUND, University of California, Riverside-Reduced relative clauses with noun phrases semantically biased against a main clause but favoring a relative clause (e.g., The portrait sketched) were read as quickly as unambiguous full relatives when the verb was followed by a short potentially disambiguating preposition. However, gardenpaths occurred when the prepositions were long. The results are consistent with Burgess et al.'s recent simulation results and they demonstrate the conjoint influence of verb-form, semantic constraint and parafoveal information in the parsing process.

\section{(546)}

Lexical Priming in American Sign Language. DAVID P. CORINA University of Southern California, \& KAREN EMMOREY, Salk 
Institute-Research on word recognition has led to detailed models of lexical representation and processing. However, the majority of studies focus solely on spoken languages thus limiting their generality. We present data from lexical decision experiments investigating structural properties of a visual language, American Sign Language. A video based priming paradigm explores semantic, morphological and phonological priming in ASL. Subjects include native and late learners of sign language. Implications for modality-free lexical representations are discussed. (547)

The Selective Loss of Concrete Words: A Case Study. SARAH D. BREEDIN, ELEANOR M. SAFFRAN, Temple University, \& H. BRANCH COSLETT, Temple University School of Medicine-It is a well-established finding that people are better at identifying and remembering concrete words than abstract words. The effect of brain damage is generally to exacerbate this pattern. We present a patient with dementia who shows the opposite pattern, that is, superior performance with abstract concepts than concrete concepts on a wide range of tasks. The implications of this pattern of performance for theories of semantic representation will be discussed.

Syntactic Strategies in Parsing Repairs. BEVERLY COLWELL ADAMS, University of Virginia, CHARLES E. CLIFTON, JR., \& KEITH RAYNER, University of Massachusetts-As there may be specific parsing strategies for making initial syntactic attachments, this study examined parsing "repair" strategies. Subjects read syntactically ambiguous sentences that differed relative to the repair site for attachment of a prepositional phrase, while their eye movements were observed. We argue that there is a hierarchical arrangement of repair strategies proceeding from the least intrusive to the most devastating.

(549)

Probing Questions. RICHARD M. ROBERTS \& DOUGLAS HERRMANN, National Center for Health Statistics-The Questionnaire Design and Research Laboratory at the National Center for Health Statistics was established to develop and test survey questions. The "goodness" of these questions is evaluated through cognitive interviews that focus on the thought processes of the respondents. We report a taxonomy of the probe questions that interviewers ask to examine these thought processes. The probe questions were rated in terms of their efficacy, and these results are discussed.

\section{(550)}

Testing the WHEN Model for Answering "When" Questions About Future Events. JONATHAN M. GOLDING, University of Kentucky, JOSEPH P. MAGLIANO, WILLIAM B. BAGGETT, \& ARTHUR C. GRAESSER, Memphis State University - This study investigated WHEN, a production rule based model that describes how answers to "when" questions are expressed. The model predicts the correct grain size and level of accuracy of an answer as a function of the interval between the present point in time and the time of the queried event (e.g., 7 days). The results from three experiments found that subject-generated answers were robustly predicted by WHEN at various intervals.

Metaphors in the Mind Are Hard to Find. MATTHEW McGLONE, SAM GLUCKSBERG, \& DEANNA MANFREDI, Princeton University (presented by Sam Glucksberg)-To what extent are conversational metaphors based upon basic conceptual metaphors? We compare two accounts of metaphor understanding, Lakoff's conceptual metaphor account, and our attributive category model. Two studies, one employing a comprehension priming paradigm and the other cued recall, provided clear results supporting our attributive category model. We conclude that conceptual metaphors are not only unnecessary for comprehension, but are also potentially misleading as explanatory constructs of metaphor processing.

Mixing Metaphor With Other Figures of Speech. RICHARD M. ROBERTS, National Center for Health Statistics, \& ROGER J. KREUZ, Memphis State University (presented by Roger J. Kreuz)-Eight kinds of nonliteral language (hyperbole, idiom, indirect requests, irony, metaphor, rhetorical questions, simile, and understatement) were deleted from a story, and subjects were asked to provide replacements. Subjects also provided difficulty and naturalness ratings. Nonliteral language deleted from the story's beginning and end was the most difficult for subjects to replace. Subjects also combined certain figures but not others. These results are discussed in terms of how context constrains the use of nonliteral language.

Definite Reference and Mutual Ignorance. BOAZ KEYSAR \& TIMOTHY S. PAEK, University of Chicago-When do listeners use information about the speaker's knowledge? Listeners received information they knew the speaker did not have (= privileged information). They then verified the speaker's descriptions of mutually known objects. Privileged information slowed verification of definite references ("the vegetable") but not indefinite references, suggesting that listeners process both referents that are known and unknown to speakers and only later consider mutual knowledge. This has implications for Relevance theory and theories of mutual knowledge.

(554)

Purpose and Importance Influence Reading Rates and Recall of Procedural Texts. VIRGINIA A. DIEHL, Western Illinois University, CAROL BERGFELD MILLS, Goucher College, \& DEBORAH P. BIRKMIRE, U.S. Army Human Engineering Laboratory-The effect of purpose for reading (to Do vs. to Recall) on recall and reading rate was investigated using two very different procedural texts (story-like vs. a series of steps). Purpose interacted with the importance of the sentence information (high vs. low) to task performance and with text for both the recall and reading rate measures; these measures varied more across levels of importance under the Read-to-Do condition, especially for the story-like procedure.

\section{(555)}

Logical Connectives and Narrative Text: The Effects of "Incorrect" Connectives. JOHN D. MURRAY, Georgia Southern University-This study examined the possible liability associated with "incorrect" connective usage. Subjects were timed in reading narrative sentence pairs conveying additive, causal, or adversative relations. Items varied with respect to the presence/absence of an incorrect connective (e.g., "but" appearing between two causally related sentences). Longer RTs were associated with the erroneous presence of additive and adversative but not causal connectives. Findings are interpreted in light of a recent model of connective processing.

\section{(556)}

Object-Initiating Verbs Affect Their Arguments' Accessibilities. STEVEN B. GREENE, Princeton University, \& GAIL McKOON, Northwestern University-Verbs that exhibit "implicit causality" can be classified by whether their grammatical subject or object initiates the interaction. As measured in an on-line recognition task, objects become relatively more accessible following object-initiating verbs, but no change in relative accessibility occurs following subject-initiating verbs. Whether a derived adjective applies to the verb's subject or object has an effect on causal ratings, but it does not predict the on-line data.

(557)

Why Do We Use Metaphor in Describing People? CRISTINA CACCIARI, University of Bologna-Traditionally, literal language has been considered fundamental to other forms of meaning. If so, why do we speak metaphorically instead of using plain literal language? Two experiments investigated the use of literal and metaphorical expressions in describing people in and out of context. Results show that metaphorical descriptions are generally preferred to literal ones especially because they provide a more compact way of predicating a set of properties. (558)

Of Metaphors and Associations. L. LYNN LESUEUR, Massachusetts General Hospital and Harvard University-Most models of metaphor comprehension assume associations between subject and predicate pre-exist metaphorical relations. To test the alternative notion that metaphors can create associations, response times to subjects of metaphorical and nonmetaphorical statements were compared when primed by one of three terms: The statements' predicates, their metaphorical "grounds," or neutral controls. Results challenge existing models, and offer implications for the role of metaphor in the development of language, categories, and conceptual structures. 


\section{(559)}

Evaluating the Inverted-U Model of Déjà Connu Experiences in Impression Formation. ROBERT J. PELLEGRINI, RANDY $\mathrm{T}$. CALDWELL, San Jose State University, \& ROBERT J. PELLEGRINI, JR., West Valley College-Data from interviews with $N=250$ respondents ( $n=125$ women, $n=125$ men) validated a previously postulated heuristic model of the relationship between acquaintance with an individual, and the likelihood of encountering others who remind one of him/her. Significant differences, as established in Chi Squared analyses, provided further support for the universality of déjà connu experiences, and the hypothesis that remembered others in such instances are most typically people whom the perceiver describes as "friends" as opposed to "very close friends," family members, or public persons not known personally to him/her.

\section{(560)}

Stereotypes Represent Overestimations of Gender Differences: Diagnostic and Criterion Ratios. BEM P. ALLEN, Western Illinois University-Men and women estimated the percentages of men and women who show each of 40 traits and indicated whether or not they possessed the traits. Diagnostic ratios were formed from the former and criterion ratios from the latter. As in Martin (1987; JPSP, \#3), results revealed that gender differences were more extreme in stereotypes (diagnostic) than in reality (criterion). It is concluded that people's perceptions of gender differences overestimate actual gender differences.

(561)

Linguistic Determinants of Social Judgment. DIANE S. BERRY, JENNIFER MUELLER, WENDY HILLER, \& JAMES W. PENNEBAKER, Southern Methodist University-Eighty stimulus persons were videotaped while participating in 2-3 minute interactions. Word contents of the interactions were subjected to a comprehensive text analysis program (Linguistic Inquiry and Word Counts; Pennebaker, in press). Relations among various language categories (e.g., positive emotion terms; negative emotion terms; use of causal reasoning), social perceptions (e.g., verbal and nonverbal expressiveness, personality impressions), and personality dimensions (e.g., emotionality, assertiveness) were revealed.

The Relation Between Anonymity and Aggressive Driving Behavior: A Field Study. PATRICIA A. ELLISON, JOHN M. GOVERN, HERBERT L. PETRI, \& MICHAEL H. FIGLER, Towson State University (presented by Michael $\mathrm{H}$. Figler)-A confederate driver pulled in front of individual convertibles and $4 \times 4 \mathrm{~s}$ with their tops up (anonymous condition) or tops down (identifiable condition), before an impending red light. Latency for each driver (subject) to honk, first honk duration, and the frequency of honks within a 12-s time period, once the light turned green, were recorded. Results showed that the anonymous condition produced a significantly higher frequency and a longer first honk duration than the identifiable condition.

(563)

Individual Differences in Early Visual Processing. BARBARA BURNS, CATHERINE GODLEWSKI, \& HOLLY IRWIN, University of Louisville-Despite decades of research on individual differences in "cognitive style," questions concerning the proper characterization, significance, and development of cognitive style remain unanswered. The present research examines individual differences in early visual processing in field-independent and field-dependent adults using a texture segregation task previously employed by T. C. Callaghan (1986; 1988; $1989 ; 1990 ; 1992)$. Results clearly supported Callaghan's previous findings of dimensional interactions in such "preattentive" tasks with the separable dimensions circle size and angle of radial line. The impact of cognitive style on this pattern of dimensional interaction was less clear and we are currently replicating this work with larger groups of subjects.

\section{(564)}

An Individual Difference Perspective Applied to Normative Associative Strength. ALAN W. STACY, University of Southern California, BARBARA C. LEIGH, \& KEN R. WEINGARDT, University of Washington-We examined the frequencies of free association responses of 1001 subjects to polysemous words, some of which had subdominant senses that were linked to behavioral habits (e.g., draft and alcohol use).
Results showed that some individual differences in habits significantly predicted responses for words linked to their respective habits. The potential effects of item presentation (grouped versus random), gender, age, ethnicity, and language background were controlled for in the analysis. Theoretical implications are discussed.

(565)

Ability-Related Differences in Cognitive Speed: Evidence for Global Processing-Time Coefficients. SANDRA HALE \& JOEL MYERSON, Washington University-Subjects performed two batteries of four information-processing tasks each, and were divided into slow and fast processors based on overall mean RTs. In two replications, a single linear function accurately predicted the slow group's RTs on both batteries based on the fast group's RTs $\left(r^{2} s>.97\right)$. These results suggest that ability-related differences are like age-related differences, in that a single processing-time coefficient can accurately predict performance on diverse tasks.

\section{(566)}

Action-Perception Transfer in Motor Learning. HEIKO HECHT, NASA-Ames Research Center, NRC, STEFAN VOGT, \& WOLFGANG PRINZ, Max Planck Institute for Psychological Research, MunichThe learning of motor sequences may rely on common representational structures for visual and motor information (common coding). This commonality predicts two transfer-mechanisms: (1) Perceptual learning facilitating subsequent motor actions. (2) Motor-practice transferring to perceptual tasks. Evidence for both mechanisms was found. In particular, practicing timed arm movements-while blindfolded-enhanced subsequent perceptual performance. Kinesthetic feedback appears to contribute more to action-perception transfer than the intention to carry out the motion.

\section{(567)}

Time Sharing a Discrete Tracking Task and a Picture Classification Task. NANCY S. ANDERSON, BLAKE SOBILOFF, University of Maryland, \& DANIEL WALLACE, Vitro Corporation-Three studies evaluated time sharing performance on two tasks presented on a computer screen; a discrete tracking task and a picture categorization task. Timing variations in the picture identification task influenced decision times but not time-on-target scores. Same-different decision times were faster than categorizing times while tracking scores changed very little.

(568)

Mood-Dependent Performance of Planned Action Sequences. PATRICIA A. MULLINS \& MARTIN SAFER, Catholic University of America-Reaction time to begin typing a prespecified sequence of keystrokes varies with mood. Responding is faster in a happy mood and slower in a sad mood, when compared to a neutral condition. However, a sad mood slows responding for faster types of sequences more than sequences that are already slow. Similar effects are seen in keystroke durations and interstroke intervals. These findings are discussed in the context of claims that mood influences cognitive processing, in this case in movement execution.

(569)

Influence of Category Learning on Perceptual "Same/Different" Judgments. ROBERT GOLDSTONE, Indiana University-The influence of concept learning on perception was investigated. Subjects were first trained on one of two orthogonal categorization tasks. Subjects then made perceptual "same/different" judgments. Perceptual dimensions that were important for categorization became perceptually sensitized (relative to no-categorization controls) in all conditions. Irrelevant dimensions became perceptually desensitized in only one condition. The perceptual sensitization that occurs for a dimension value generalized to other values on the same dimension to a limited extent.

(570)

Instruction and Induction: Property Type and Instruction Level Effects. ELIZABETH F. SHIPLEY, University of PennsylvaniaPreschoolers were told properties of basic level categories (birds) or two subordinate categories (sandpipers and rails) followed by an induction task. Induction involved either "over-hypothesis" properties (types of properties provided during subordinate level instruction) or "isolated properties" (properties unrelated to instruction properties). Prior in- 
struction influenced Ss' inferences. For over-hypothesis properties, Ss with subordinate instruction limited inferences to members of subordinate categories more than $\mathrm{Ss}$ with basic level instruction.

(571)

Conceptual Representation Throughout the Continuum of Expertise. KATHY E. JOHNSON, Indiana University-Purdue University at Indianapolis, \& CAROLYN B. MERVIS, Emory University-The effects of varying levels of expertise on individuals' identification and representation of object categories were explored. Advanced and intermediate birdwatchers were systematically interviewed and given a triad task. Quantitative and qualitative differences were found between groups in individuals' representations of the relations among categories and in descriptions of canonical images. Support was provided for flexibility in the basic level of categorization and for the transfer of information from expert to related domains.

Selective Processing of Feature Conjunctions in Classification Learning. JUN SAIKI \& JOHN E. HUMMEL, UCLA (presented by John E. Hummel)-The effect of selective feature conjunction in learning object categories was examined. Stimuli were colored line drawings of 3-D objects with two parts, one constant in shape over all stimuli and one varying. The varying shape conjoined with either color or relative location defined category membership. Classification accuracy was higher for shape/location than shape/color conjunctions.

(573)

Knowledge and Linear Separability. WILLIAM D. WATTENMAKER \& STEPHANIE J. SCHWERTZ, University of PittsburghPrevious research (Wattenmaker, in press) has found that linear separability is more compatible with the social than the object domain. The present research examined whether this difference in compatibility is due to differences in the abstractness of object and social domains. The results support the conclusion that linear separability is more compatible with the social than the object domain, and indicate that this result is not exclusively attributable to the abstractness of the social domain. (574)

Mental Spatial Models Guide Search of Observed Spatial Arrays. DAVID J. BRYANT, Northeastern University, BARBARA TVERSKY, Stanford University, MARGARET LANCA, Northeastern University, \& BHUVANA NARASIMHAN, Boston University-Subjects viewed spatial arrays of objects and were probed for objects with direction terms. Response times to identify objects in the visible display conformed to the spatial framework pattern observed in memory for perceived (Bryant \& Tversky, Psychonomic Society Meeting, 1992) and described arrays (Bryant, Tversky, \& Franklin, 1992) when subjects were prevented from pre-computing responses. The results indicate that viewers employ internal spatial models to guide perceptual search of observed scenes in response to verbal cues.

Consciousness and Tradition. NG TAI-KEE, South China Normal University-Consciousness may be conceptualized as a function involving the difference between stimulus and response which may be represented in a three-dimensional space. Derivatives of this function with respect to time may be connected with each other. This conceptual framework is related to results from genetics and modern medicine that are concerned with heritability and individuality in consciousness. Also, group or social consciousness may be considered within this framework and related to notions of tradition.

Research Support From the National Science Foundation. JOSEPH YOUNG \& FRED STOLLNITZ, National Science Foundation. 


\section{HUMAN MEMORY V \\ Palladian Room, Sunday Morning, 8:00-10:00}

Chaired by Joan Gay Snodgrass, New York University

8:00-8:15 (577)

Strengthening Is Not Enough: Evidence Against Blocking Models of Retrieval Inhibition. MICHAEL C. ANDERSON, ELIZABETH LIGON BJORK, \& ROBERT A. BJORK, UCLA (read by Elizabeth Ligon Bjork)-According to relative-strength models, strengthening the association of an item to a retrieval cue impairs access to competitors sharing that cue. Two experiments demonstrate, however, that strengthening a subset of category-examplar associations (e.g., Fruit Orange) studied earlier need not impair subsequent recall of the remaining examplars (e.g., Fruit Banana). That strengthening via retrieval practice, which requires selection among memory targets, did yield such impairment, supports suppression rather than blocking models of retrieval inhibition.

\section{8:20-8:35 (578)}

Imminence and Familiarity in Tip-of-the-Tongue and Feeling-ofKnowing Reports. ROBERT LEE WIDNER, JR. \& STEVEN M. SMITH, Texas A\&M University (read by Steven M. Smith)-Tip-ofthe-tongue (TOT) judgments express both familiarity with the target, and a sense of imminent recall. TOT states may represent very strong feelings-of-knowing (FOK) if such can produce a sense of imminence. Alternatively, imminence may be determined independently of familiarity. Three experiments show that TOT levels, but not FOK rates, are greater when pressure to perform well is higher, suggesting that imminence in TOT reports is independent of FOK.

\section{8:40-8:50 (579)}

Recency for Dance Gestures. ALLISON R. MARKS, ROBERT G. CROWDER, \& HEIDI E. WENK, Yale University (read by Robert G. Crowder)-Two experiments indicated that the duration of visuallypresented ballet movements affected recency. Subjects with ballet training remembered 7-item lists of ballet-movement names. The names had been presented either aloud, printed, or as movements. Recency was not different for the orthographic and animated-movement conditions when they were of the same duration. However, a comparison of animation conditions which varied in duration showed that the slope of the recency effect was correlated with the animated movements duration.

$$
\text { 8:55-9:15 (580) }
$$

Why Do We Have a Special Learning System in the Hippocampus? JAMES L. MCCLELLAND, Carnegie-Mellon University, BRUCE L. MCNAUGHTON, University of Arizona, \& RANDALL C. O'REILLY, Carnegie-Mellon University-Hippocampal amnesia suggests that some learning takes place directly in the cognitive system, but explicit, declarative memories are initially stored in the hippocampus, then gradually consolidated into the cognitive system. We use insights from the successes and failures of connectionist models of learning and memory to answer two questions: Why do we need a hippocampus? Why is consolidation into the cognitive system so slow? We also present simulations of consolidation experiments based on these answers.

\section{9:20-9:35 (581)}

A Neuropsychological Approach to Prospective Memory. PATRIZIA S. BISIACCHI, University of Trieste, \& TERESA M. SGARAMELLA, University of Padova-An approach informative in the neuropsychological study of aging consists in using standardized neuropsychological tests to infer integrity and/or deterioration of brain structures. A battery of standardized neuropsychological tests and two new prospective memory tasks were administered to 131 subjects (ranging in age from 50 to 96 years). Factorial and discriminant analyses of results showed that different factors are involved under 70s and over 70s, particularly for what concerns prospective memory tasks. The results are discussed in the light of a componential analysis of prospective memory.

9:40-9:55 (582)

Dissociation of Spatial and Object Working Memory in Humans Using PET. JOHN JONIDES, EDWARD E. SMITH, ROBERT A. KOEPPE, EDWARD AWH, SATOSHI MINOSHIMA, \& ERIC H.
SCHUMACHER, University of Michigan-Subjects were given either a spatial or an object working memory task while PET measurements were taken. The spatial task engaged processes of right hemisphere occipital, parietal, prefrontal, and premotor areas while the object task engaged processes of left hemisphere temporal, parietal, prefrontal, and cingulate areas. These experiments show that the processes of spatial and object working memory can be doubly dissociated using PET in normal humans.

\section{VISION II}

Diplomat Room, Sunday Morning, 8:00-9:45

\section{Chaired by Lloyd L. Avant, Iowa State University}

\section{8:00-8:15 (583)}

Further Evidence for Object Integration Despite Violations of Spatio-Temporal Continuity. JOHN M. HENDERSON, PHILIP A. WEEKS, JR., \& MICHAEL D. ANES, Michigan State University-Last year we reported that robust preview benefits can be obtained across saccades despite violations of spatio-temporal object continuity. This year we extend these results by showing that spatio-temporal continuity need not be maintained either within or across saccades for object integration to take place. Our results suggest that while violations of object continuity can reduce the efficiency of integrating object representations, maintenance of object continuity is not necessary for integration. 8:20-8:35 (584)

Background-Color Effects on Visual Reaction Time and Scanning Rate. BRUNO G. BREITMEYER \& JOSH BREIER, University of Houston-Relative to green and blue backgrounds, equiluminant red ones produce somewhat decreased RTs to small ON-targets but more pronounced increases to larger targets. These effects of stimulus size and background color are not found with OFF-targets. Additionally, scanning rates for target letters in multi-letter displays are slower with red than with blue or green backgrounds. The results are discussed in terms of background-color effect on magno- and parvocellular pathways.

\section{8:40-9:00 (585)}

Decrease in Visibility of a Simultaneous Identical Distant Second Line. DONALD L. KING, JACQUELINE F. MOSE, \& NIKOLA S. NIXON, Howard University-An unmasked hence more visible line decreases the visibility of a masked thus less visible simultaneous identical distant second line according to detection (presence-versus-absence) evidence. This dominant-subordinate decrease in visibility continues when the lines are further apart, reverses when the lines are closer together, and disappears without the mask. It explains metacontrast, is also a contrast outcome, and hints that two distant objects produce two interacting representations rather than a single representation.

$$
\text { 9:05-9:20 (586) }
$$

Effects of Contrast on the Perceived Size of Visual Patterns. ELIZABETH THORPE DAVIS, Georgia Institute of Technology, DEAN YAGER, SUNY State College of Optometry, B. ARTHUR KIRKLAND, R. TROY SURDICK, \& ALLISON HOCHSTEIN, Georgia Institute of Technology-The perceived spatial frequency of a low-contrast pattern can vary with changes in contrast. Because size is inversely related to spatial frequency and is an important distance cue, this phenomenon can affect task performance such as driving on a foggy day. We tested the qualitatively different predictions of three models of human vision and found that a model which posits noisy visual mechanisms best accounts for all of our data sets.

\section{9:25-9:40 (587)}

Combined Image Degradation Effects in a Discrimination Task. WILLIAM R. UTTAL, TODD BARUCH, \& LINDA ALLEN, Arizona State University-This report describes the results of a study using a discrimination task in which three kinds of image degradation (low bandpass filtering, acuity reduction by local area averaging, and superimposition of random punctate visual interference) are imposed upon stimuli. Applying the degradations in various combinations and orders shows that the effects are mainly additive and commutative. No evidence of a perceptual advantage of any degradation was found as had been reported for recognition tasks. 
CATEgORIZATION II

Hampton Room, Sunday Morning, 8:00-10:05

Chaired by Patricia Siple, Wayne State University

8:00-8:15 (588)

Categorical Effects in the Perception of Faces. JAMES BEALE \& FRANK KEIL, Cornell University (read by Frank Keil)-To test the nature of individual face representations, a linear continuum of "morphed" faces was generated between individual exemplars of familiar faces. In separate categorization and discrimination tasks, subjects viewed pairs of faces from these continua. Subjects discriminate most accurately when face-pairs straddle apparent category boundaries. Other studies explore face (and face-like) stimuli that cause such effects to disappear.

\section{8:20-8:40 (589)}

Learning Distributional Information in a Categorization Task. ROBIN D. THOMAS \& JAMES T. TOWNSEND, Indiana University (read by James $\mathrm{T}$. Townsend)-A current model of categorization assumes the use of quadratic decision bounds defined on multidimensional space (Ashby \& Maddox, 1992) - quadratic because subjects are believed to represent natural categories as multivariate normal distributions. However, the use of boolean rules over specific exemplar information has received some support (Nosofsky, et al., 1992). Several experiments reported here based on the generalized randomization technique establish the extent to which subjects represent distribution information such as correlations within categories.

\section{8:45-9:00 (590)}

Constraints on Inductive Learning of Functions and Categories. KYUNGHEE KOH, University of California, Santa Barbara-This research investigates how people learn to combine multiple stimulus cues in function learning (where the required responses are continuous) and in category learning (where the required responses are discrete). Patterns of response bias during the early stages of learning reveal prior assumptions people have about the type of combination rule (e.g., additive or multiplicative) to be learned. A constraint-based model for learning of functions and categories is discussed.

\section{9:05-9:20 (591)}

Mean-Integrality of Rectangles: A Detection-Theory Approach. NEIL A. MACMILLAN \& ADAM S. ORNSTEIN, Brooklyn College, $C U N Y$ - To assess perceptual interaction between the height and width of rectangles (and also line pairs), we measured discriminability in an accuracy variant of the Garner paradigm. Using $d^{\prime}$ values from two-stimulus conditions (baseline and correlated tasks) to estimate perceptual distances, we inferred a "mean-integral" decision-space representation that successfully predicted performance in the fourstimulus conditions (selective and divided attention). We describe a process model for rectangle discrimination that is consistent with the inferred representation.

\section{9:25-9:40 (592)}

Effects of Acquisition Method and Similarity in Category Learning of Archeological Objects. ANDRÉ VANDIERENDONCK, University of Ghent-In studies of category learning and representation usually only two categories are involved. In the present study, subjects learned a five-category system of archeological spearheads, under several conditions of acquisition: learning the five categories at once, progressive differentiation of a hierarchical system of classes, and progressive extension starting from two categories and gradually adding the other ones. The effects of acquisition method and intercategorical similarity on learning efficiency and on form of representation are reported.

$$
\text { 9:45-10:00 (593) }
$$

The Effect of Processing Approach on Category Exemplar Generation. THOMAS B. WARD, Texas A\&M University-When people generate novel, imaginary instances of a category, those new instances are structured by the characteristic attributes of the category. This structuring effect is stronger when subjects rely on specific category instances than when they report basing their creations on more general knowledge. An experiment in which subjects' approaches were manipulated indicates that this effect is due more to the processing approach itself than to individual differences in creative ability.

\section{PHONOLOGICAL CODING IN READING Blue Room, Sunday Morning, 8:00-10:30}

Chaired by Veronika Coltheart, Macquarie University

\section{8:00-8:15 (594)}

At First, Roses Are Reezes: Toward a Nonlinear Model of Phonological Assembly in Reading. IRIS BERENT \& CHARLES A. PERFETTI, University of Pittsburgh (read by Charles A. Perfetti)-Phonological assembly in word recognition research shows a split personality: both slow and fast, unreliable and reliable, attention-demanding and automatic. A model in which consonant and vowel phonemes are assembled in two processing cycles successfully treats this disorder. We support the model with experiments that limit processing time, using masked presentations in both single and dual task situations. Results suggest that phonological representations develop over two brief temporal periods, first consonants and then vowels.

\section{8:20-8:40 (595)}

Lexical and Prelexical Computation of Phonology: Evidence From Unpointed Hebrew. RAM FROST, Hebrew University-Is phonology in deep orthographies assembled by applying letter-to-phoneme computation rules or retrieved as a unit from the mental lexicon? Readers in unpointed Hebrew named words that had many or few missing vowels in their printed forms. Naming latencies were linearly related to the number of missing voewls. These results suggest that even in deep orthographies phonology is not retrieved as a lexical unit but computed using GPC rules, while ambiguity is resolved through top-down activation. 8:45-9:05 (596)

Semantic Effects in Single Word Naming. KARALYN E. PATTERSON \& EAMON STRAIN, MRC Applied Psychology Unit, Cambridge-Two experiments demonstrated that, for lower frequency words, naming is affected not only by spelling-sound typicality but also by a semantic variable, imageability. Subjects were slower and more error-prone to name exception words with abstract meanings than either abstract regular words or imageable exception words. Results are discussed in relation to (1) the Seidenberg and McClelland framework for computing pronunciation from print, and (2) observations from patients with acquired disorders of reading.

\section{9:10-9:30 (597)}

When Bluebeards Fly: Assembled Phonology and the Activation of Meaning. MARY LESCH \& ALEXANDER POLLATSEK, University of Massachusetts (read by Alexander Pollatsek)-The role of phonology in visual word perception was investigated using a task in which subjects judged whether two words were semantically related. Of primary interest were trials with "false homphones": (e.g., ROBINBEARD where BEARD could be pronounced/bird/). A $55 \mathrm{~ms}$ interference effect was found on these trials. The effect for true homophones (e.g., SAND-BEECH) was $95 \mathrm{~ms}$. This indicates that both assembled and addressed phonology are involved in accessing word meanings.

\section{9:35-9:50 (598)}

Spelling-Sound Relations in English and Their Effects on Reading. REBECCA TREIMAN, JOHN W. MULLENNIX, Wayne State University, \& RANKA BIJELJAC-BABIC, University of Poitiers-This study concerns the nature of spelling-sound relations in English and how people use these relations in pronouncing words. Examining all of the CVC words in a computerized dictionary, we found that VC units had more consistent pronunciations than $\mathrm{CV}$ units or single vowels. Once the consistency of the individual graphemes was taken into account, the consistency of the VC made a significant additional contribution to the prediction of performance in word pronunciation studies.

$$
\text { 9:55-10:10 (599) }
$$

Deficiencies in Auditory Information Processing in Poor Readers. CATHERINE G. PENNEY \& ANNETTE GODSELL, Memorial University of Newfoundland-One sample of 40 university students and another sample of 48 Grade 8 students were tested on six subtests of the Woodcock Johnson Battery (Revised). Nonword reading scores were 
found to correlate with ability to read words, Peabody Picture Vocabulary Test scores, and measures of auditory information processing. When subjects were classified as being good or poor readers on the basis of nonword reading ability, reading ability was found to interact with presentation modality in immediate serial recall.

\section{0:15-10:25 (600)}

Frequency Effects in a Pseudohomophone Reading Task. HARVEY MARMUREK, University of Guelph, \& PETER KWANTES, Queen's University-Pseudohomophones (nonwords that sound like words, e.g., nerse) yielded a frequency effect in a reading aloud task when subjects were aware that each item in a list sounded like a word. There was no frequency effect for pseudohomophones when they appeared in a list with nonwords that did not sound like words. The frequency effect was interpreted to ensue from a lexical route which may be accessed phonologically.

\section{ANIMAL COGNITION/MEMORY III \\ Empire Room, Sunday Morning, 8:00-10:35}

\section{Chaired by Herbert L. Roitblat, University of Hawaii}

\section{8:00-8:20 (601)}

Transfer of Value From $S+$ to $S-$ in a Simultaneous Discrimination. THOMAS R. ZENTALL \& LOU M. SHERBURNE, University of Kentucky-Pigeons were trained on two simultaneous hue discriminations (A vs. B, and C vs. D) on randomly alternating trials. Responses to $A$ were always reinforced. Responses to $C$ were reinforced on half of the trials. Responses to B and D were never reinforced. Later, when presented with B and D, pigeons consistently chose B. Apparently, in a simultaneous discrimination, value transfers proportionately from stimuli associated with reinforcement to the other stimuli.

$$
\text { 8:25-8:40 (602) }
$$

Temporal Comparison and the Internal Clock Model. LEON R. DREYFUS \& YONATAN FISHMAN, Vassar College-The internal clock model accounts for timing under a number of different procedures. Under most procedures, however, the consequences of responding are arranged with respect to a fixed temporal criterion, a feature not shared by the duration comparison procedure. Although the internal clock model, in its most common form, could not account for pigeons' performance under a duration comparison task, an elaborated version of the model accommodated some features of the data.

$$
\text { 8:45-9:05 (603) }
$$

An Apparent Order-of-Training Effect in Mediated Transfer by Pigeons. PETER J. URCUIOLI, Purdue University, \& THOMAS R. ZENTALL, University of Kentucky-Pigeons learned the same three sets of sample-comparison relations but in different orders (or groups). One ordered sequence consisted of many-to-one followed by one-toone matching-to-sample; the other consisted of one-to-many followed by one-to-one matching. Mediated transfer effects were subsequently found only when initial training involved the many-to-one task.

\section{9:10-9:25 (604)}

Enhancing and Reducing Rats' Proactive Interference in the Radial Maze. J. S. COHEN, C. STURDY, \& K. LEONARD, University of Windsor-Forcing rats to arm locations opposite to those experienced in a later study segment causes proactive interference (PI) during the final free choice segment of a trial in the radial maze (Hoffman \& Maki, 1986). In the present experiments, such within-trial PI was either enhanced or reduced by changing proximal arm stimuli and the sequence of projected distal stimuli between the interference and study forced choice segments. Thus, changes in attention influence PI.

$$
\text { 9:30-9:45 (605) }
$$

A Signal Detection Analysis of Memory for Nonoccurrence. JOHN T. WIXTED, University of California, San Diego-In a relatively new memory procedure, pigeons must report whether or not an event recently occurred. If a sample stimulus was presented since the outcome of the last trial, choosing the "yes" key is reinforced. If not, a response to the "no" key is reinforced. Recent research suggests that performance on no-sample trials is governed by a default response strategy, but a signal detection analysis suggests otherwise.

\section{9:50-10:05 (606)}

Performance of Honey Bees in a Radial-Arm Maze Analog Task. GREGORY E. DEMAS \& MICHAEL F. BROWN, Villanova University (read by Michael F. Brown)-Honey bees were allowed to forage on a $2 \times 3$ matrix of cells, each one baited with a small amount of sugar solution. Each trial consisted of a bee visiting cells until all 6 cells had been visited. Individually marked bees returned to the matrix for multiple trials. Revisits to cells within each trial occurred less frequently than expected by chance. Experiments designed to investigate the mechanisms underlying this behavior will be described.

10:10-10:30 (607)

Knowledge of Ordinal Position of List Items by Pigeons and Monkeys. H. S. TERRACE, SHAOFU CHEN, \& ALLISON B. NEWMAN, Columbia University-After pigeons learned to produce 3-, 4-, and 5item lists, a wild card was substituted on randomly selected trials for one of the list items. Accurate responding to the wild card occurred in the initial and terminal positions of all lists but, with the exception of the 3-item list, not at interior positions. Monkeys respond accurately at all positions (D'Amato \& Colombo, 1989) indicating fundamental differences in a pigeon's and a monkey's knowledge of a list item's ordinal position.

\section{JUDGMENT/DECISION MAKING III \\ Ambassador Room, Sunday Morning, 8:00-10:15}

Chaired by Ruth H. Maki, North Dakota State University

\section{8:00-8:15 (608)}

Attitudes and Arguments Occurring Before and After the Gulf War. JAMES F. VOSS, JENNIFER WILEY, JOEL KENNET, \& LAURIE SILFIES, University of Pittsburgh-Thirty individuals were interviewed before and after the Gulf War. Ratings regarding U.S. military involvement, justifying arguments, and beliefs regarding U.S. foreign involvement were measured. While before the war two-thirds were opposed to military action, afterwards two-thirds favored it, the changing one-third demonstrating a hindsight effect. Analyses supported hypotheses stating that subjects maintaining their position had better and more stable arguments, and stronger ideologies about U.S. foreign involvement, than did individuals changing their position.

$$
\text { 8:20-8:35 (609) }
$$

Effects of the Costs of Decision Errors on Decision Strategies. CAROLYN M. JAGACINSKI, Purdue University-Two experiments were conducted in which subjects evaluated job applications or patients based on two scores. In Experiment 1 overprediction was more costly than underprediction. When the scores were discrepant, subjects assigned more weight to the lower score. In Experiment 2, underprediction was more costly than overprediction. In this case when the scores were discrepant, greater weight was assigned to the higher score. Results are consistent with configural weight theory.

8:40-8:50 (610)

Weighting of Features in Pleasant Versus Unpleasant Life Domains. KIMIHIKO YAMAGISHI \& JOHN M. MIYAMOTO, University of Washington (read by John M. Miyamoto)-Judgments of "How much better is Choice A than B?" differ from "How much worse is B than A?" in their magnitudes. We argue that the differences occur because people weight different features of multicomponent stimuli. Data showed that, in pleasant stimulus domains, "better" judgments exceeded "worse" judgments. In unpleasant domains, the pattern reversed. These results confirmed our prediction that desirable features are weighted in pleasant domains, whereas undesirable features are weighted in unpleasant domains.

$$
\text { 8:55-9:10 (611) }
$$

Determinants of Performance in Dynamic Decision Making. ALEXANDER J. WEARING, NOEL OLVER, \& MARY M. OMODEI, University of Melbourne-What factors determine performance in dynamic decision making? Subjects (engineers and technicians) fought a series of computer simulated bushfires in which appliance and fire speed, fire predictability, and goal complexity were varied. In addition each 
subject completed an embedded figures test and the NEO-PI-R. Performance varied as a function of the task variables, field dependence, age, the NEO traits of Determination, Impulsiveness, Angry Hostile, and Actions, as well as their interactions.

$$
\text { 9:15-9:30 (612) }
$$

Retrospective Studies of Real Life Decision Making. DEBORAH FRISCH, University of Oregon, \& STEVEN K. JONES, Ohio University-We conducted two studies in which subjects described decisions they had actually made. In one study, subjects described a difficult decision. In the second study, subjects described either a positive or negative outcome they had experienced. We found that the source of difficulty in decision making varied as a function of the content (personal versus professional) of the decision. We also found that professional decisions were associated with more favorable outcomes than personal ones. 9:35-9:45 (613)

Adolescents Making Real Life Decisions: How Rational Are They? KATHLEEN M. GALOTTI, Carleton College-Ninety college-bound high school juniors were surveyed three times during their junior and senior year of high school as they made decisions about which college to attend. (Two other samples of students participated twice, and once, respectively, bringing the total sample size to 322). At each point, respondents described the factors (criteria) they used in making a decision, the weights (importance ratings) they gave to each factor, the alternatives (colleges) they were currently considering, and their rank-ordered preferences. Using the weights and ranks respondents provided, we were able to determine a multiattribute utility analysis of their decisions at different points. Correlations between respondents' intuitions about their preferences and predictions from the multiattribute utility theory analyses were quite high.

$$
\text { 9:50-10:10 (614) }
$$

The "Interference" Explanation of Random Behavior in Dyadic Zerosum Games. DAVID D. BUDESCU, University of Illinois, AMNON RAPOPORT, University of Arizona, \& IRIT FREIMAN, University of Haifa-Rapoport and Budescu (1992) reported that in repeated zerosum games subjects behavior is "almost" random. They speculated that the need to monitor the opponents' behavior interferes with subjects' memory, inducing a "memoriless" generation process. In the current study one group (R) generated random series, while another (D) played a zerosum game. All subjects were asked to recall the responses. Consistent with the interference hypothesis subjects in group $D$ behaved more randomly, recalled fewer responses, but remembered equally well their opponents' moves.

\section{RECOGNITION/RECALL II}

Palladian Room, Sunday Morning, 10:10-12:55

\section{Chaired by Norman J. Slamecka, University of Toronto}

\section{0:10-10:30 (615)}

Primacy and Recency in Serial Recall and Recognition. BENNET B. MURDOCK, University of Toronto-Serial recall typically shows an extensive primacy effect whereas item recognition typically shows an extensive recency effect. Simulations of the chunking model show that the model can at least mimic the general pattern of these effects. 10:35-10:55 (616)

Target Similarity Effects in a Short-Term Cued Recall Paradigm. GERALD TEHAN, University of Southern Queensland, \& MICHAEL S. HUMPHREYS, University of Queensland (read by Michael S. Humphreys)-Interference occurred at shorter retention intervals when the target in the last list and the interfering item in an earlier list where physically similar. In addition, the presence of an item in the last list, which was physically similar to the interfering item, increased interference even though it was unrelated to the cue. The implications for the role of phonological information in short-term memory and for the superposition of memory traces are discussed.

\section{1:00-11:15 (617)}

Awareness as a Continuum: Implications for Memory Research. FRANCIS S. BELLEZZA \& CHICAKO INOUE, Ohio University-A word-recognition task was administered after a one-week retention interval. Each subject was then immediately retested with items first labeled as targets and then with items first labeled as foils. In the retests some target words not remembered a few minutes earlier were correctly identified as targets. Similarly, foils mislabeled a few minutes earlier were correctly labeled as foils. Memory sensitivity in all three tests was above chance level. A signal-detection model is proposed for these results.

\section{1:20-11:40 (618)}

Within-List Declines in Recognition Accuracy. MURRAY GLANZER \& KISOK KIM, New York University-Four experiments were run to analyze within-list declines in recognition accuracy. We replicated what appeared to be a proactive interference effect found in earlier work (Schulman, 1974) and found that the effect was determined by test order of items, not by study order. The response times show, however, a speed-accuracy trade-off. Control of response times eliminated the decline in recognition accuracy. Declines found earlier are interpreted as resulting from changes in attention.

$$
\text { 11:45-12:00 (619) }
$$

More About the Nature of Recognition Memory. DAVID L. HORTON \& TIMOTHY J. PAVLICK, University of Maryland-Further evidence will be presented for two kinds of recognition memory that depend on qualitatively different underlying processes. It will be shown that improvements in performance in these two kinds of recognition memory are often inversely related to one another. Some implications of this interpretation will be discussed, particularly as it pertains to the distinction between episodic and semantic memory.

$$
\text { 12:05-12:25 (620) }
$$

Fractionating Memory Retrieval. DOUGLAS L. HINTZMAN, DAVID A. CAULTON, \& TIM CURRAN, University of OregonThe response-signal method of studying memory retrieval dynamics traces out the growth of information during a retrieval episode. We combine that method with various types of memory judgments-both episodic and generic-to determine when different kinds of information first become available during retrieval. We will report on several tasks, including recognition memory, list discrimination, frequency judgments, lexical decisions, judgments of category membership, and any additional tasks we have investigated by meeting time.

\section{2:30-12:50 (621)}

Incongruous Item Generation Effects: A Multiple-Cue Perspective. SAL A. SORACI, Tufts University, JEFFERY J. FRANKS, Vanderbilt University, RICHARD CHECHILE, MICHAEL CARLIN, Tufis University, \& JOHN BRANSFORD, Vanderbilt University-We have obtained generation effects under encoding conditions designed to induce incongruous item generation even when responses are uniquely determined, thus eliminating idiosyncratic item selection as an explanation (Soraci et al., in press). These results, and additional data to be discussed, support a multiple-cue account of facilitated recall for incongruous item generation. The multiple-cue perspective is consistent with (a) multiple-trace notions, (b) recent distinctions between cue-target relational and item-specific processing, and (c) transfer appropriate processing.

\section{ATTENTION $v$}

Diplomat Room, Sunday Morning, 9:55-12:30

Chaired by Gordon C. Baylis, University of California, San Diego

$$
\text { 9:55-10:15 (622) }
$$

Spatial Precuing in Single-Element Displays: Noise Reduction or Signal Enhancement? LING-PO SHIU \& HAROLD PASHLER, University of California, San Diego (read by Harold Pashler)-It is widely supposed that spatial precuing enhances perception of even a single object against a blank field, despite early findings to the contrary. We report new experiments using vernier judgments, character discrimination, and word recognition. The results do not show true enhancement, but they reveal artifacts capable of producing cuing effects (multiple target-confusable masks, speed-accuracy tradeoffs). The view that spatial attention simply excludes decision noise appears to explain these results along with many others. 


\section{0:20-10:30 (623)}

A Gradient-Filter Metaphor for Attention. MARYLOU CHEAL, DON R. LYON, University of Dayton Research Institute, \& LAWRENCE G. GOTTLOB, University of Dayton Research Institute and Arizona State University-A new metaphor for attention is suggested that combines the spatial characteristics of a gradient with the temporal characteristics of an attention filter. In this metaphor, attention can be represented as a gradient, the spatial and temporal distribution of which can vary with the demands of the task. Data from the location-cuing paradigm will be presented to support various characteristics of the metaphor.

\section{0:35-10:55 (624)}

ERP and Functional MRI Measurement of Attention Shifting. JUDITH M. SHEDDEN, WALTER SCHNEIDER, University of Pittsburgh, \& DOUG NOLL, University of Pittsburgh and Carnegie-Mellon University (read by Walter Schneider)-These experiments examine control of attention switching within and between hemifields. Subjects monitor multiple-frame displays on which the digits ' 1 ' through ' 9 ' are repeated in numeric sequence, responding if a digit occurs out of sequence. Attentional effects on early ERP components illustrate differences in processing when attention is fixed in one location, shifting within the same visual hemifield, and shifting between visual hemifields (e.g., upper/lower hemifields; left/right hemifields). The spatial locations of activation are determined with Functional MRI determining lateralization of attentional control operations.

$$
\text { 11:00-11:20 (625) }
$$

Saccadic Eye Movements and Shifts of Visual Attention. EILEEN KOWLER, Rutgers University, BARBARA DOSHER, University of California, Irvine, ERIC ANDERSON, Rutgers University, \& ERIK BLASER, University of California, Irvine-Can we shift attention and simultaneously make saccades in different directions? No. Subjects were much better at identifying a letter located at the intended saccadic goal than elsewhere. Identification at non-goal locations improved dramatically when saccadic latency increased by only $20-50 \mathrm{msec}$. So, shifts of attention are a prerequisite of saccades, but attention shifts are fast, allowing different eccentric locations to be attended with only modest cost in saccadic latency.

\section{1:25-11:45 (626)}

Shifting Visual Attention Through Space: A Test of Two Models. DAVID LABERGE, BLYNN BUNNEY, \& ROBERT CARLSON, University of California, Irvine-Subjects were induced to concentrate attention at a central location, identify a letter there, then identify a letter to the extreme left or right of a central horizontal range of five locations, and then identify a letter at one of the central five locations. A moving-spotlight model predicts that RT's to the last letter will show a monotonic curve across the five locations, while a gradeddistribution/selection model predicts a V-curve. The data showed Vcurves.

$$
\text { 11:50-12:10 (627) }
$$

Shifting Attention Between Visual Domains: Evidence From HeadUp Displays. ROBERT S. MCCANN, Sterling Software, JAMES C. JOHNSTON, DAVID C. FOYLE, NASA-Ames Research Center, \& JEANNIE LYNCH, San Jose State University-Advanced cockpits use Head-Up Displays (HUDs) that superimpose a control-panel image on the pilot's forward field of view. We investigated whether it takes time to shift attention between the two visual domains. Subjects first processed a cue and then searched for a target symbol. Responses were faster when cue and target appeared within domains rather than across domains. The size of the within-domain advantage depended on the perceptual cues distinguishing the domains.

\section{2:15-12:25 (628)}

Signal Detection in Two-Person Games: Implications to Attention Sharing of Team Members. DANIEL GOPHER, IDO EREV, REVITAL ITKIN, \& YAAKOV GRUNSHPAN, Technion, Haifa-Game theoretical analysis is used to extend the predictions of classical Signal Detection Theory to situations in which the detection task is performed by two observers. The equilibrium predictions were tested in an experiment in which Dyads performed a signal detection task. In accordance with the predictions subjects were less likely to detect signals when the utility of detection was a public good, and the magnitude of the criteria shift depended on the subjects sensitivity $\left(d^{\prime}\right)$.

\author{
DEVELOPMENT/AGING II \\ Hampton Room, Sunday Morning, 10:15-12:50 \\ Chaired by Lynn Hasher, Duke University
}

10:15-10:30 (629)

Memory for Focal and Contextual Information: Comparisons of Young and Old. MOSHE NAVEH-BENJAMIN, Ben-Gurion University of the Negev, \& FERGUS I. M. CRAIK, University of TorontoThe current research compared memory for words and the voice speaking them, in young and old subjects, in order to determine the elderly's relative disadvantage in memory for focal and contextual information. In two experiments, young and old subjects listened and tried to memorize a series of words, each presented by one of two male voices. Results indicated that patterns of word and voice memory for young and old depended on subjects' encoding activities and the reinstatement of the original context.

\section{0:35-10:55 (630)}

Developmental Dissociations Between Verbatim and Gist Memories. C. J. BRAINERD \& L. L. GORDON, University of ArizonaTwo models of the on-line relationship between children's verbatim and gist memories of numbers were studied: fuzzy-trace theory's representational independence hypothesis (verbatim and gist memories are functionally dissociated) and the integration hypothesis (gist memories are constructive inferences from verbatim memories). The findings favored representational independence. At all age levels, children's verbatim memory for presented numbers was stochastically independent of their memory for numerical gists that were instantiated by the numbers. Also, manipulations were identified that improved verbatim number memory without improving gist memory, and other manipulations were identified that had the opposite effect.

\section{1:00-11:15 (631)}

Children's Strategy Use: In Search of Intentionality. HARRIET S. WATERS \& THOMAS W. KUNNMANN, SUNY at Stony BrookThe present study examines temporal characteristics of children's recall (intercategory and intracategory time intervals) to determine whether children are intentionally using category structure to help themselves remember. Both developmental level (1st, 3rd grade) and cognitive load ( 8 versus 16 pictures) impact on the temporal characteristics of recall The results support the hypothesis that intentionality involves the construction of a retrieval plan which speeds up intracategory times relative to intercategory time intervals. Automatization effects are seen in overall faster times with age.

\section{1:20-11:40 (632)}

Improved Recall With Age is Due to Retrieval, Not Encoding. RANDALL H. BENDER, THOMAS S. WALLSTEN, \& PETER A. ORNSTEIN, University of North Carolina at Chapel Hill (read by Thomas S. Wallsten)-Baker-Ward et al. (in press) showed that recall improves over ages 3-7 for events experienced during a physical exam. We used a joint multinomial model to ask whether the improvement was due to encoding, retrieval, or likelihood to report. The model fit the Baker-Ward data well and showed (1) retrieval and reporting cannot be distinguished and (2) the observed effects most likely were due to age-related improvement in retrieval-reporting only.

\section{1:45-12:00 (633)}

Adult Eyewitness Memory: Age Differences in Susceptibility to Suggestion. MARA E. KARPEL, Syracuse University, MICHAEL P. TOGLIA, SUNY at Cortland, \& WILLIAM J. HOYER, Syracuse University (read by Michael $P$. Toglia)-Adult age differences in the accuracy and qualitative characteristics of real and suggested memories were investigated. Subjects viewed slides of a theft, once or twice, and then misled about several details. Two exposures enhanced performance for each group. Older adults affirmed seeing suggested items with greater frequency and confidence, and rated some perceptual qualities of sug- 
gested items more vividly. Thus, distinctions between real and suggested memories were clearer for younger adults. Psycholegal implications are discussed.

$$
\text { 12:05-12:25 (634) }
$$

Contributions of Inhibitory Mechanisms to Unified Theory in Psychology and Neuroscience. JAMES M. CLARK, University of Winnipeg-Building on the work of others, I describe a general theory in which the central construct of inhibition mediates many relations between causes and behavioral effects. Such varied causes as childhood development, aging, brain damage, and psychopathology affect inhibitory mechanisms, which in turn contribute to diverse behaviors from such areas as physiology, attention, memory, and emotion. Current theories also implicate inhibitory processes, which provide mechanistic and unified explanations for countless relations in psychology and neuroscience.

\section{2:30-12:45 (635)}

Memory at Three Years: Robust Facilitation of Perceptual Identification, Failure of Recognition. ANNA BULLOCK \& NORA NEWCOMBE, Temple University (read by Nora Newcombe)-Children ( $n=35$, mean age 3.5 years) were read a colorful book about animals on each of two days. A three-choice verbal recognition test given on the third day showed $77 \%$ correct choices. After 3 months, the children showed no recognition memory (assessed in a yes-no format) for the pictures, but they showed robust facilitation of perceptual identification, relative to both identification of pictures not seen before and to a control group.

\section{LANGUAGE/DISCOURSE PROCESSING III Blue Room, Sunday Morning, 10:40-12:25}

Chaired by Morton Ann Gernsbacher, University of Wisconsin-Madison

\section{0:40-10:55 (636)}

How Scissors Cut Agreement. KATHRYN BOCK, University of Illinois, ANTJE S. MEYER, Max Planck Institute for Psycholinguistics, KATHLEEN M. EBERHARD, University of Rochester, \& J. COOPER CUTTING, University of Illinois-In English, invariant plural words like scissors denote single objects. To explore whether mismatches between grammatical and conceptual number affect linguistic relationships, we elicited errors of agreement between subjects and verbs, and subjects and pronouns. Both types of agreement revealed reliable modulations of grammatical number by conceptual number. The Dutch equivalents of the invariant plurals are singular, and behaved like simple singulars in a parallel experiment. The resuits suggest that conceptual singularity dilutes grammatical plurality.

11:00-11:15 (637)

Unheralded Pronouns and the Accessibility of Discourse Referents. RICHARD J. GERRIG, Yale University, STEVEN B. GREENE, Princeton University, GAIL MCKOON, \& ROGER RATCLIFF, North western University-Pronouns are unheralded when they appear with out an explicit referent in the immediate context. Speakers use such pronouns when they believe, by virtue of common ground with an addressee, that a referent is implicitly in the focus of attention. In a series of five experiments, we use unheralded pronouns to demonstrate the waxing and waning of discourse referents as a function of common ground.

$$
\text { 11:20-11:35 (638) }
$$

Contextual Effects on the Durations of English Nouns and Verbs. SALLY DAVIS, JOANNA MORRIS, \& MICHAEL H. KELLY, University of Pennsylvania (read by Michael $\mathrm{H}$. Kelly)-Grammatical categories often differ in phonological properties. This paper explores one possible cause of these phonological differences. Since words from different grammatical classes vary in distributional privileges, they will appear consistently in different syntactic contexts. If these contexts are associated with phonological reflexes, then members of different classes will tend to vary along the phonological dimensions associated with those contexts. Three experiments apply this general scenario to durational differences between English nouns and verbs.

\section{1:40-12:00 (639)}

The Role of Global and Local Context on Lexical Processing. DAVID HESS, DONALD J. FOSS, \& PATRICK CARROLL, University of Texas at Austin (read by Donald J. Foss) - We examined the roles of "local" and "global" contexts on lexical processing. Contextual material was presented auditorily, and naming times for the last (visually presented) word were collected. Globally related material af fected naming latency in all cases, while locally related material did not. We argue that the results are inconsistent with associatively based models and with some hybrid models, and we argue that a discoursebased model best accounts for the data.

12:05-12:20 (640)

Constructing Motive-Bridging Inferences Between Nonadjacent Text Ideas. MURRAY SINGER, University of Manitoba-Two experiments favored a global-over a minimalist-inference analysis. According to the validation model, a tentative global motive inference between the sentences, Laurie left early for the birthday party, She went to the mall, must be validated against relevant knowledge. Experiment 1 confirmed that, even with four intervening sentences, the relevant question, Do birthday parties involve presents?, is systematically facilitated. Experiment 2 revealed comparable validation effects under normal and causal reading instructions but not for proofreading.

\section{SPEECH PERCEPTION}

Empire Room, Sunday Morning, 10:45-12:50

Chaired by Dominic W. Massaro, University of California, Santa Cruz

10:45-11:00 (641)

The Effect of Rate of Speech Delivery on the Use of the Uniqueness Point. MONIQUE RADEAU \& PHILIPPE MOUSTY, Université libre de Bruxelles-Gender classification latencies to trisyllabic French nouns with early or late uniqueness point (UP) were compared in three conditions of delivery: normal, fast (65\%), and slow (165\%). A small but significant UP effect was found in the normal condition, it increased in the slow condition, and completely disappeared in the fast condition. These results obtained for isolated words are discussed in terms of the utility of the UP notion in processing fluent continuous speech.

11:05-11:25 (642)

Cracking the Laugh Code: Insights Into Vocal Production, Perception, and Speech. ROBERT R. PROVINE, University of Maryland, Baltimore County-The species-wide distribution and stereotypic structure (i.e., Sonographic analyses reveal regular duration of vowel-like notes and regular internote-intervals) of laughter facilitate the analysis of the neurobehavioral mechanisms of human vocal production and perception. Naturalistic studies of laughter in speech show laughter to occur almost exclusively at phrase boundaries, indicating that a lawful process governs the placement of laughter in the speech stream and that speech is dominant. Laughter "punctuates" speech.

\section{1:30-11:40 (643)}

Vertical Similarity in Spoken Word Recognition. CYNTHIA M. CONNINE, DEBRA TITONE, \& JANE FERRIBY, SUNY at Binghamton-Most models of word recognition assume that lexical activation is modulated by the degree of successful mapping from the input to a lexical representation (vertical similarity). A phoneme monitoring task was used to investigate vertical similarity in activation of spoken words. Phoneme detection responses increased as similarity to a real word decreased. These results are consistent with findings from cross modal priming and demonstrate that lexical activation is a graded function based on vertical similarity.

\section{1:45-12:00 (644)}

Voice Recognition Based on Phonetic Information. ROBERT E. REMEZ, JENNIFER M. FELLOWES, JENNIFER S. PARDO, Barnard College, \& PHILIP E. RUBIN, Haskins Laboratories-Word recognition and voice recognition are often described as separate processes, though recent studies undermine a conceptualization of purely independent functions. Our tests gauged the plausibility of a single code com- 
mon to voices and words, in tests of voice recognition using acoustically transformed signals lacking the typical correlates of voice quality. Relying only on phonetic information, subjects identified the talkers from the transformed signals. This outcome suggests that perception of words and voices alike can rest on phonetic attributes.

$$
\text { 12:05-12:20 (645) }
$$

A General Theory of Speech Perception Must Account for Speech Perception Without Audition (Lipreading/Speechreading). LYNNE E. BERNSTEIN, Gallaudet University, \& MARILYN E. DEMOREST, University of Maryland, Baltimore County-Audiovisual effects have been studied in speech perception research, vision being considered only as supplementary to audition. Our observations of expert visual speech perception by some profoundly deaf individuals led to a normative study of lipreading in deaf vs. hearing young adults. Results indicate that lipreading on some deaf subjects is comparable to listening in noise by hearing subjects. The deaf subjects' performance requires account by theories of speech perception for which generality is claimed.

$$
\text { 12:25-12:45 (646) }
$$

Is Perceptual Degradation Caused by a Confused Sound Source Assignment Process? ARTHUR SAMUEL, SUNY at Stony BrookWhen a message is alternately presented to the right and left ears over headphones, intelligibility is greatly disrupted at an alternation rate of 3-4 Hz. We have shown that this effect is not due to syllabic disruption, contrary to previous belief. We will present the results of several experiments that test the hypothesis that the perceptual degradation is caused by processes that normally assign sound inputs to sound sources.

\section{JUDGMENT/DECISION MAKING IV \\ Ambassador Room, Sunday Morning, 10:25-12:50 \\ Chaired by Jerome Busemeyer, Purdue University}

\section{0:25-10:40 (647)}

Subtractive Versus Ratio Model of "Fair" Allocations: A Developmental Analysis. RAMADHAR SINGH \& ANGELIA S. T. HUANG, National University of Singapore (sponsored by Michael H. Birnbaum)-Subjects divided money between two claimants based on needs and deeds. Monotone transformations of data from 9-, 13-, and 17-yearolds rescaled the nonparallel original ratings to perfect parallelism and thereby eliminated the need to theorize configural weighting. Developmental differences were opposite of American findings and resided in valuation of inputs rather than the model. Findings supported the subtractive model with nonlinear judgment function but questioned the ratio model of "fair" allocations.

$$
\text { 10:45-11:00 (648) }
$$

Experienced Utility in Real-Time and in Retrospect. CHARLES A. SCHREIBER \& DANIEL KAHNEMAN, University of California, Berkeley (read by Daniel Kahneman)-Initial results will be presented from a technique using aversive sounds varying in loudness, waveform, and duration to study momentary affect and retrospective evaluations. Real-time ratings and retrospective global ratings, as well as choices, were obtained from subjects exposed to sounds differing in aversiveness. Rules for deriving retrospective evaluations from "real-time" ex- perienced utility will be discussed with particular attention to the effects of contrast and adaptation.

$$
\text { 11:05-11:20 (649) }
$$

Using Belief Functions to Represent Degrees of Belief. SHAWN P. CURLEY \& JAMES M. CONLEY, University of Minnesota-Belief functions are an alternative to probabilities for representing individuals' degrees of belief and uses of evidence. We argue that the calculus has several useful properties for communicating beliefs, and apply the theory in a hypothetical legal decision situation: (a) to determine if individuals can use the representation meaningfully in terms of reliability and validity; and (b) to identify patterns in individuals' belief functions that inform our understanding of their uses of evidence.

\section{1:25-11:45 (650)}

Scenario Structure and Feelings of Likelihood. CHARLES F. GETTYS, University of Oklahoma-Feelings of likelihood are assumed to be derived from act-event scenarios constructed from mental models. Two questions were addressed: First, are the scenarios complete? Second, how are chance forks represented in scenarios? Very tentative results suggest that scenarios are often incomplete, consisting only of the surface structure of the problem statement. Apparently chance forks in scenarios are processed either by making a "best-guess assumption" or by a modification of Bayes theorem.

\section{1:50-12:05 (651)}

A Review and Synthesis of Inconsistent Findings in Framing Effects Research. IRWIN P. LEVIN, GARY J. GAETH, \& AMY B. CONLON, University of Iowa-The literature has been mixed as to whether information presentations are more effective under positive or negative framing conditions. Based on a literature review and new empirical data, we argue that this inconsistency occurs because different studies have tapped different underlying processes. We distinguish between attribute framing effects and message framing effects and suggest that their causes are quite different.

$$
\text { 12:10-12:30 (652) }
$$

Are Humans Good Intuitive Statisticians After All? An Evolutionary and Ecological Perspective. LEDA COSMIDES \& JOHN TOOBY, University of California, Santa Barbara-Recent intuitive reasoning studies have shown that people judging frequencies do much better than those given single event probabilities. This raises the question: What kinds of content is it easy to construct a frequency representation of? This paper tests the "flapjack hypothesis": that it is easier to compute the frequency of wholes, rather than inseparable facets. By manipulating just the statistical presentation and surface content of a problem, correct performance can be brought from $13 \%$ to $73 \%$.

\section{2:35-12:45 (653)}

To Guess or Not To Guess: Decision Theoretic Aspects of Formula Scoring. MAYA BAR-HILLEL, Hebrew University, \& DAVID D. BUDESCU, University of Illinois-The pros and cons of correcting for guessing in multiple choice tests has been debated in the psychometric literature for decades. Interestingly, the decision facing testees operating under formula scoring has not been seriously addressed. We criticize the oversimplification and naivete of standard models of testees, analyzing their decision from the standpoint of empirical JDM research as well as from a normative standpoint. This analysis yields a clear recommendation for the simple "number right" scoring rule. 